DANIEL COELHO DE SÁ

\title{
Análise da expressão do inflamassoma em melanoma cutâneo e nevo melanocítico
}

Tese apresentada a Faculdade de Medicina da Universidade de São Paulo para a obtenção do título de Doutor em Ciências.

Programa de Dermatologia

Orientador: Prof. Cyro Festa Neto

Coorientadora: Prof. Telma Oshiro

Versão corrigida. Resolução CoPGr 6018/11, de 1 de novembro de 2011

(a versão original encontra-se disponível na Biblioteca da FMUSP)

SÃO PAULO

2018 
Dados Internacionais de Catalogação na Publicação (CIP)

Preparada pela Biblioteca da

Faculdade de Medicina da Universidade de São Paulo

Creprodução autorizada pelo autor

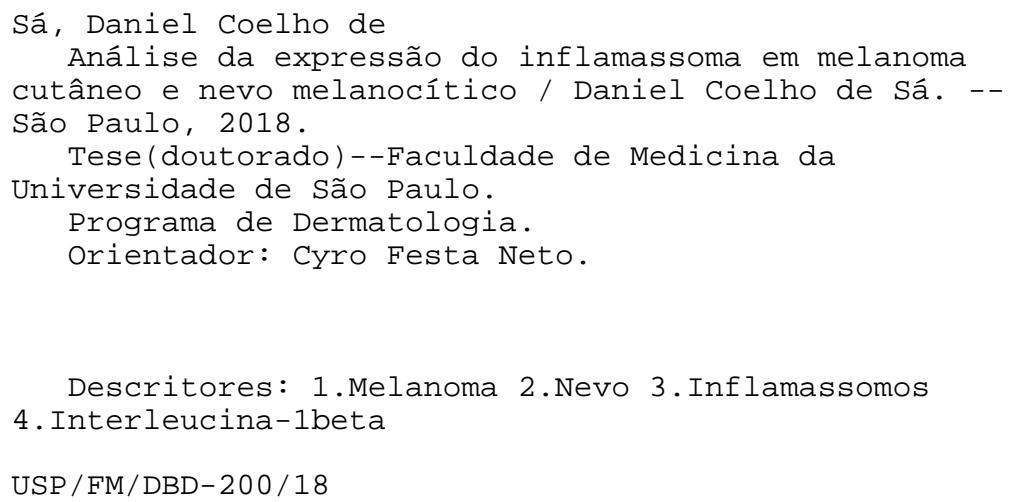




\section{Dedico esta tese:}

Ao meu pai, Raimundo (in memorium), e à minha mãe, Elba, pelo amor e por todo esforço e dedicação despendidos para que eu tivesse oportunidades para minha formação. 


\section{AGRADECIMENTOS}

"O sucesso nasce do querer, da determinação e persistência em se chegar a um objetivo." (José de Alencar)

Ao Professor Cyro Festa Neto, meu orientador, por ter-me recebido tão bem nesta instituição, pelo seu interesse em que eu conseguisse sucesso em minha carreira profissional e por sua dedicação, amizade e ensinamentos transmitidos durante o período de construção deste trabalho.

À Professora Telma Oshiro, minha coorientadora, a quem serei sempre grato por toda a disponibilidade, dedicação e total apoio que recebi desde a primeira reunião sobre a discussão deste trabalho até os momentos finais de conclusão desta tese.

À Professora Alessandra Pontillo, uma referência no tema do inflamassoma, pelos ensinamentos que compartilhou de forma abundante durante todo esse período.

À Professora Mirian Nakagami Sotto, pelos ensinamentos passados durante a elaboração deste trabalho.

Ao Professor Luiz Fernando Ferraz da Silva, patologista, por ter-me ajudado em etapa fundamental desta pesquisa.

À Dra. Camila Farias, dermatopatologista, pela imensa ajuda na análise de todas as lâminas do estudo.

Ao amigos do Ambulatório de Melanoma da Dermatologia da FMUSP, Dilci Franco e Walmar Roncalli, pela amizade durante todo este período. 
À Dra. Wanessa Cardoso da Silva, biomédica, pela parceria e troca de experiências durante todo o período do projeto.

À Dra. Naiura Vieira, bióloga, pela presteza, paciência e competência na realização dos exames de imuno-histoquímica no Laboratório LIM-56.

À Professora Raquel Leão Orfali, por ter-me incentivado e apoiado para o início desta jornada.

Aos integrantes da banca de qualificação do doutorado: Walmar Roncalli, Valéria Aoki, Alessandra Pontillo, pelas correções e sugestões no aprimoramento do projeto.

Aos funcionários do LIM-56 e do Laboratório de Dermatopatologia FMUSP pela contribuição nas etapas desta pesquisa.

À Fundação de Amparo à Pesquisa do Estado de São Paulo (FAPESP) pelo apoio financeiro para a realização desta pesquisa. 


\section{NORMALIZAÇÃO ADOTADA}

Esta tese está de acordo com as seguintes normas em vigor no momento desta publicação:

Referências: adaptado de International Comittee of Medical Journals Editors (Vancouver).

Universidade de São Paulo. Faculdade de Medicina. Divisão de Biblioteca e Documentação. Guia de apresentação de dissertações, teses e monografias. Elaborado por: Anneliese Carneiro da Cunha. Maria Julia de A. L. Freddi. Maria Fazanelli Crestana. Marinalva de Souza Aragão. Suely Campos Cardoso. Valéria Vilhena. 3a ed. São Paulo: Divisão de Biblioteca e Documentação; 2011.

Abreviaturas dos títulos dos periódicos de acordo com List of Journals Indexed in Index Medicus. 


\section{SUMÁRIO}

Lista de abreviaturas

Lista de figuras

Lista de tabelas

Resumo

Abstract

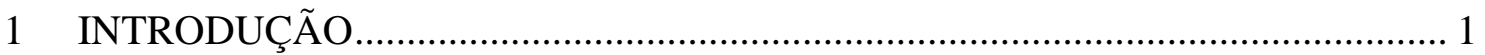

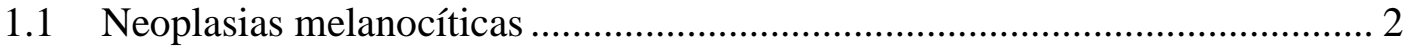

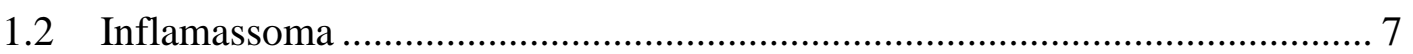

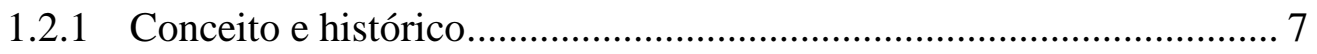

1.2.2 Funções do inflamassoma ............................................................ 10

1.2.3 Inflamassoma e câncer ................................................................. 11

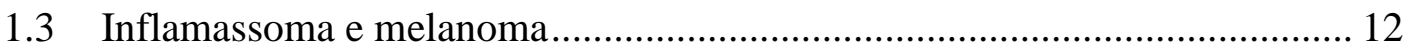

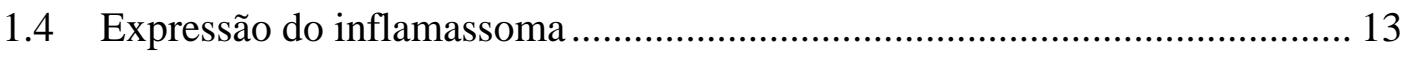

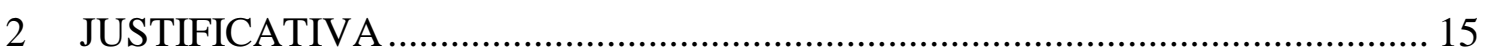

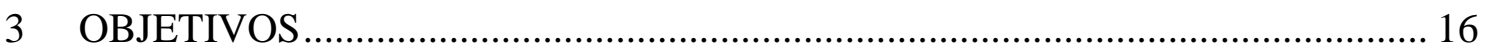

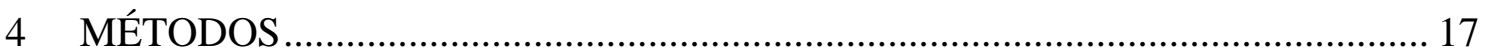

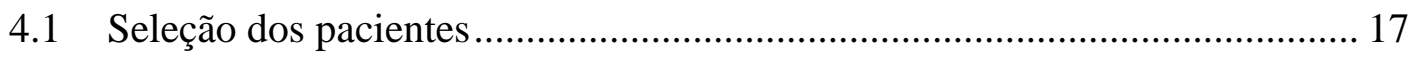

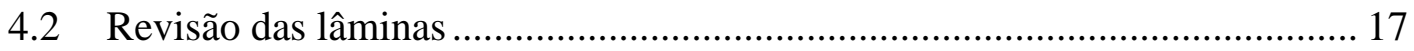

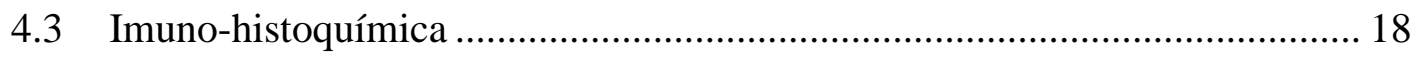

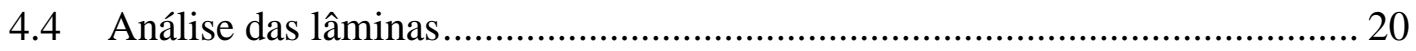

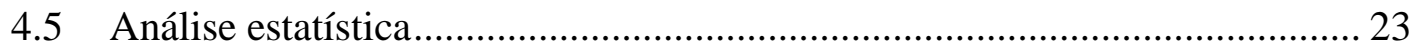

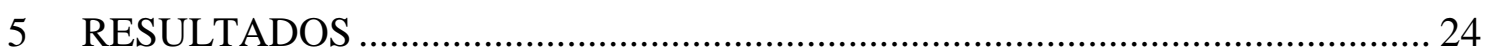

5.1 Comparação entre a expressão dos anticorpos entre os subgrupos (nevo displásico, nevo intradérmico, melanoma fino e melanoma intermediário-

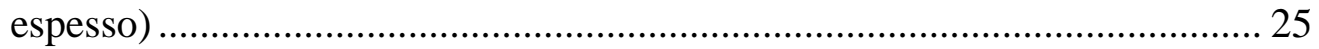

5.2 Comparação da expressão dos anticorpos entre nevos e melanomas ............ 26

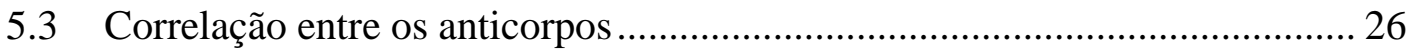

5.4 Comparação das características dos pacientes segundo a positividade dos

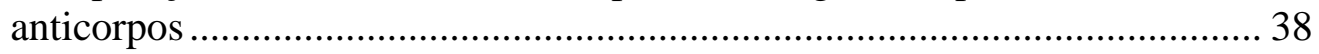

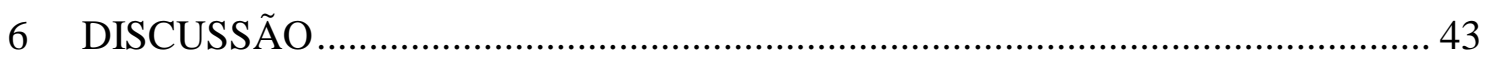

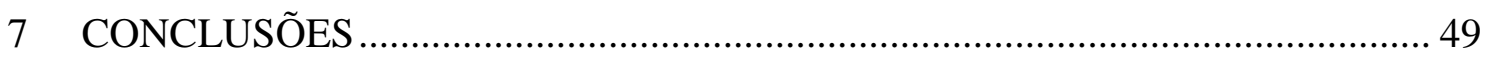

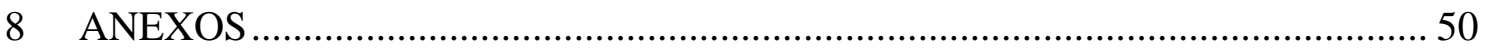

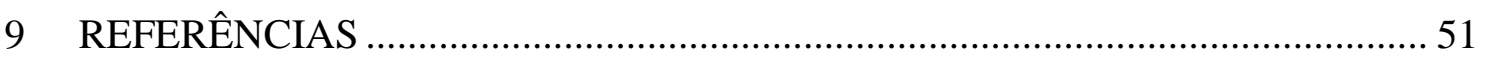




\section{Lista de abreviaturas}

AIM2: $\quad$ Absent in melanoma 2

AJCC: $\quad$ American Joint Committee on Cancer

ASC: $\quad$ Proteína Speck-like associada à apoptose com domínio de recrutamento de caspase, do inglês: Apoptosis-associated Speck-like protein containing a CARD.

$B R A F^{V 600 E}$ : Mutação em que a valina é substituída pelo glutamato no códon 600 (denominado V600E) no gene humano que codifica a proteína B-Raf.

BSA: $\quad$ Soro albumina bovina, do inglês: Bovine serum albumin

CARD: Domínio de recrutamento associado à caspase, do inglês: Caspase activation and recruitment domains

DAMP: Padrão molecular associado a dano, do inglês: Damage-associated molecular pattern

DP: $\quad$ Desvio padrão

dsDNA: $\quad$ DNA de cadeia dupla citosólica

FMUSP: $\quad$ Faculdade de Medicina da Universidade de São Paulo

HIN-200: $\quad$ C-terminal Hematopoietic Interferon-inducible Nuclear Protein with 200 amino acid Repeat

HIV: Vírus da imunodeficiência humana, do inglês: Human Immunodeficiency Virus

IC: $\quad$ Intervalo de confiança

IL: $\quad$ Interleucina

INCA: Instituto Nacional do Câncer

IFN: $\quad$ Interferon

IPAF: $\quad$ Ice protease-activating factor, também conhecido como NLRC4

JPEG: $\quad$ Joint Photographics Experts Group

LRR: $\quad$ Leucine rich repeat domain

MAPK: Proteína kinase ativada em mitógeno

NACHT: Central nucleotide-binding domain/NOD 
NCCN: Associação que reúne centros de oncologia dos EUA, do inglês: National Comprehensive Cancer Network.

NF-k: $\quad$ Fator nuclear kappa B, do inglês: Nuclear Factor kappa B

NIH: Intitutos Nacionais de Saúde dos Estados Unidos, do inglês: National Institutes of Health.

NK: $\quad$ Natural Killer

NLR: $\quad$ Receptores de ligação a nucleotídeos contendo domínio com sequências repetidas de resíduos do aminoácido leucina, do inglês: nucleotide binding leucin-rich repeat containing.

NLRC: $\quad$ NLR family containing a CARD domain

NLRP: $\quad$ NLR family containing a PYD domain

NOD: $\quad$ Nucleotide-binding oligomerization domain-like receptors

OMS: $\quad$ Organização Mundial da Saúde

PAMP: $\quad$ Padrão molecular associado a patógeno, do inglês: Pathogen-associated molecular pattern

PBS: $\quad$ Solução salina tamponada

PRR: $\quad$ Receptores de reconhecimento de padrões moleculares, do inglês: Pattern Recognition Receptors

PYD: $\quad$ N-terminal pyrin

RIG-I: $\quad$ Retinoic Acid-inducible Gene-I

SNP: $\quad$ Polimorfismos de base única, do inglês: Single Nucleotide Polymorphism

STAT1: $\quad$ Signal Transducer and Activator of Transcription 1

TIFF: $\quad$ Tagged Image File Format

TLR: $\quad$ Toll-like Receptor

TGF- $\beta$ : $\quad$ Fator de transformação do crescimento beta

UV: $\quad$ Ultravioleta 


\section{Lista de figuras}

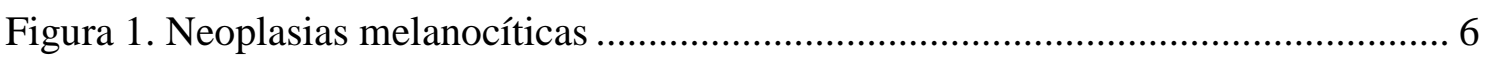

Figura 2. Etapas na formação do inflamassoma ..................................................... 8

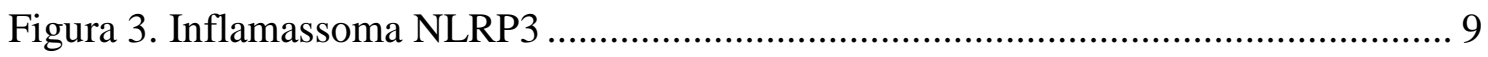

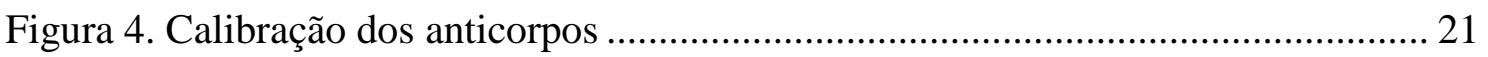

Figura 5. Seleção das áreas tumorais para análise da positividade da marcação ........... 22

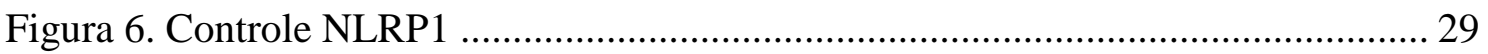

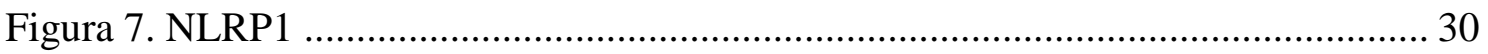

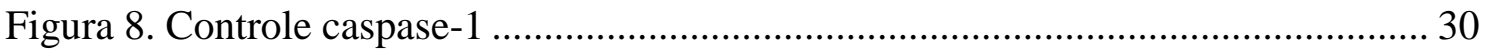

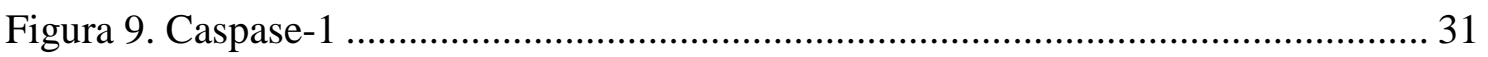

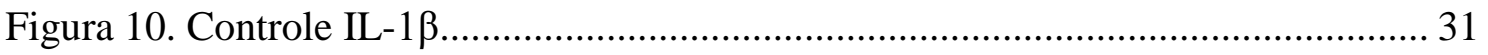

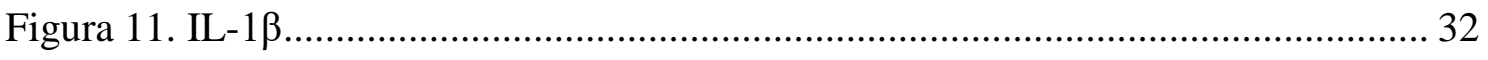

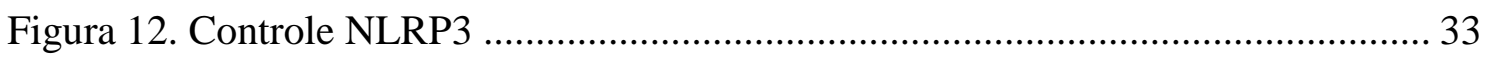

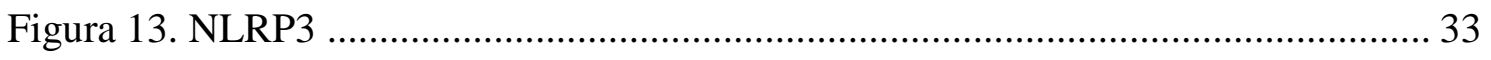

Figura 14. Caspase-1 para os pacientes com nevo e melanoma ................................... 34

Figura 15. IL-1 $\beta$ para os pacientes com nevo e melanoma ....................................... 34

Figura 16. NLRP1 para os pacientes com nevo e melanoma ...................................... 35

Figura 17. NLRP3 para os pacientes com nevo e melanoma ......................................... 35

Figura 18. Caspase-1 para os subgrupos de nevos e melanomas ................................... 36

Figura 19. IL-1 $\beta$ para os subgrupos de nevos e melanomas......................................... 36

Figura 20. NLRP1 para os subgrupos de nevos e melanomas...................................... 37

Figura 21. NLRP3 para os subgrupos de nevos e melanomas..................................... 37 


\section{Lista de tabelas}

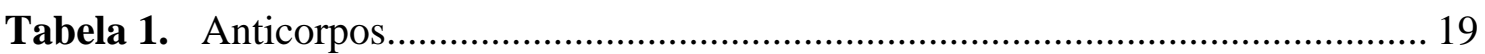

Tabela 2. Descrição dos pacientes com melanoma e nevo....................................... 24

Tabela 3. Comparação entre os níveis de porcentagens positivas dos anticorpos nos subgrupos de nevos e melanomas ..................................................... 25

Tabela 4. Comparação entre os níveis de porcentagens positivas dos anticorpos nos nevos e melanomas ......................................................................... 26

Tabela 5. Correlação entre os anticorpos dos pacientes com melanoma e nevo .......... 27

Tabela 6. Associação entre caspase-1, NLRP1, NLRP3 e IL-1 $\beta$ em pacientes com

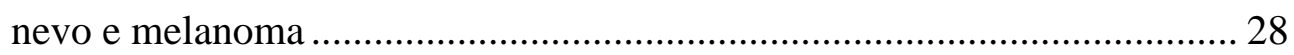

Tabela 7. Características dos pacientes com nevo segundo caspase-1, IL-1 $\beta$, NLRP1 e NLRP3

Tabela 8. Características dos pacientes com melanoma segundo caspase-1, IL-1 $\beta$, NLRP1 e NLRP3

Tabela 9. Características clínicas dos pacientes com melanoma segundo caspase-

1, IL-1 $\beta$, NLRP1 e NLRP3.

Tabela 10. Correlação entre nível Clark e Caspase-1, IL-1 $\beta$, NLRP1 e NLRP3 em pacientes com melanoma 42

Tabela 11. Estudos que avaliaram expressão de IL-1ß por imuno-histoquímica. 46 


\section{RESUMO}

de Sá DC. Análise da expressão do inflamassoma em melanoma cutâneo e nevo melanocítico [tese]. São Paulo: Faculdade de Medicina, Universidade de São Paulo; 2018.

A resposta inflamatória está envolvida em muitos aspectos da biologia do câncer. O inflamassoma é um complexo multiprotéico intracelular compostos por três elementos: um receptor de reconhecimento de padrões moleculares (PRR), uma proteína ligadora ASC (proteína speck-like associada à apoptose com domínio de recrutamento de caspase) e o zimogênio pró-caspase-1. A ativação da caspase-1 é responsável pela síntese de IL-18 e, principalmente, de IL-1 $\beta$. A ativação da caspase-1 é ainda capaz de induzir a piroptose, um tipo de morte celular inflamatória. O papel dos inflamassomas no câncer ainda é mal definido, devido às suas funções contrastantes na oncogênese, variando a depender do tipo de tecido e do estágio da tumorigênese em que são ativados. Estudos recentes mostraram uma ativação do inflamassoma à medida que o melanoma progride. Avaliamos a expressão de componentes do inflamassoma, incluindo dois tipos de PRR (NLRP1 e NLRP3), da enzima caspase-1, e da IL-1 $\beta$ em neoplasias melanocíticas benignas e malignas, por meio de técnica de imunohistoquímica. Foram analisadas amostras de tecidos embebidos em parafina de 25 pacientes com melanoma (16 melanomas finos e 9 melanomas intermediários-espessos) e 22 pacientes com nevo melanocítico (12 nevos intradérmicos e 10 nevos displásicos). Todas as amostras de pele foram recuperadas dos arquivos do Departamento de Dermatologia do Hospital das Clínicas da Faculdade de Medicina da Universidade de São Paulo. Evidenciamos uma maior expressão de NLRP1, NLRP3 e caspase-1 nos melanomas quando comparados aos nevos. Não houve diferença estatisticamente significativa quanto a expressão de IL-1ß entre os grupos. De forma inesperada, a descoberta mais interessante foi uma maior expressão de NLRP1 em melanomas finos do que nos tumores mais espessos. Esses achados sugerem que um aumento de NLRP1 poderia representar um evento promotor na transformação de melanócitos, mas que não estaria envolvido na progressão tumoral. Estudos adicionais são necessários para esclarecer esta complexa relação entre as proliferações melanocíticas e o inflamassoma.

Palavras-chave: Melanoma, Nevo, Inflamassoma, NLRP1, IL-1ß 


\section{ABSTRACT}

de Sá DC. Expression of inflammasome in melanoma and melanocytic nevus [thesis]. São Paulo: Faculdade de Medicina, Universidade de São Paulo; 2018.

Inflammatory response is involved in many aspects of cancer biology. Inflammasomes are a group of cytosolic multiprotein complexes, classically consisting of an upstream sensor protein of the NOD-like receptor (NLR) family, the adaptor protein ASC, and the downstream effector caspase-1. Its activation leads to the production of biologically active IL-1ß and IL-18, and consequently contributing to the inflammatory process. Caspase- 1 activation can also induce pyroptotic cell death, that is accompanied by the release of cytosolic contents to the extracellular space eliciting local inflammation. The roles of the inflammasomes in cancer are still ill defined, due to their contrasting roles in oncogenesis. Recent studies have shown an activation of the inflammosome as melanoma progresses. We evaluated the expression of inflamassome components (NLRP1, NLRP3, caspase-1) and of IL-1 $\beta$ in melanocytic neoplasms, by immunohistochemistry. Formalin-fixed, paraffin-embedded tissue samples from 25 patients with melanoma (16 thin melanomas and 9 intermediate-thick melanomas), and 22 patients with melanocytic nevus (12 intradermal nevi and 10 dysplastic nevi) were analyzed. All skin samples were retrieved from the files of the Department of Dermatology at Clinics Hospital of Faculty of Medicine, University of São Paulo. Comparing all nevi with all melanomas, we found a higher expression of NLRP1, NLRP3 and caspase-1 in melanomas. There was no difference of IL-1ß expression between the groups. For the first time, to our knowledge, we reported an increasing expression of NLRP1 in melanoma compared to melanocytic nevus. Unexpectantly, NLRP1 expression resulted augmented NLRP1 in thin melanomas compared with intermediate-thick melanomas. These data may suggest a role of NLRP1 in oncogenesis, but that its expression decreases as disease progresses. We can hypothesize that an increase of NLRP1 could represent a promoter event in melanocyte transformation, but it does not be involved in tumour progression. The association between nevus, melanoma and inflammasomes seems to be complex and further studies are necessary to clarify this.

Keywords: Melanoma, Nevus, Inflammasomes, NLRP1, IL-1ß. 


\section{INTRODUÇÃO}

A resposta inflamatória é um fenômeno de defesa fundamental do organismo, fazendo parte do sistema imune inato, efetivo no reconhecimento e na destruição de alvos selecionados. Quando o tecido é danificado, seja por trauma físico ou por patógeno, é desencadeada uma cascata complexa de eventos. Numerosas células inflamatórias colaboram para atacar o patógeno invasor, limpar detritos, reconstituir a matriz extracelular e auxiliar na proliferação e na transferência de células saudáveis para o local alvo. ${ }^{1}$ Este mecanismo de autodefesa protege o corpo das ameaças imediatas, mas este processo também pode prejudicar os próprios tecidos. Quando a homeostase é quebrada, as patologias podem surgir. ${ }^{2,3}$ Ocorrem então reações exacerbadas a alvos inocentes ou inadequados, causando alergias, doenças auto-imunes, desordens degenerativas. ${ }^{4}$

A resposta inflamatória está envolvida em muitos aspectos da biologia do câncer, como a iniciação, progressão, metástase e tratamento do tumor. ${ }^{5}$ Rudolf Virchow, em 1863, foi o primeiro a postular uma ligação entre inflamação e câncer, observando infiltração de leucócitos em tecidos neoplásicos. ${ }^{6,7}$ Estudos epidemiológicos demonstraram que a inflamação crônica é um fator predisponente para o desenvolvimento de vários tipos de câncer, ${ }^{8}$ estimando-se que as infecções subjacentes e as respostas inflamatórias estejam ligadas a 15-20\% de todas as mortes por câncer. ${ }^{9,10}$ Neoplasias de bexiga, colo do útero, esôfago, estômago, intestino, ovário, próstata e tireoide já foram associadas a doenças inflamatórias crônicas. Entretanto a associação entre resposta inflamatória e câncer segue controversa e a inflamação associada a uma neoplasia maligna pode representar tanto um fator que inibe o desenvolvimento do tumor quanto um promotor associado a um curso mais agressivo da doença. ${ }^{11-13}$

Mediadores da resposta inflamatória, como citocinas, radicais livres, prostaglandinas e fatores de crescimento, podem induzir alterações genéticas e epigenéticas, incluindo mutações pontuais em genes supressores tumorais, metilação do DNA, causando alterações nas vias críticas responsáveis por manter a homeostase celular e levando ao desenvolvimento e progressão do câncer. ${ }^{14}$ 
A maioria das citocinas pró-inflamatórias produzidas por células imunes do hospedeiro ou pelas próprias células tumorais, demonstraram promover o desenvolvimento do tumor. Em contrapartida, citocinas pro-apoptóticas e anti-inflamatórias (IL-10, TGF- $\beta$ ) interferem no próprio desenvolvimento da neoplasia. ${ }^{1}$

\subsection{Neoplasias melanocíticas}

Os melanócitos são originários de células pluripotentes da crista neural, que gradualmente se diferenciam em linhagem de células produtoras de melanina durante o desenvolvimento. São residentes da pele, na epiderme, na junção dermoepidérmica e nos folículos pilosos, onde exercem funções na pigmentação e na proteção à radiação ultravioleta. Além da pele, estão presentes no trato uveal e ainda em outros tecidos com funções pouco entendidas, como esôfago, meninges, mucosa oral, mucosa da cavidade nasal, ânus, reto, pênis, vulva, vagina e conjuntiva. ${ }^{16,17}$

As neoplasias melanocíticas (Figura 1) são iniciadas por mutações somáticas que ativam os oncogenes. Lesão benigna é denominada nevo melanocítico e a maligna, melanoma. O termo melanoma maligno, frequentemente utilizado, apenas expressa uma redundância. ${ }^{18}$ Os nevos melanocíticos são proliferações clonais benignas, resultantes da proliferação dos melanócitos, derivados de mutações oncogênicas individuais, iniciadas na via da proteína kinase ativada em mitógeno (MAPK - mitogen-activated protein kinase), mais comumente pela ativação da mutação $B R A F^{V 600 E}$. A proliferação de melanócitos dentro do nevo é limitada por uma multiplicidade de fatores, incluindo pontos de controle do ciclo celular, comprimento do telômero, fatores segregados e sistema imunológico. ${ }^{16,18,19}$ A maioria dos nevos melanocíticos exibem uma proliferação inicial, mas em seguida permanecem estáveis ou involuem ao longo da vida. ${ }^{20}$ A distribuição simétrica das células neoplásicas na maioria dos nevos, a monotonia de seus melanócitos e a presença de mutações identificáveis em populações de células névicas sugerem que eles resultem da expansão clonal de uma única célula. ${ }^{17}$ A distinção entre melanoma e nevo parece ser a capacidade da célula névica de sofrer senescência após a manutenção de mutações pró-proliferativas. Apesar dessas diferenças de comportamento, nevos e melanomas compartilham mutações somáticas em comum. ${ }^{20}$ A senescência celular induzida por oncogene está emergindo como uma potente resposta protetora 
contra o câncer em eventos oncogênicos, cujas vias que a coordenam são complexas e incompletamente elucidadas. Kuilman et al demonstraram uma relação causal entre a indução de algumas citocinas, em particular IL-6 e IL-8, e a capacidade das células de serem submetidas a senescência, incluindo os melanócitos. Considerando a IL-6 como um regulador essencial da senescência, outros genes inflamatórios também mostraramse ativados neste processo como a $I L I B .^{21}$

Os nevos são usualmente classificados baseados em critérios clínicos e histopatológicos. Eles são categorizados como adquiridos ou congênitos, ambos subdivididos em juncional, dérmico ou composto com base na localização dos melanócitos dentro da epiderme, da derme ou de ambos, respectivamente. ${ }^{22}$ Há uma controvérsia se os nevos se originam na junção dermo-epidérmica, com alguns melanócitos subsequentemente "caindo" na derme subjacente, ou se eles se originam em estruturas mais profundas com posterior ascensão de melanócitos para a epiderme. ${ }^{17}$

O nevo displásico tem sido fonte de controvérsias, desde que foi descrito pela primeira vez por Clark et al, em 1978, em indivíduos de famílias propensas ao melanoma. ${ }^{23,24}$ Eder et al postularam que tais nevos seriam precursores do melanoma, baseados na displasia miscroscópica. ${ }^{25}$ Morfologicamente, o nevo displásico mostra uma mistura de desordem arquitetural e atipia citológica, muitas vezes acompanhada por uma resposta imunológica do hospedeiro. ${ }^{24}$ Apesar de em 1992 um Consenso do National Institutes of Health (NIH) ter sugerido que este termo fosse abandonado, ${ }^{26} \mathrm{o}$ uso da nomenclatura nevo displásico persiste até os dias atuais, carregando consigo diversas polêmicas quanto ao risco de progressão para melanoma ou se pode ser considerado um marcador de risco para melanoma. ${ }^{27}$

A Organização Mundial da Saúde (OMS), definiu os principais critérios para o diagnóstico do nevo displásico. Os critérios maiores são: 1. proliferação de melanócitos atípicos na região da membrana basal se estendendo por três cristas epidérmicas em relação ao componente intradérmico; 2. proliferação melanocítica intraepidérmica (lentiginosa ou epitelióide). Os critérios menores são: 1. fibrose concêntrica eosinofílica envolvendo as cristas epidérmicas ou fibroplasia lamelar; 2. neovascularização; 3. resposta inflamatória dérmica; 4. fusão de cristas. O diagnóstico é realizado quando houver dois critérios maiores e pelo menos dois critérios menores. ${ }^{28}$ 
Metanálise recente estimou que $29 \%$ dos melanomas surgem a partir de um nevo preexistente, não tendo sido observada diferença quanto ao fato de o nevo ser displásico ou não. ${ }^{29}$

O melanoma é o terceiro tipo de câncer cutâneo mais comum e é responsável pela maioria das mortes por câncer de pele. Nos Estados Unidos, estimava-se para o ano de 2017 mais de 87 mil casos novos, o que representaria 5,2\% de todas as novas neoplasias, estando na quinta posição entre os cânceres mais frequentes. A mesma estatística aponta para mais de 9 mil mortes por melanoma em 2017, sendo o segundo câncer com maior perda em potencial de anos de vida, atrás apenas das leucemias em adultos. ${ }^{30}$ Embora as taxas em geral sejam mais elevadas entre os adultos mais velhos, este é o terceiro câncer mais comum entre adolescentes e jovens. ${ }^{31}$ Apesar de a taxa de incidência de cânceres em geral estar diminuindo, a incidência de melanoma continuou a aumentar nos últimos anos, com uma elevação média de $1,4 \%$ ao ano nos últimos 10 anos. ${ }^{30,32}$ Baseados em dados divulgados entre 2012 e 2014 , calculou-se que $2,2 \%$ dos homens e mulheres desenvolverão melanoma durante a vida nos EUA. ${ }^{30}$ Análises recentes encontraram aumentos na incidência em todas as espessuras tumorais e estágios, e este é o único tipo de câncer que não está previsto de atingir os objetivos para reduções nas taxas de mortalidade até o ano de 2020, segundo o estimativa do Departamento de Saúde e Serviços Humanos dos EUA. ${ }^{33}$

No Brasil, os dados do Instituto Nacional do Câncer (INCA) para o ano de 2016 estimavam 5.670 novos casos, sendo 3 mil em homens e 2.670 em mulheres, com as taxas mais altas observadas nos estados da região Sul. ${ }^{34}$

A incidência do melanoma parece ser influenciada pela interação de fatores genéticos e ambientais, ainda não totalmente compreendidos. São considerados como fatores de risco a exposição à radiação ultravioleta (UV), tanto solar como por qualquer tipo de bronzeamento artificial, fototipo baixo, cabelos ruivos, número e localização dos nevos, presença de nevos displásicos e história pessoal e familiar de melanoma. ${ }^{35,36}$

A relação causal da radiação UV apresenta variação a depender do sítio anatômico. No lentigo maligno melanoma, que mais comumente atinge a face, a exposição solar crônica seria o principal fator de risco, enquanto no tronco e membros, a exposição intermitente seria a causadora. Em relação ao melanoma acral, parece não haver relação com exposição. ${ }^{37}$ 
A maioria dos estudos mostra o tronco como o principal sítio de acometimento nos homens, enquanto nas mulheres, os membros inferiores seriam as áreas mais afetadas. Essa diferença pode ser explicada, pelo menos em parte, pelos hábitos de vida, de vestuário e ocupacional que levariam a variações na exposição solar. Especulações acerca de influência hormonal no desenvolvimento do melanoma permanecem incertas. ${ }^{38-40}$

Diante de uma lesão suspeita de melanoma, deve-se proceder a uma biópsia excisional, com margens de 1 a $3 \mathrm{~mm}$. O Painel de Melanoma do National Comprehensive Cancer Network (NCCN) recomenda que o laudo histopatológico deve conter as seguintes informações: espessura de Breslow em milímetros; estado de ulceração; índice mitótico; estado de margem profunda e periférica; presença ou ausência de microsatélites; desmoplasia pura se presente; e nível de Clark para lesões nãoulceradas com até $1 \mathrm{~mm}$ de Breslow, onde o índice mitótico não pode ser determinado. ${ }^{41}$

O estadiamento proposto pela American Joint Committee on Cancer (AJCC) leva em consideração os seguintes parâmetros: espessura do tumor (índice de Breslow) e ulceração, acometimento linfonodal micro ou macroscópico, metástase satélite, metástase em trânsito, microssatelitose, metástase à distância e nível de DHL nos pacientes com metástase à distância. Isoladamente, o índice de Breslow é considerado o principal fator prognóstico. Outros fatores não levados em consideração no estadiamento e que têm influência na prognose são: mitoses, localização anatômica do tumor, idade, sexo, número de metástases à distância e tempo de sobrevida do paciente. ${ }^{42-45}$

O melanoma geralmente evolui através de três estágios de progressão. No início, os melanócitos neoplásicos proliferam acima da membrana basal da epiderme (fase de crescimento radial in situ ou epidérmica); eles então invadem a derme papilar (a fase de crescimento radial micro-invasiva); e subsequentemente adquirem a capacidade de crescer como um tumor maligno (a fase de crescimento vertical invasiva). ${ }^{46}$

O melanoma é dito in situ quando está restrito a epiderme e seus anexos. São classificados como estágio zero no estadiamento da AJCC, e considerados curados após a cirurgia de ampliação de margens. ${ }^{41}$ Denominam-se melanomas finos aqueles com Breslow inferior a $1 \mathrm{~mm}$, porque apresentam um bom prognóstico após a excisão cirúrgica, com uma taxa de sobrevivência de mais de 95\%, no caso de uma margem livre de tumor $\geq 1 \mathrm{~cm} ;{ }^{47}$ os com espessura entre 1,01 e $4 \mathrm{~mm}$ são ditos intermediários; e os acima de $4 \mathrm{~mm}$, espessos. ${ }^{48}$ Para pacientes com melanomas localizados com mais de 1 mm de espessura, as taxas de sobrevida variam de $50 \%$ a $90 \%$, dependendo da espessura 
do tumor, ulceração e índice mitótico. A chance de envolvimento linfonodal (estágio III) aumenta de acordo com o índice de Breslow, bem como com a presença de ulceração e de mitoses. Nesse estágio, as taxas de sobrevida em 5 anos variam de $20 \%$ a $70 \%$. A taxa de sobrevida em 5 anos é inferior a $10 \%$ no estágio IV (metástase à distância). ${ }^{49}$

A

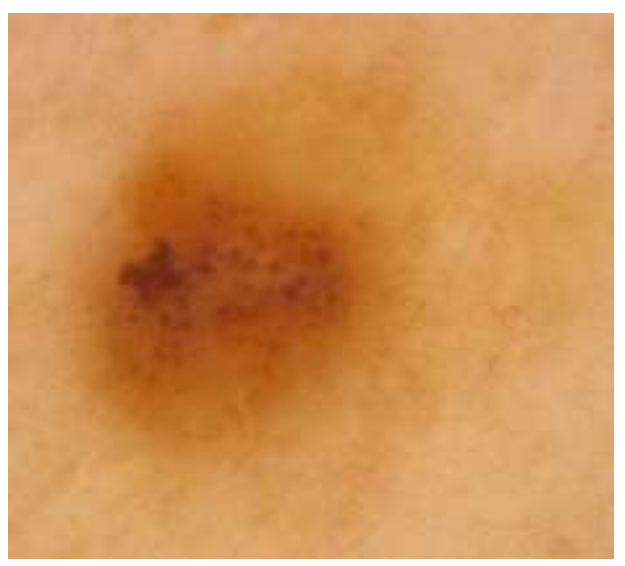

C

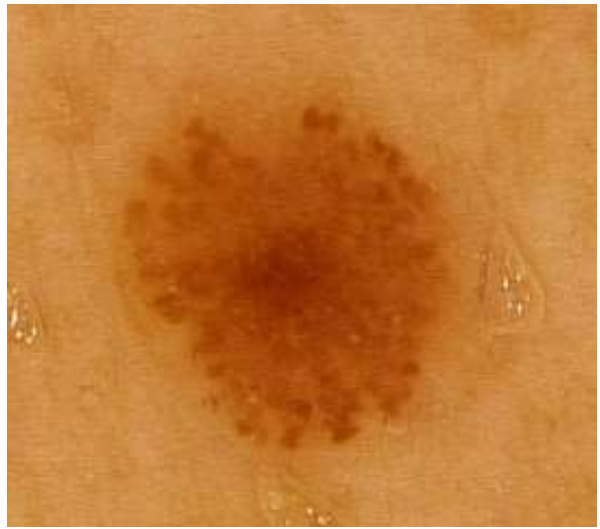

B

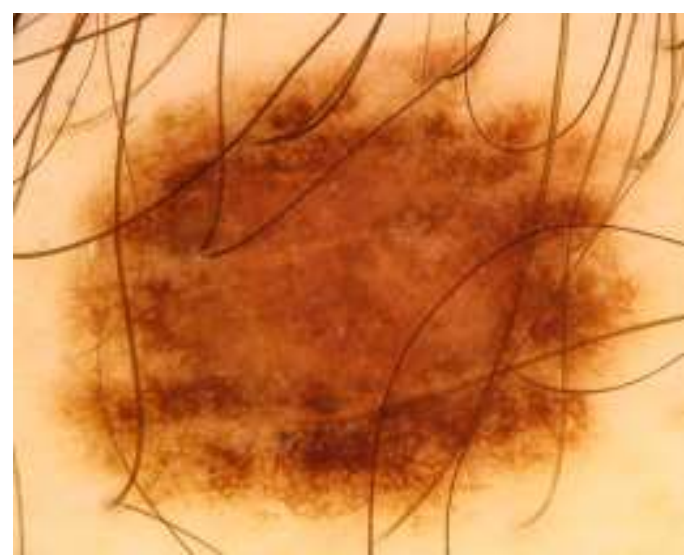

D

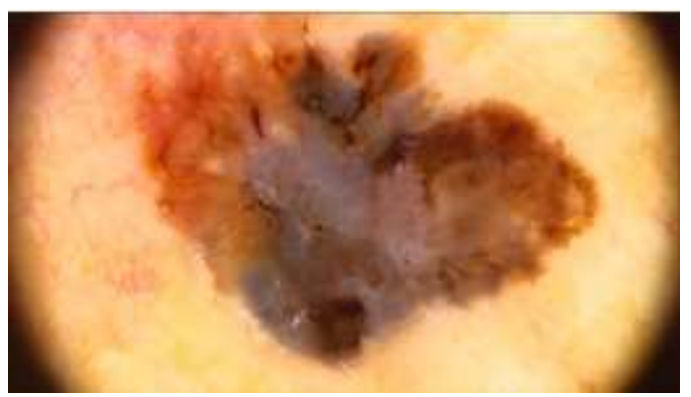

Imagens de dermatoscopia exemplificando cada um dos tipos de lesões melanocíticas em análise neste estudo. A, nevo intradérmico. B, nevo displásico. C, melanoma fino (in situ). $\mathrm{D}$, melanoma intermediário (Breslow 1,4 mm).

Fonte: arquivo pessoal

Figura 1. Neoplasias melanocíticas 


\subsection{Inflamassoma}

\subsubsection{Conceito e histórico}

Os inflamassomas são constituintes do sistema imune inato, sendo responsáveis por regular a resposta inflamatória a diversos estímulos. Até a publicação do artigo de Martinon et al em 2002, o mecanismo que levava à conversão da pró-IL-1 $\beta$ em IL-1 $\beta$, por meio da ativação da enzima caspase-1, era desconhecido. Neste artigo, os autores demonstraram um complexo de ativação da caspase e o denominaram inflamassoma. ${ }^{1}$ Desde então, o papel do inflamassoma na resposta inflamatória inata e a sua participação em diversas condições patológicas vêm sendo pesquisados. ${ }^{50-52}$

A imunidade inata funciona a partir do reconhecimento de potenciais agentes danosos por receptores de reconhecimento de padrões moleculares (PRR). Há dois tipos de estímulos, sendo denominado exógeno, quando induzido por partículas de agentes infecciosos, chamado de padrão molecular associado a patógeno (PAMP), e o estímulo endógeno, quando induzido por moléculas produzidas por células submetidas a algum estresse, chamado de padrão molecular associado a dano (DAMP). Neste último caso, denomina-se inflamação estéril, devido à ausência de microorganismos. ${ }^{53,54}$

Os inflamassomas são complexos multiprotéicos intracelulares, compostos por três elementos: um receptor de reconhecimento de padrões moleculares (PRR), uma proteína ligadora ASC (proteína speck-like associada à apoptose com domínio de recrutamento de caspase) e o zimogênio pró-caspase-1..$^{50,51}$

A montagem e a ativação do inflamassoma têm início pelo reconhecimento de estímulos por receptores PRR, que então interagem com a molécula adaptadora ASC. Segue-se a ligação da proteína ASC com a pró-caspase-1, que é então clivada, ativando caspase-1. A ativação da caspase-1 culmina na clivagem das pró-IL-1 $\beta$ e pró-IL18, gerando suas formas ativas, IL-1 $\beta$ e IL18, respectivamente, que estimulam a resposta inflamatória (Figura 2). ${ }^{51,55,56}$ 


\section{PAMPs / DAMPS \\ Ativação do receptor do inflamassoma (NLRP) \\ Recrutamento da proteína ASC \\ Recrutamento da pró-caspase-1 \\ Formação do complexo do inflamassoma \\ Ativação da Caspase-1 \\ $\boldsymbol{k}$ \\ Pró-IL-1 - Pró-IL-18 Piroptose \\ Secreção de IL-1 $\beta$ e IL-18}

Etapas na formação do inflamassoma: DAMPs ou PAMPs ativam o receptor do inflamassoma (NLRP). Isso leva ao recrutamento da proteína adaptadora ASC e da pró-caspase-1 levando à formação do complexo do inflamassoma, que ativa a caspase-1. Esta enzima matura de forma proteolítica a pró-IL1 $\beta$ e a pro-IL18, levando à sua secreção. Ativação de caspase-1 também pode induzir piroptose.

Figura 2. Etapas na formação do inflamassoma

O inflamassoma é denominado de acordo com a nomenclatura do seu receptor intracelular. Pelo menos 6 tipos de inflamassoma já foram descritos: NLRP1, NLRP3, NLRP6, NLRP12, NLRC4/IPAF, AIM-2. ${ }^{56,57}$

Os receptores de reconhecimento de padrões moleculares (PRR) podem estar presentes na membrana celular ou no citoplasma e são divididos em cinco grupos de acordo com a sua estrutura. São duas as classes de receptores transmembrana: os receptores tipo Toll (TLR- Toll like receptors) e os receptores de lecitina tipo C (CLR- C-type lectin receptors. Já os receptores intracelulares são: receptores tipo gene induzível do ácido retinóico-I (RLR - RIG-1 like receptors), os receptores tipo domínio de oligomerização de ligação de nucleotídeos (NLR- NOD like receptors) e os receptores tipo ausente no melanoma 2 (ALR- AIM2-like receptors). ${ }^{53,58}$ Dentre estes, duas classes de receptores já foram identificadas como sendo constituintes do inflamassoma: a dos receptores do tipo NOD (NLR) e a dos receptores do tipo AIM2 (ALR). ${ }^{56,57}$ 
Já foram identificados pelo menos 22 tipos de receptores NLR em humanos. Destes, quatro já mostraram papel fisiológico relevante na formação do inflamassoma: NLRP1, NLRP3, NLRC4 e NLRP5. A estrutura comum a todos os receptores NLR, é o domínio de ligação de nucleótidos e de oligomerização central (NACHT). Ele encontrase comumente ligado a um domínio de repetições ricas em leucina C-terminal (LRR). Ainda na constituição do NLR, existe ou um domínio N-terminal de recrutamento de caspase (CARD) ou um domínio de pirina (PYD). ${ }^{57}$ Os receptores NLCR possuem um domínio de recrutamento de caspase necessário para ativar o NF-kB (CARD); já os receptores NLRP apresentam um domínio de pirina (PYD), essencial para indução e regulação do inflamassoma (Figura 3). ${ }^{58}$

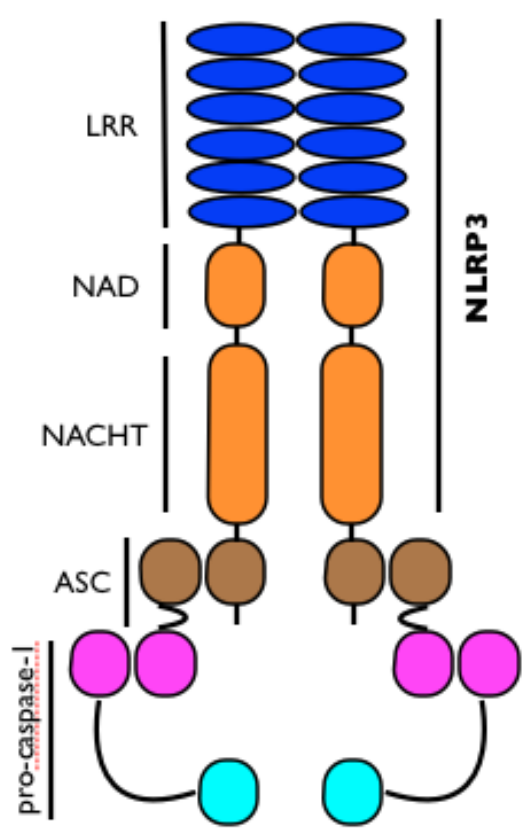

Esquema do inflamassoma NLRP3. Receptor NLRP3 formado pelo domínio LRR, NAD e NACHT, que liga-se a proteína de adaptação ASC. Esta última liga-se a pró-caspase-1 por meio de uma interação CARD

Figura 3. Inflamassoma NLRP3 
Os receptores da família ALR, são constituídos por um PYD e por um ou dois domínios HIN-200. O domínio HIN-200 liga-se diretamente a um DNA de cadeia dupla citosólica (dsDNA), levando à ativação do ALR. ${ }^{52,59}$

O estímulo por PAMPs ou DAMPs leva à oligomerização dos PRR, a partir do domínio NACHT nos NLR e do domínio HIN nos ALR. ${ }^{7}$ Isso tira os receptores PRR de um estado de auto-inibição ${ }^{60}$ e leva a um recrutamento da proteína adaptadora ASC, por meio da interação do PYD do receptor NLR ou ALR, com o PYD da proteína ASC (interação PYD/PYD. ${ }^{52,61}$ Isso desencadeia um processo de nucleação na proteína ASC, que também é composta por um domínio CARD. Cai et al e Lu et al demonstraram que este processo de nucleação de ASC é semelhante à nucleação que acontece nos prions, o que amplifica enormemente a resposta, pois uma pequena quantidade de ASC ativada leva ao recrutamento de grande proporção de moléculas ASC, formando filamentos estáveis para a ativação da pró-caspase. A interação com a pró-enzima se dá por meio da porção CARD da caspase (interação CARD/CARD), levando a ativação e polimerização da caspase-1. ${ }^{60-62}$ A ativação da caspase-1 culmina na clivagem das próIL-1 $\beta$ e pró-IL18, gerando suas formas ativas, IL-1 $\beta$ e IL18, respectivamente, que estimulam a resposta inflamatória. ${ }^{51,55,56}$

Diferentemente, do NLRP3, que requer a proteína adaptadora ASC, a ativação da caspase-1 pelo NLRP1 não requer ASC, pois NLRP1 contém um domínio CARD C-terminal que facilita a ativação direta da caspase-1 através da interação CARD-CARD. ${ }^{63}$

A ativação da caspase-1 pela via do inflamassoma é ainda capaz de induzir a piroptose, um tipo de morte celular inflamatória, ${ }^{64,65}$ que ocorre via clivagem da gasdermina $\mathrm{D}$, levando a formação de poros na membrana plasmática. ${ }^{66,67}$ Seguindo-se a morte celular, proteínas ASC acumulam-se no espaço extracelular, sendo ingeridas por macrófagos e levando a dano lisossomal, agindo como DAMP, levando a produção de IL-1 $\beta$. Este mecanismo aponta para uma possível auto-perpetuação da resposta inflamatória mediada pelo inflamassoma. ${ }^{52}$

\subsubsection{Funções do inflamassoma}

Através da síntese de IL18 e, principalmente, de IL-1 $\beta$, a via do inflamassoma desempenha seu papel para que o sistema imune inato aja de forma eficaz contra vírus, fungos e bactérias e contra outras doenças, inclusive alguns tipos de câncer. Quando sua 
atividade torna-se excessiva, efeitos deletérios no organismo podem ocorrer em diversos órgãos, e os distúrbios do inflamassoma tem sido implicados em diversas doenças, tornando-se um possível alvo para ação terapêutica. ${ }^{68} \mathrm{O}$ grupo de patologias inicialmente associado ao inflamassoma foi o das síndromes febris autoinflamatórias genéticas. ${ }^{69}$ Além dessas, outras também tiveram nos últimos anos sua fisiopatogenia relacionada ao inflamassoma como: doenças metabólicas (diabetes tipo 2, obesidade, aterosclerose), ${ }^{70}$ desordens neurológicas (doença de Parkinson, epilepsia, esclerose lateral amiotrófica, doença de Alzheimer, esclerose múltipla, desordens do espectro do autismo), ${ }^{71,72}$ doenças psiquiátricas (transtorno bipolar, depressão), ${ }^{72}$ doenças autoimunes (dermatomiosite, vitiligo, esclerodermia, artrite reumatóide, diabetes tipo 1, doença de Addison, lúpus eritematoso sistêmico, síndrome de Sjögren), ${ }^{73,74}$ infecções (Treponema pallidum, Francisella tularensis, Legionella pneumophila, Listeria monocytogenes, Mycobacterium tuberculosis, S. pneumoniae, HIV, Vírus Varicela-Zoster, Herpes simples, citomegalovírus) ${ }^{75-80}$ e neoplasias (gástrica, hepática, colorretal, pulmonar, mama, melanoma e linfoma). ${ }^{81,82}$

\subsubsection{Inflamassoma e câncer}

O papel do inflamassoma no câncer ainda está mal definido, devido ao seu papel contrastante na oncogênese, sendo o resultado dependente do tipo de tecido e do estágio de tumorigênese em que são ativados. ${ }^{83-87}$

A IL-1 $\beta$ é uma citocina pleiotrópica que participa da resposta tumoral induzindo inflamação, angiogênese, remodelamento tecidual e regulação da resposta imune. A resposta inflamatória com produção de IL-1 $\beta$ mostrou-se em alguns estudos como uma condição que promoveria o crescimento tumoral. ${ }^{88,89}$

Por outro lado, Ghiringhelli et al (2009) mostraram em modelo experimental murino que a ativação do NLRP3 em células dendríticas culmina com a produção de IL-1beta, estimulando a produção de IFN-gama por células T CD8+ e deste modo mediando a atividade anti-tumoral de linfócitos T. Neste mesmo estudo, mostraram que a ativação do NLRP3 inflamassoma nas células dendríticas é decisiva para resposta imune contra células tumorais mortas, revelando uma ligação entre sistema imune adquirido e inato. ${ }^{90}$ Em outro trabalho, NLRP3 inflamassoma mostrou papel protetor na 
tumorigenese colorretal através da IL-18 que induz supressores tumorais como IFNgama e STAT1. ${ }^{91}$

A ativação do AIM-2 inflamassoma mostrou induzir a apoptose de células de câncer de mama in vitro em um modelo murino. ${ }^{92}$ Em outro estudo, a inibição do gene de AIM2 por meio de metilação do DNA associou-se à imortalização das células. Já quando pesquisada sua interação com o câncer colorretal, o AIM2 revelou-se um promotor da invasão das células neoplásicas. ${ }^{93}$ IPAF foi associado a supressão de tumor colorretal em estudo com murinos. ${ }^{94}$

A ativação de sensores de inflamassoma é amplamente benéfica no câncer colorretal associado à colite, em grande parte devido aos efeitos de cicatrização epitelial da via de sinalização da IL18, regulação da proliferação celular, maturação e morte celular e manutenção de uma microbiota intestinal saudável. Em outros casos, a inflamação desencadeada pelo inflamassoma e a sinalização de IL1 conduz à supressão da imunidade antitumoral conferida por células NK e células T que é prejudicial ao desenvolvimento de fibrossarcoma, melanoma, carcinoma gástrico e metástase pulmonar. Como resultado, aumentar ou reduzir a atividade dos inflamassomas ou das suas moléculas efetoras pode ser eficaz na terapia de tipos específicos de câncer ${ }^{95}$

No contexto do câncer, os polimorfismos no gene que codifica NLRP1 estão ligados ao mesotelioma, ao melanoma, e à hiperplasia epidérmica. Os de NLRP3 estão associados com melanoma e câncer colorretal; e aqueles de AIM2 com câncer colorretal. $^{95}$

\subsection{Inflamassoma e melanoma}

Em estudo com células de melanoma, Okamoto et al identificaram que melanomas em fase avançada exibiam características de doenças autoinflamatórias, com ativação constitutiva de NLRP3 e produção independente de IL-1 $\beta$, sem necessidade de estímulo exógeno. Em melanomas em fase intermediária, a ativação ocorria através da estimulação de receptores de IL-1 (IL-1R). Já nos estágios iniciais, havia a necessidade de estimulação de IL-1R e uma co-estimulação com muramil dipeptídeo. Os mecanismos que levariam a esta diferença na ativação do inflamassoma permanecem 
incertos. Neste mesmo estudo, culturas de células de melanoma promoveram quimiotaxia de macrófagos e angiogênese. ${ }^{96}$

Baseando-se no conhecimento de que a IL-1 $\beta$ participa da invasão e da angiogênese tumoral e que a síntese de IL-1 $\beta$ é modulada pelo NLRP1/NLRP3 inflamassoma, Verma et al investigaram a associação de polimorfimos do NLRP1 e NLRP3 com a suscetibilidade a melanoma e identificaram uma associação forte entre melanoma nodular e uma variante de NLRP1. ${ }^{97}$

Avaliando linhagens de células humanas de melanomas primários e metastáticos, Liu et al mostraram um papel duplo da proteína ASC. Nos melanomas primários, a expressão de ASC seria inibidora da tumorigênese, enquanto nos melanomas metastáticos, seria um fator promotor da progressão tumoral. ${ }^{98}$ Trabalhando com linhagens de células humanas, Gehrke et al demonstraram que as células de melanoma metastático são incapazes de secretar IL-1 $\beta$, devido à ausência de pelo menos um dos componentes do inflamassoma. Entretanto macrófagos mostraram-se capazes de sintetizar grande quantidade de IL-1 $\beta$, estimulados por fatores originados de células necróticas de melanoma. Discute-se então que embora não sejam produtoras de IL- $1 \beta$, as células tumorais se beneficiariam da citocina produzida pelos macrófagos. ${ }^{99}$

Ahmad et al demonstraram que a substância timoquinona inibiu a migração de células de melanoma humano e murino em um modelo in vitro, e também mostrou efeito inibidor de metástases em um modelo in vivo em camundongos, por meio da inibição do NLRP3, com consequente diminuição da síntese de IL-1 $\beta$ e IL18. ${ }^{100}$ Ellis et al demonstraram que doses fisiológicas de epigalocatequina-3-galato, um componente do chá verde, tiveram efeito inibidor na proliferação de linhagem celular humana de melanoma metastático, por meio da inibição do NLRP1. ${ }^{101}$

\subsection{Expressão do inflamassoma}

Alguns estudos avaliaram a expressão das proteínas do inflamassoma nos tecidos. Em 2001, Matsumoto et al, utilizando anticorpos monoclonais anti-ASC, avaliaram por meio de hibridização in situ e imuno-histoquímica a expressão de ASC em tecidos humanos normais e evidenciaram que a proteína adaptadora ASC apresenta uma distribuição generalizada, com altos níveis de expressão em células epiteliais e 
leucócitos, envolvidos na defesa do hospedeiro contra patógenos externos. Foram evidenciados em células do corno anterior da medula espinhal, trofoblastos das vilosidades placentárias, epitélio tubular do rim, túbulos seminíferos e células de Leydig dos testículos, nos hepatócitos e ductos biliares interlobulares do fígado, células epiteliais escamosas da amígdala e da pele, folículos pilosos, glândulas sebáceas e écrinas e leucócitos do sangue periférico. No cólon, ASC foi detectado principalmente nas células epiteliais maduras do lúmen em comparação com as células imaturas localizadas mais profundamente nas criptas. Não foi observada expressão significativa de ASC no epitélio ciliado da traquéia, glomérulos renais, músculo cardíaco, epitélio alveolar do pulmão ou linfócitos. ${ }^{102}$

Kummer et al, em 2006, avaliaram a expressão dos componentes NLRP1 e NLRP3 nos tecidos, através de análise imuno-histoquímica e imunoblotting, com o uso de anticorpos monoclonais anti-NLRP1 e anti-NLRP3. A distribuição tecidual mostrou diferenças e apenas algumas sobreposições entre eles, o que sugeriu papéis diversos em tipos celulares distintos. ${ }^{103}$

Sobreposição foi observada em granulócitos, monócitos, células dendríticas e em linfócitos B e T. Níveis mais elevados de NLRP1 foram encontrados em células T e células de Langerhans. NLRP1 foi detectado também em neurônios, testículo e em estruturas epiteliais glandulares, como estômago, intestino, traquéia, brônquios, endométrio, próstata e mama. Em contraste, NLRP3 mostrou uma distribuição mais restrita, com expressão principalmente no epitélio não-queratinizado da orofaringe, do esôfago e da ectocérvice, e ainda na camada urotelial na bexiga e nos corpúsculos de Hassal do timo. Dado interessante foi a presença de NLRP1 com distribuição intranuclear, em linfócitos e neurônios, contrastando com a esperada distribuição intracitoplasmática das proteínas da família NLRP. Nos queratinócitos da pele, NLRP1 e NLRP3 foram detectados apenas fracamente. ${ }^{103}$

Em 2010, Okamoto et al, analisaram tecidos de melanoma por meio de imunohistoquímica, utilizando anticorpo policlonal contra IL-1 $\beta$ humana. A coloração só mostrou-se positiva nos materiais de melanomas metastáticos, enquanto as lesões de melanoma primário foram negativas à coloração. ${ }^{96}$ 


\section{JUSTIFICATIVA}

O inflamassoma desempenha papel fundamental na resposta imune a neoplasias, através do controle da secreção de citocinas, entre elas a IL-1 $\beta$ e IL-18. A associação entre melanoma e inflamassoma vem sendo demonstrada em estudos recentes e novas descobertas são necessárias para melhor elucidação deste mecanismo.

A expressão de alguns componentes do inflamassoma em diferentes tecidos foi analisada em alguns estudos, entretanto a literatura ainda apresenta uma lacuna quanto à expressão de seus componentes no espectro das lesões melanocíticas.

Este estudo pretende investigar através da técnica de imuno-histoquímica a expressão dos diferentes componentes do inflamassoma (NLRP1, NLRP3, caspase-1) e da IL-1 $\beta$ nas lesões de melanoma e de nevo melanocítico.

Nossa hipótese consistia em que os componentes do inflamassoma seriam expressos de forma diferente entre nevos e melanomas, e que, nos melanomas, encontraríamos uma maior expressão à medida que analisássemos lesões mais espessas. 


\section{OBJETIVOS}

\section{Geral}

Analisar a expressão do inflamassoma no espectro de neoplasias melanocíticas, incluindo quatro grupos: nevo intradérmico, nevo displásico, melanoma fino e melanoma intermediário-espesso.

\section{Específicos}

a) estudar a expressão dos componentes do inflamassoma (NLRP-1, NLRP-3, caspase-1) e da IL-1 $\beta$ nas lesões de melanoma e comparar com a expressão nos nevos melanocíticos;

b) analisar se a expressão do inflamassoma apresenta variação relacionada à espessura do melanoma;

c) avaliar se a expressão do inflamassoma apresenta variação entre nevos displásicos e intradérmicos. 


\section{MÉTODOS}

O presente estudo é observacional, retrospectivo, e foi aprovado pela Comissão de Ética para Análise de Projetos de Pesquisa do Hospital das Clínicas da Faculdade de Medicina da Universidade de São Paulo (CAPPesq 656.689).

\subsection{Seleção dos pacientes}

Foram selecionados 25 pacientes com diagnóstico de melanoma, dos 578 casos catalogados no banco de dados do Ambulatório de Oncologia Cutânea da Divisão de Dermatologia do Hospital das Clínicas da FMUSP, em novembro de 2012. Dentre as amostras selecionadas, 16 enquadravam-se no grupo de melanomas in situ ou com índice de Breslow menor que $1 \mathrm{~mm}$; e 9 apresentavam Breslow maior que $1 \mathrm{~mm}$.

Também foram selecionados 22 pacientes com diagnóstico de nevo melanocítico, que foram removidos no Ambulatório de Cirurgia da Divisão de Dermatologia do Hospital das Clínicas da FMUSP. Destes, 12 eram nevos intradérmicos e 10 nevos displásicos.

\subsection{Revisão das lâminas}

Foram obtidas lâminas com seções de amostras de tecido, fixados em formalina do banco de tecidos do Departamento de Dermatologia do Hospital das Clínicas da FMUSP. O diagnóstico de melanoma e nevo baseou-se em critérios histológicos, bem como na classificação subsequente em melanoma fino $(<1 \mathrm{~mm})$ ou intermediárioespesso (> 1mm), e em nevo intradérmico ou displásico.

A seguir foram feitas 8 lâminas silanizadas em branco de cada bloco de parafina dos casos incluídos no estudo. Estas foram encaminhadas, então, aos laboratórios para os testes imuno-histoquímicos. 


\subsection{Imuno-histoquímica}

Para a demonstração da expressão de NLRP1, NLRP3, IL-1 $\beta$ e caspase-1 nos espécimes de melanoma e de nevo foi utilizada a técnica de imuno-histoquímica.

Cortes histológicos de $4 \mu \mathrm{m}$ de espessura foram obtidos a partir de material embebido em parafina e colhidos em lâminas previamente preparadas com solução adesiva de 3 amino-propyltriethoxy-silane (Sigma Chemical Co., St. Louis, MO/USA, cód. A3648) a 2\%. A seguir, os cortes histológicos foram desparafinizados em dois banhos de xilol de 20 e 10 minutos, respectivamente, à temperatura ambiente. Na seqüência, os espécimes foram hidratados em bateria decrescente de etanol (100\%, 95\% e 70\%) e lavagem em água corrente por cinco minutos.

O bloqueio de peroxidase endógena foi feito em câmara escura com três incubações em água oxigenada $3 \%$ por 10 minutos cada.

Posteriormente, as lâminas foram lavadas em água corrente durante cinco minutos e submetidas a tratamento para exposição dos sítios antigênicos em calor úmido, em banho maria a $95^{\circ} \mathrm{C}$. As lâminas utilizadas para a identificação de NLRP3 e IL-1 $\beta$ foram colocadas na solução Target Retrieval Solution pH 9,0 (cód. S2367, DakoCytomation, Carpinteria, CA, USA) por 20 minutos. Já as lâminas para Caspase-1 e NLRP1 foram imersas na solução Target Retrieval Solution (cód. S1699, DakoCytomation, Carpinteria, CA, USA) por 40 minutos.

As lâminas foram lavadas em água corrente e água destilada por cinco minutos cada e submersas em solução salina tamponada (PBS) pH 7.4.

A seguir, foi feito o bloqueio de proteínas inespecíficas do tecido com incubação em solução de leite desnatado (Molico, Nestlé ${ }^{\circledR}$ ) a $10 \%$ durante 30 minutos à temperatura ambiente.

As lâminas foram incubadas com os anticorpos primários diluídos (Tabela 1) em BSA fração V (SERVA. 1930. Heidelberg, Alemanha) 1\%, acrescida de azida sódica 0,1\% em tampão PBS pH 7.4, “overnight" a $4^{\circ} \mathrm{C}$. 
Tabela 1. Anticorpos

\begin{tabular}{lccccccc}
\hline Anticorpo & Descrição & Clone & Isotipo & Código & Marca & Diluição & Sistema \\
\hline NLRP1 & $\begin{array}{c}\text { Policlonal de } \\
\text { coelho para } \\
\text { NLRP1 }\end{array}$ & - & IgG & ab3683 & Abcam & $1: 50$ & N-Histofine \\
\hline CIAS1/NLRP3 & $\begin{array}{c}\text { Monoclonal } \\
\text { murino para } \\
\text { NLRP3 }\end{array}$ & nalpy3-b & IgG1 & ab17267 & Abcam & $1: 50$ & $\begin{array}{c}\text { EnVision } \\
\text { G2 }\end{array}$ \\
\hline Caspase-1 & $\begin{array}{c}\text { Policlonal de } \\
\text { coelho para } \\
\text { caspase-1 }\end{array}$ & - & IgG & ab62698 & Abcam & $1: 50$ & EnVision \\
IL-1 $\beta$ & $\begin{array}{c}\text { Policlonal de } \\
\text { coelho para } \\
\text { IL-1 } \beta\end{array}$ & - & IgG & ab2105 & Abcam & $1: 50$ & EnVision \\
G2
\end{tabular}

Após o procedimento de lavagem das lâminas por duas vezes em tampão PBS pH 7.4 durante cinco minutos cada, procedeu-se à incubação das lâminas para identificação das proteínas NLRP3, IL-1 $\beta$ e Caspase-1 com o anticorpo secundário, chamado de Link (Envision G2 System/AP, cód. KK5355, DakoCytomation, Carpinteria, CA, USA) pronto para uso, em câmara úmida durante 30 minutos a $37^{\circ} \mathrm{C}$.

A seguir, as mesmas lâminas foram lavadas em tampão PBS pH 7.4, por duas vezes, durante cinco minutos cada e incubadas com o polímero de amplificação marcado com a fosfatase alcalina, denominado AP enzime (enhancer) (Envision G2 System/AP, cód. KK5355, DakoCytomation, Carpinteria, CA, USA) pronto para uso, em câmara úmida durante 30 minutos a $37^{\circ} \mathrm{C}$.

Para a identificação de NLRP1 foi utilizado outro sistema de visualização, chamado N-Histofine Simple Stain AP (cód. 414261F, Nichirei Biosciences, Tokyo, Japan). Esse sistema é constituído de um único reagente (polímero), com o qual as lâminas foram incubadas por 30 minutos a temperatura ambiente.

A seguir, os sítios de ligações foram revelados com solução cromógena Permanent Red (cód. K0640, DakoCytomation, Carpinteria, CA, USA), na diluição 1:100. 
As lâminas foram lavadas em água corrente por cinco minutos, contracoradas com Hematoxilina de Carazzi por 20 segundos. A seguir foram lavadas em água corrente, e secas à temperatura ambiente.

A montagem das lâminas foi feita com resina Permount (FISHER Scientific, Fair Lawn, NJ/USA, cód. SP15-100).

\subsection{Análise das lâminas}

As lâminas foram escaneadas e digitalizadas pelo Scanner de Lâminas no Departamento de Patologia da FMUSP. As imagens foram visualizadas utilizando-se o software Pannoramic Viewer, da empresa 3DHistech (Budapeste, Hungria), de uso livre e disponível no site https://www.3dhistech.com. Para cada lâmina foram selecionadas todas as áreas neoplásicas que correspondiam ao tumor em questão, nevo ou melanoma a depender de cada caso. As imagens selecionadas de cada lâmina foram convertidas em um arquivo do tipo TIFF, um acrônimo para Tagged Image File Format, um formato de arquivo para imagens digitais. Antes de utilizarmos o programa de análise de imagens, procedemos à conversão dos arquivos TIFF em JPEG, através do software de edição de imagens, Adobe Photoshop, da Adobe Systems, San José, Califórnia, Estados Unidos, adquirido no sítio eletrônico https://www.adobe.com/br.

O programa utilizado para a análise das lâminas foi o Image Pro Plus, da empresa Media Cybernetics, Maryland, Estados Unidos. Inicialmente avaliamos o espectro de cor considerado como marcação positiva para cada anticorpo. O programa permite a criação de uma ferramenta na qual escolhemos o tom mais claro e o tom mais escuro que consideramos reagente, e então criamos um padrão de positividade das colorações para cada anticorpo (Figura 4). 

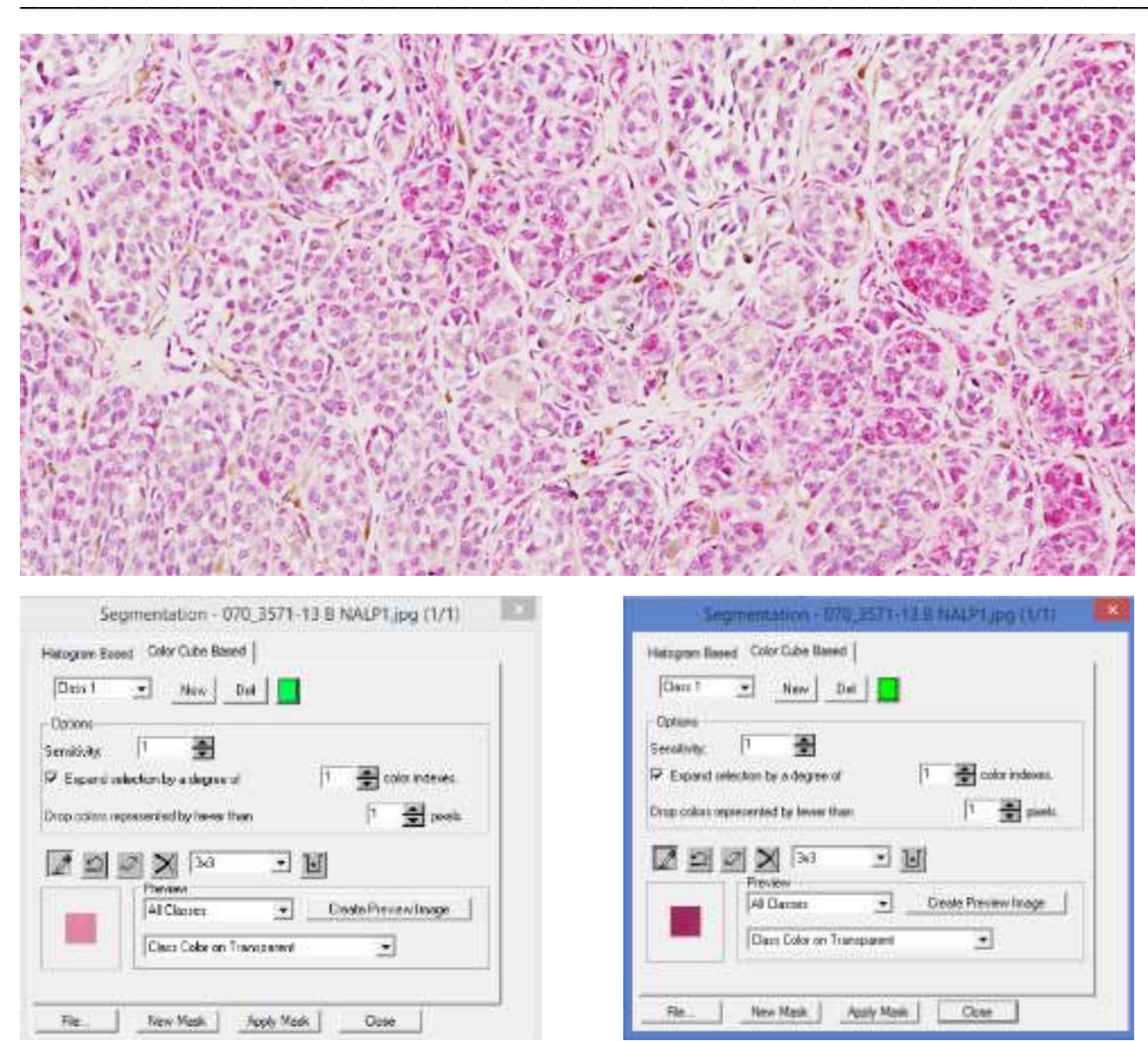

Exemplo de calibração do espectro de cor a ser considerado positivo. Determina-se o tom mais claro e tom mais escuro da coloração a ser interpretado como marcação positiva. Dentro deste espectro, o programa fará a leitura como área reagente.

Figura 4. Calibração dos anticorpos

A área tumoral foi selecionada manualmente, e a proporção de área corada positiva versus a área total selecionada foi calculada para obter o escore de positividade. Artefatos ou áreas muito pigmentadas foram excluídas da análise (Figura 5). 
a

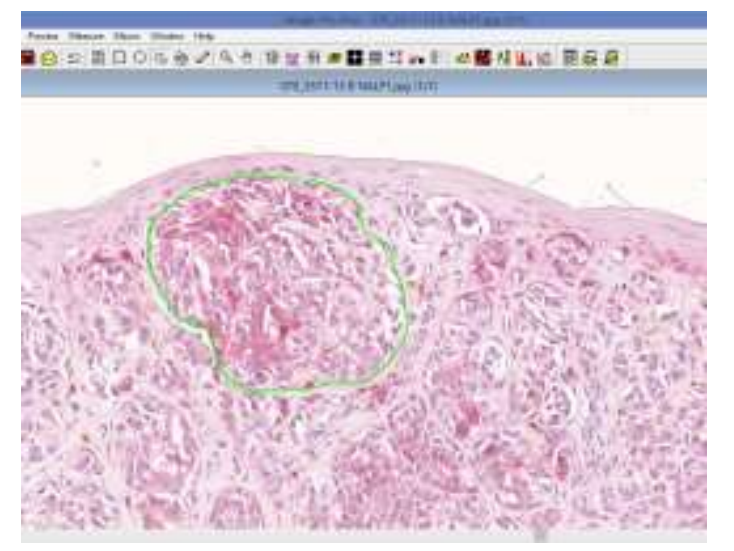

C
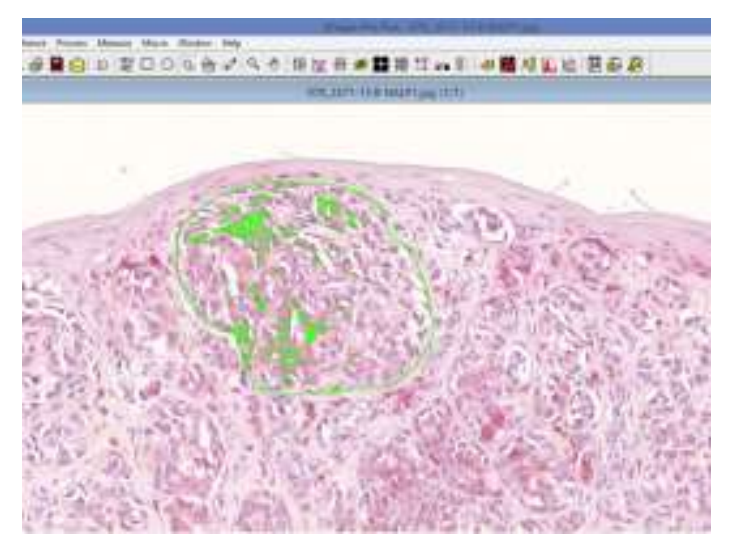

b

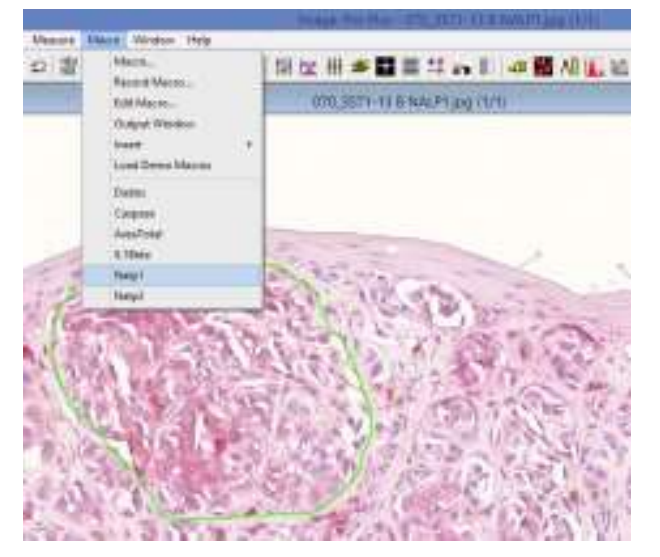

d

\begin{tabular}{|c|c|c|}
\hline 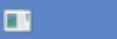 & Statistics & $\square$ \\
\hline \multicolumn{3}{|l|}{ File } \\
\hline$\sqrt{\checkmark}$ Locate the object. & \multicolumn{2}{|c|}{ Г Scroll to the object. } \\
\hline Stats & Area & 100 \\
\hline Min & .23225297 & 25.392992 \\
\hline (8) (Obj.\#) & 1 & 884 \\
\hline Max & 351.86325 & 56882.547 \\
\hline ( $\quad(\mathrm{Obj} . \not{H})$ & 197 & 197 \\
\hline Range & 351.63101 & 56857.152 \\
\hline Mean & 4.3438115 & 701.47363 \\
\hline Std.Dev & 21.750605 & 3478.2065 \\
\hline Sum & 4591.4092 & 741457.63 \\
\hline Samples & 1057 & 1057 \\
\hline
\end{tabular}

Análise. a, área selecionada manualmente para análise em um caso de melanoma. b. selecionada a padronização para o anticorpo NLRP1. c, a cor verde representa as áreas em que a coloração foi lida como positiva. d, nesta tabela, na linha Sum (soma, em português), Area significa a área marcada como positiva e IOD (integrated optical density), a área total selecionada.

Figura 5. Seleção das áreas tumorais para análise da positividade da marcação 


\subsection{Análise estatística}

Estatísticas descritivas foram utilizadas para representar as variáveis. As variáveis qualitativas foram apresentadas pelas suas frequências e porcentagens, e as variáveis quantitativas pela média, desvio padrão, mediana e valores mínimo e máximo.

Associação entre as variáveis qualitativas foi calculada pelo teste exato de Fisher. Comparação entre os valores de positividade dos anticorpos em mais de dois grupos foi realizada pela análise de variância (ANOVA) ou pelo teste de Kruskal-Wallis dependendo do pressuposto da distribuição amostral e testes de comparações múltiplas post-hoc foram calculados segundo o método de Bonferroni. Quando comparados dois grupos foi realizado o teste $\mathrm{t}$ de Student ou teste não paramétrico de Mann-Whitney segundo a distribuição normal ou não dos dados.

O coeficiente de correlação de Spearman (r) permitiu calcular a correlação entre duas variáveis quantitativas. Quando avaliada relação linear entre as proteínas, o método de regressão linear múltiplo foi utilizado, considerando em ambos os modelos a variável IL-1 $\beta$ como variável dependente, o ajuste do modelo foi avaliado pelo coeficiente de determinação simples $\left(\mathrm{R}^{2}\right)$ e o ajustado ( $\mathrm{R}^{2}$ ajustado).

Gráficos de dispersão para avaliar associação entre variáveis quantitativas foram construídos. Na avaliação de uma variável quantitativa segundo categorias foram construídos gráficos de boxplot.

Todas as análises foram realizadas utilizando o software estatístico SPSS for Windows v.18. O nível de significância adotado em todos os testes estatísticos foi de $5 \%$. 


\section{RESULTADOS}

O estudo analisou 47 lesões de indivíduos com melanoma intermediário/espesso $(n=9)$, melanoma fino $(n=16)$, nevo intradérmico $(n=12)$ e nevo displásico $(n=10)$. As características dos pacientes encontram-se na Tabela 2. A maioria dos nevos intradérmicos foi de mulheres $(83,3 \%)$, distribuição similar entre homens e mulheres observou-se para as outras lesões, e não resultou em diferenças significativas $(p=0,344)$. Não houve associação entre a faixa etária e o tipo de lesão, embora tenha se observado que nos melanomas finos houve maioritariamente pessoas acima dos 51 anos.

Presença de ulceração mostrou-se associada com o tipo de melanoma $(p=0,040)$ assim como a metástase linfonodal $(\mathrm{p}=0,037)$

Tabela 2. Descrição dos pacientes com melanoma e nevo

\begin{tabular}{|c|c|c|c|c|c|}
\hline Característica & $\begin{array}{c}\text { Nevo } \\
\text { intradérmico } \\
\mathrm{n}=12 \\
\mathrm{n}(\%)\end{array}$ & $\begin{array}{c}\text { Nevo } \\
\text { displásico } \\
\mathrm{n}=10 \\
\mathrm{n}(\%)\end{array}$ & $\begin{array}{c}\text { Melanoma } \\
\text { espesso } \\
\mathrm{n}=9 \\
\mathrm{n}(\%)\end{array}$ & $\begin{array}{c}\text { Melanoma } \\
\text { fino } \\
\mathrm{n}=16 \\
\mathrm{n}(\%)\end{array}$ & $\underset{p^{2}}{\text { Valor de }}$ \\
\hline Sexo & & & & & 0,344 \\
\hline Masculino & $2(16,7)$ & $5(50,0)$ & $4(44,4)$ & $7(43,8)$ & \\
\hline Feminino & $10(83,3)$ & $5(50,0)$ & $5(55,6)$ & $9(56,2)$ & \\
\hline Faixa etária & & & & & 0,065 \\
\hline$\leq 40$ anos & $6(50,0)$ & $4(40,0)$ & $4(44,4)$ & $1(6,3)$ & \\
\hline $41-50$ anos & $4(33,3)$ & $1(10,0)$ & 0 & $2(12,5)$ & \\
\hline $51-60$ anos & $1(8,3)$ & $2(20,0)$ & $2(22,2)$ & $6(37,5)$ & \\
\hline$\geq 61$ anos & $1(8,3)$ & $3(30,0)$ & $3(33,3)$ & $7(43,8)$ & \\
\hline Média (DP) & $41,8(14,0)$ & $45,1(20,8)$ & $49,6(13,3)$ & $58,9(13,2)$ & \\
\hline Ulceração $^{l}$ & & & & & 0,040 \\
\hline Não & & & $5(55,6)$ & $15(93,8)$ & \\
\hline Sim & & & $4(44,4)$ & $1(6,3)$ & \\
\hline Regressãa ${ }^{l}$ & & & & & 0,280 \\
\hline Não & & & $9(100)$ & $13(81,2)$ & \\
\hline Sim & & & 0 & $3(18,8)$ & \\
\hline $\begin{array}{l}\text { Metástase } \\
\text { linfonodal }^{I}\end{array}$ & & & & & 0,037 \\
\hline Não & & & $6(66,7)$ & $16(100)$ & \\
\hline Sim & & & $3(33,3)$ & 0 & \\
\hline $\begin{array}{l}\text { Metástase } \\
\text { visceral }^{l}\end{array}$ & & & & & 0,333 \\
\hline Não & & & $7(87,5)$ & $16(100)$ & \\
\hline Sim & & & $1(12,5)$ & 0 & \\
\hline
\end{tabular}

DP: desvio padrão. ${ }^{1}$ Comparação entre subtipos de melanoma; ${ }^{2}$ Teste exato de Fisher. 


\subsection{Comparação entre a expressão dos anticorpos entre os subgrupos (nevo displásico, nevo intradérmico, melanoma fino e melanoma intermediário-espesso)}

A análise da expressão das proteínas do inflamassoma segundo o tipo de lesão é apresentada na Tabela 3.

Diferenças estatisticamente significativas foram observadas com relação à expressão de caspase-1 segundo as lesões, no entanto, o teste post-hoc para comparação de pares não foi significativo. Diferenças entre as médias dos valores de positividade para NLRP1 segundo o tipo de lesão foram estatisticamente significantes $(\mathrm{p}<0,001)$, observando-se diferença entre melanoma fino e os outros tipos de lesão. Os anticorpos IL-1 $\beta$ e NLRP3 não apresentaram evidência de diferenças entre os valores médios de positividade entre os grupos.

Tabela 3. Comparação entre os níveis de porcentagens positivas dos anticorpos nos subgrupos de nevos e melanomas

\begin{tabular}{|c|c|c|c|c|c|}
\hline Anticorpo & $\begin{array}{c}\text { Nevo } \\
\text { intradérmico }\end{array}$ & Nevo displásico & $\begin{array}{l}\text { Melanoma } \\
\text { intermediário- } \\
\text { espesso }\end{array}$ & Melanoma fino & Estatística $\mathbf{F}$ \\
\hline & $\mathrm{n}=12$ & $\mathrm{n}=10$ & $\mathrm{n}=9$ & $\mathrm{n}=16$ & Valor de $p^{1}$ \\
\hline Caspase-1 & & & & & 3,07 \\
\hline Média (DP) ${ }^{2}$ & $0,03(0,05)^{\mathrm{a}}$ & $0,01(0,03)^{\mathrm{a}}$ & $0,87(1,22)^{a}$ & $1,67(2,80)^{\mathrm{a}}$ & 0,038 \\
\hline Mediana (min-máx) & $0,002(0-0,16)$ & $0,002(0-0,09)$ & $0,31(0,04-3,89)$ & $0,26(0,003-10,08)$ & \\
\hline IL- $1 \beta$ & & & & & 2,02 \\
\hline Média (DP) ${ }^{2}$ & $3,03(7,46)^{\mathrm{a}}$ & $7,19(8,72)^{\mathrm{a}}$ & $4,69(7,49)^{\mathrm{a}}$ & $10,94(11,05)^{\mathrm{a}}$ & 0,126 \\
\hline Mediana (min-máx) & $0,40(0,02-25,33)$ & $3,82(0,23-29,75)$ & $1,88(0,01-22,71)$ & $8,51(0,13-36,09)$ & \\
\hline$N L R P 1$ & & & & & 14,95 \\
\hline Média (DP) ${ }^{2}$ & $1,23(1,47)^{\mathrm{a}}$ & $3,62(4,32)^{\mathrm{a}}$ & $4,42(5,07)^{\mathrm{a}}$ & $17,94(12,00)^{\mathrm{b}}$ & $<0,001$ \\
\hline Mediana (min-máx) & $0,49(0,004-4,30)$ & $1,53(0,05-12,78)$ & $1,99(0,23-13,73)$ & $15,01(1,68-47,02)$ & \\
\hline$N L R P 3$ & & & & & 1,29 \\
\hline Média (DP) ${ }^{2}$ & $1,77(4,26)^{\mathrm{a}}$ & $2,34(3,90)^{\mathrm{a}}$ & $2,16(3,58)^{\mathrm{a}}$ & $3,99(5,20)^{\mathrm{a}}$ & 0,290 \\
\hline Mediana (min-máx) & $0,25(0,21-14,48)$ & $0,14(0,01-10,16)$ & $0,92(0,02-11,35)$ & $0,79(0,01-16,26)$ & \\
\hline
\end{tabular}

DP: desvio padrão; min-máx: valores mínimo e máximo. ${ }^{1}$ Análise de variância; ${ }^{2}$ Teste post-hoc de Bonferroni para comparações múltiplas, grupos com a mesma letra não apresentaram diferenças significativas. 


\subsection{Comparação da expressão dos anticorpos entre nevos e melanomas}

Nesta análise foram comparadas a expressão dos anticorpos para os nevos e melanomas agrupados.

Diferenças entre valores médios de positividade de nevos e melanomas foram significativas para caspase-1 ( $p<0,001), \operatorname{NLRP1}(\mathrm{p}<0,001)$ e NLRP3 $(\mathrm{p}=0,043)$. Não foi observada diferença estatisticamente significativa para IL-1 $\beta(p=0,244)$ (Tabela 4).

Tabela 4. Comparação entre os níveis de porcentagens positivas dos anticorpos nos nevos e melanomas

\begin{tabular}{|c|c|c|c|}
\hline Anticorpo & $\begin{array}{l}\text { Nevo } \\
n=21\end{array}$ & $\begin{array}{c}\text { Melanoma } \\
n=24\end{array}$ & $\begin{array}{l}\text { Estatística } \\
\text { Valor de p }\end{array}$ \\
\hline Caspase-1 & & & $-5,18^{1}$ \\
\hline Média (DP) & $0,02(0,04)$ & $1,37(2,33)$ & $<0,001$ \\
\hline Mediana (min-máx) & $0,002(0-0,16)$ & $0,29(0,003-10,08)$ & \\
\hline IL-1 $\beta$ & & & $-1,17^{1}$ \\
\hline Média (DP) & $5,01(8,16)$ & $8,60(10,17)$ & 0,244 \\
\hline Mediana (min-máx) & $2,08(0,02-29,75)$ & $4,21(0,006-36,09)$ & \\
\hline$N L R P 1$ & & & $-4,20^{2}$ \\
\hline Média (DP) & $2,37(3,31)$ & $12,87(11,88)$ & $<0,001$ \\
\hline Mediana (min-máx) & $0,75(0,004-12,78)$ & $11,65(0,23-47,02)$ & \\
\hline$N L R P 3$ & & & $-2,03^{1}$ \\
\hline Média (DP) & $2,04(4,00)$ & $3,30(4,66)$ & 0,043 \\
\hline Mediana (min-máx) & $0,23(0,01-14,48)$ & $0,86(0,01-16,26)$ & \\
\hline
\end{tabular}

DP: desvio padrão; min-máx: valores mínimo e máximo. ${ }^{1}$ Teste não-paramétrico de Mann-Whitney; ${ }^{2}$ Teste $\mathrm{t}$ de Student.

\subsection{Correlação entre os anticorpos}

A fim de avaliarmos se havia uma correlação entre os anticorpos expressos nos pacientes, procedemos a uma associação linear entre os diferentes anticorpos para o grupo geral (nevos + melanomas) e logo para os grupos (nevos e melanomas) e subgrupos das lesões (nevos intradérmicos, nevos displásicos, melanomas finos, melanomas intermediários-espessos) (Tabela 5). 
Analisando todos os casos, os coeficientes de correlação apontam para uma correlação moderada a baixa entre caspase-1 e NLRP1 e entre caspase-1 e NLRP3; assim como IL-1 $\beta$ e NLRP1; entre IL-1 $\beta$ e NLRP3; e entre NLRP1 e NLRP3.

Para o grupo de nevos, correlação moderada entre IL-1 $\beta$ e NLRP1 foi a única que resultou significativa. No grupo de melanomas, correlação moderada entre caspase1 e IL-1 $\beta$ foi significativa.

$\mathrm{Na}$ análise por subgrupos, não houve correlação significativa entre os anticorpos nos casos de nevos intradérmicos e de melanomas finos. Para o subgrupo de nevo displásico foi observada correlação moderada entre IL-1 $\beta$ e NLRP1. Para as lesões de melanoma espesso, uma correlação moderada a boa foi vista entre caspase-1 e IL-1 $\beta$ e entre caspase-1 e NLRP1. Já uma associação forte foi observada entre IL-1 $\beta$ e NLRP1 $(\mathrm{r}=0,833 ; \mathrm{p}=0,005)$.

Tabela 5. Correlação entre os anticorpos dos pacientes com melanoma e nevo

\begin{tabular}{|c|c|c|c|c|}
\hline Grupo & & $\begin{array}{c}\text { IL-1 } \beta \\
\mathrm{r}(\text { valor de } \mathrm{p})^{1}\end{array}$ & $\begin{array}{c}\text { NLRP1 } \\
\mathrm{r}(\text { valor de } \mathrm{p})^{1}\end{array}$ & $\begin{array}{c}\text { NLRP3 } \\
\mathrm{r}(\text { valor de } \mathrm{p})^{1}\end{array}$ \\
\hline \multirow[t]{3}{*}{ Geral } & Caspase-1 & $0,284(0,058)$ & $0,599(<0,001)$ & $0,312(0,035)$ \\
\hline & IL-1 $\beta$ & 1 & $0,538(<0,001)$ & $0,310(0,036)$ \\
\hline & NLRP1 & & 1 & $0,308(0,035)$ \\
\hline \multirow[t]{3}{*}{ Nevo } & Caspase-1 & $-0,058(0,804)$ & $0,285(0,211)$ & $0,038(0,870)$ \\
\hline & IL-1 $\beta$ & 1 & $0,512(0,015)$ & $0,291(0,189)$ \\
\hline & NLRP1 & & 1 & $0,357(0,102)$ \\
\hline \multirow[t]{3}{*}{ Melanoma } & Caspase-1 & $0,500(0,013)$ & $0,275(0,183)$ & $0,115(0,585)$ \\
\hline & IL-1 $\beta$ & 1 & $0,385(0,063)$ & $0,151(0,480)$ \\
\hline & NLRP1 & & 1 & $-0,065(0,759)$ \\
\hline \multirow[t]{3}{*}{ Nevo intradérmico } & Caspase-1 & $-0,422(0,196)$ & $0,101(0,768)$ & $-0,532(0,092)$ \\
\hline & $\mathrm{IL}-1 \beta$ & 1 & $0,434(0,159)$ & $0,315(0,319)$ \\
\hline & NLRP1 & & 1 & $0,266(0,404)$ \\
\hline \multirow[t]{3}{*}{ Nevo displásico } & Caspase-1 & $0,462(0,179)$ & $0,505(0,137)$ & $0,565(0,089)$ \\
\hline & $\mathrm{IL}-1 \beta$ & 1 & $0,636(0,048)$ & $0,624(0,054)$ \\
\hline & NLRP1 & & 1 & $0,527(0,117)$ \\
\hline \multirow[t]{3}{*}{ Melanoma espesso } & Caspase-1 & $0,683(0,042)$ & $0,767(0,016)$ & $-0,417(0,265)$ \\
\hline & $\mathrm{IL}-1 \beta$ & 1 & $0,833(0,005)$ & $-0,317(0,406)$ \\
\hline & NLRP1 & & 1 & $-0,317(0,406)$ \\
\hline \multirow[t]{3}{*}{ Melanoma fino } & Caspase-1 & $0,507(0,054)$ & $0,259(0,333)$ & $0,409(0,116)$ \\
\hline & IL-1 $\beta$ & 1 & $-0,093(0,742)$ & $0,393(0,147)$ \\
\hline & NLRP1 & & 1 & $-0,147(0,587)$ \\
\hline
\end{tabular}

\footnotetext{
${ }^{1}$ Coeficiente de correlação de Spearman.
} 


\section{Relação entre caspase-1, NLRP1, NLRP3 e IL-1 $\beta$}

A expressão de IL-1 $\beta$ pode estar correlacionada com a expressão de caspase-1, NLRP1 e/ou NLRP3 de forma linear. Para avaliar se a IL-1 $\beta$ é uma função dos outros dois anticorpos (CASPASE-1 + NLRP1 ou CASPASE-1 + NLRP3), foi utilizada a regressão linear múltipla.

Modelo de regressão linear

$$
Y=f\left(x_{1}, x_{2}\right)
$$

Onde:

$I L 1 B=f(C A S P A S E, N A L P 1)$

ou

$I L 1 B=f(C A S P A S E, N A L P 3)$

Equação de regressão linear

$$
\begin{aligned}
& \mathrm{IL}-1 \beta=\beta_{0}+\beta_{1} . \text { CASPASE }-1+\beta_{2} . N L R P 1 \\
& \mathrm{IL}-1 \beta=\beta_{0}+\beta_{1} . \text { CASPASE }-1+\beta_{2} . N L R P 3
\end{aligned}
$$

\begin{tabular}{|c|c|c|c|c|c|}
\hline Modelo & Variáveis & $\begin{array}{c}\text { Coeficiente beta }(\beta) \\
(\text { IC95\%) }\end{array}$ & Valor de $p$ & $\mathbf{R}^{2 \S}$ & $\mathbf{R}^{2}$ ajustado \\
\hline \multicolumn{6}{|l|}{ Nevo } \\
\hline \multirow[t]{3}{*}{$\underline{\text { Modelo I }}$} & Constante & $0,79(-2,15 ; 3,73)$ & 0,578 & 0,820 & 0,673 \\
\hline & Caspase-1 & $-30,93(-88,77 ; 26,92)$ & 0,276 & & \\
\hline & NLRP1 & $2,05(1,34-2,76)$ & $<0,001$ & & \\
\hline \multirow[t]{3}{*}{ Modelo 2} & Constante & $1,41(-0,92 ; 3,75)$ & 0,220 & 0,879 & 0,773 \\
\hline & Caspase-1 & $-3,04(-50,62 ; 44,54)$ & 0,895 & & \\
\hline & NLRP3 & $1,79(1,31 ; 2,78)$ & $<0,001$ & & \\
\hline \multicolumn{6}{|l|}{ Melanoma } \\
\hline \multirow[t]{3}{*}{ Modelo 1} & Constante & $3,41(-2,66 ; 9,47)$ & 0,256 & 0,526 & 0,277 \\
\hline & Caspase-1 & $2,01(0,32 ; 3,69)$ & 0,022 & & \\
\hline & NLRP1 & $0,19(-0,14 ; 0,52)$ & 0,247 & & \\
\hline \multirow[t]{3}{*}{ Modelo 2} & Constante & $2,48(-2,21 ; 7,17)$ & 0,284 & 0,656 & 0,430 \\
\hline & Caspase-1 & $2,10(0,61 ; 3,59)$ & 0,008 & & \\
\hline & NLRP3 & $0,98(0,23 ; 1,73)$ & 0,013 & & \\
\hline
\end{tabular}

Tabela 6. Associação entre caspase-1, NLRP1, NLRP3 e IL-1 $\beta$ em pacientes com nevo e melanoma

$\overline{{ }^{\mathbb{I}} \text { IC95\%: intervalo com } 95 \% \text { de confiança para beta }(\beta) ;{ }^{\S} \text { Coeficiente de determinação; }{ }^{¥} \text { Coeficiente de }}$ determinação ajustado. 
Foram construídos dois modelos de regressão em cada um dos grupos de lesões (nevo e melanoma). Para o grupo nevo, o modelo com a variável NLRP3 mostrou-se melhor no ajuste, sendo que o valor do coeficiente de determinação foi $R^{2}=0,879$ (quanto mais próximo de 1 o modelo se ajusta melhor).

No caso do grupo melanoma também o segundo modelo com a variável NLRP3 mostrou melhor ajuste $\left(\mathrm{R}^{2}=0,656\right)$ (Tabela 6).

Entretanto, a baixa expressão da caspase-1 em todos os subgrupos limita alguma conclusão sobre a viabilidade destes modelos em nossas amostras.

A

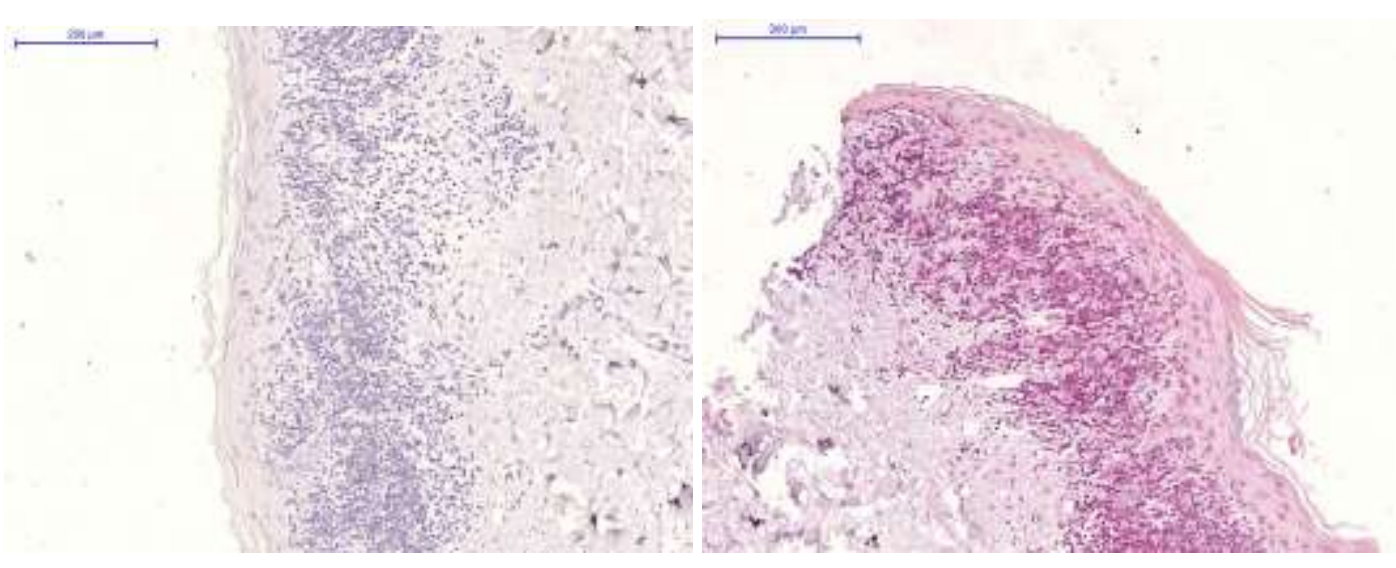

B

Aumento em 10x de imagens dos controles para NLRP1. A, controle negativo. B, controle positivo.

Figura 6. Controle NLRP1 
A

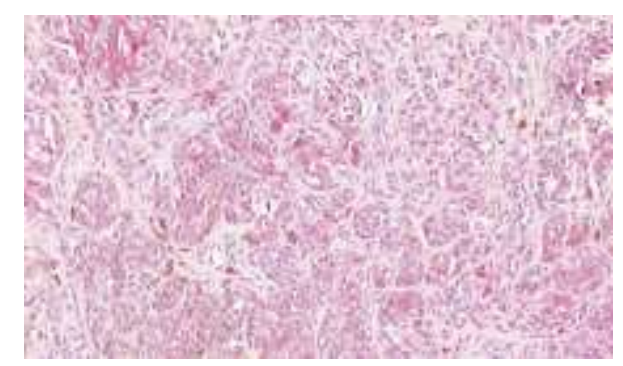

Melanoma espesso

C

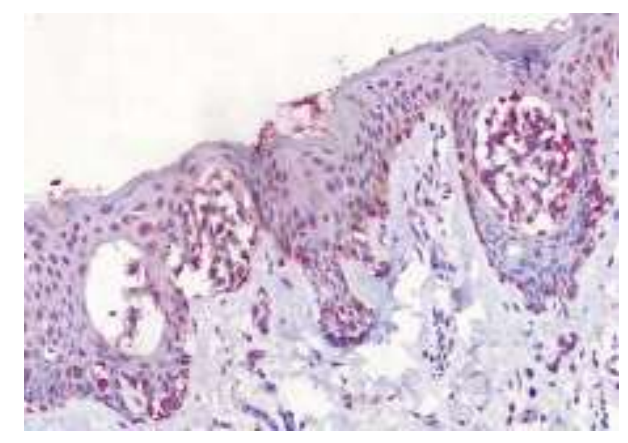

Nevo displásico
B

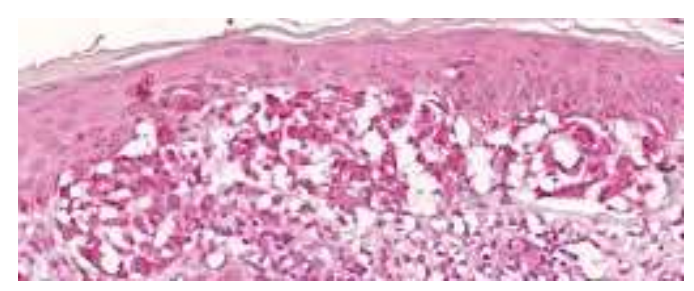

Melanoma fino

D

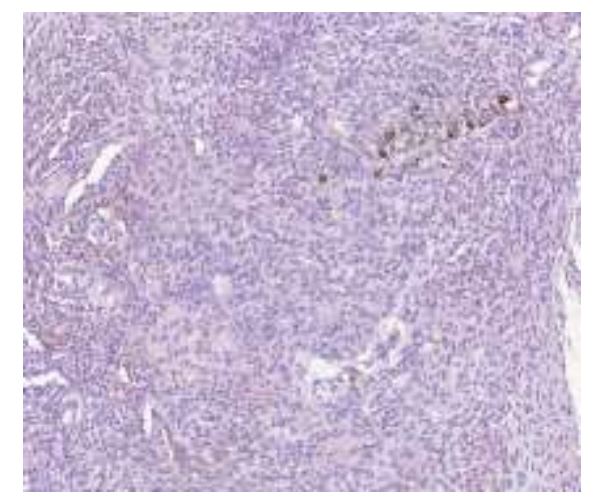

Nevo intradérmico

NLRP1. Técnica de imuno-histoquímica. Aumento em 20x. Ninhos de melanócitos em melanoma fino mostram maior marcação. O cromógeno utilizado foi a solução Permanent Red. Slides foram contrastados com Hematoxilina de Carazzi. A, melanoma espesso. B, melanoma fino. C, nevo displásico. D, nevo intradérmico

\section{Figura 7. NLRP1}
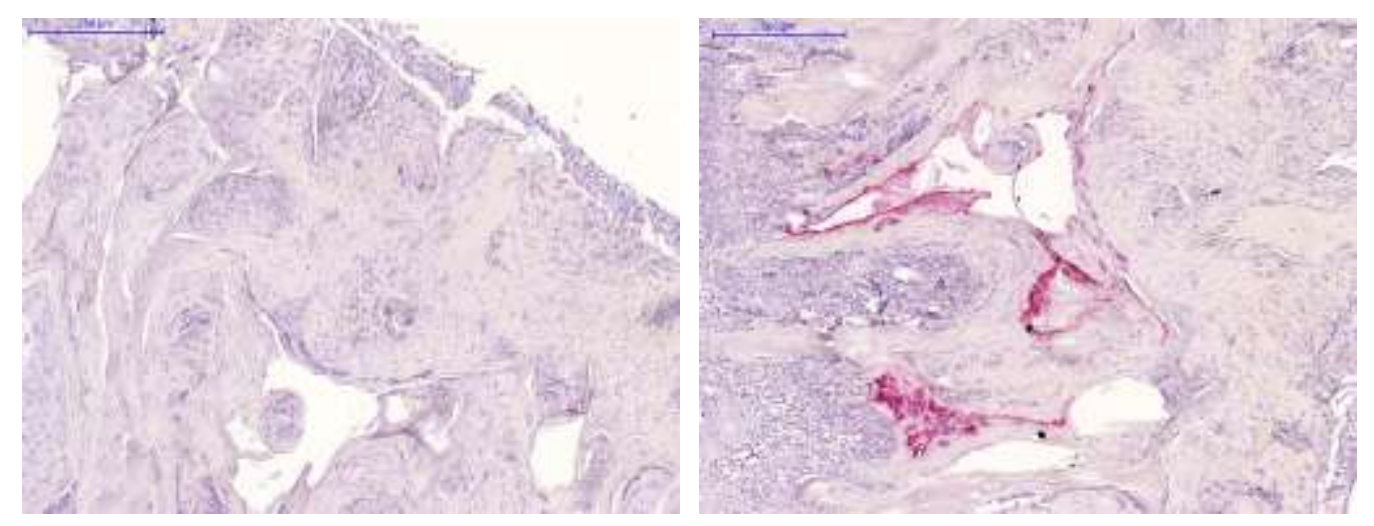

Aumento em 10x de imagens dos controles para caspase-1. A, controle negativo. B, controle positivo.

Figura 8. Controle caspase-1 


\section{A}

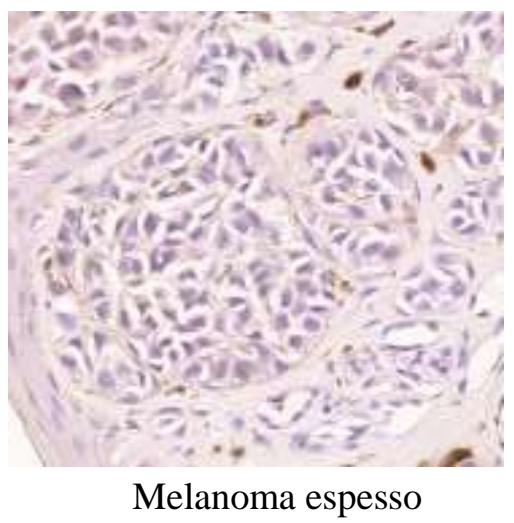

C

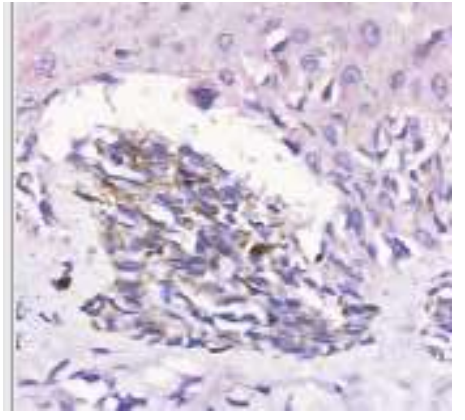

Nevo displásico
B

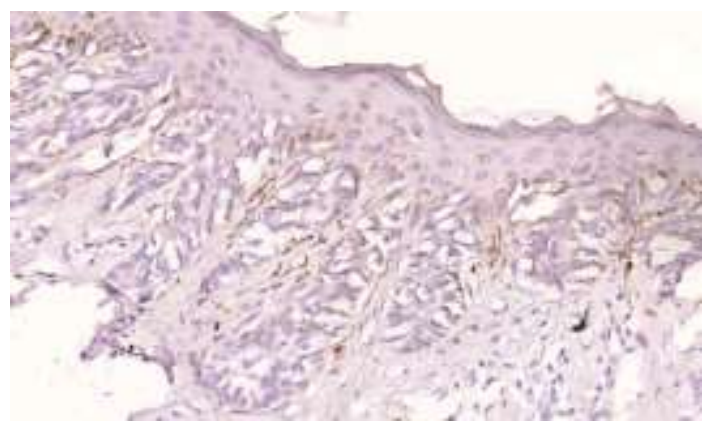

Melanoma fino

D

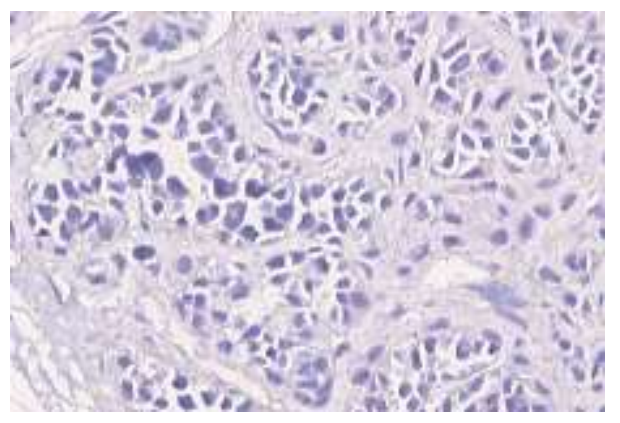

Nevo intradérmico

Caspase-1. Técnica de imuno-histoquímica. Marcação negativa nas 4 amostras. O cromógeno utilizado foi a solução Permanent Red. Slides foram contrastados com Hematoxilina de Carazzi. Aumento de 40x em A, C e D, e de 20x em B. A, melanoma espesso. B, melanoma fino. C, nevo displásico. D, nevo intradérmico.

Figura 9. Caspase-1

A

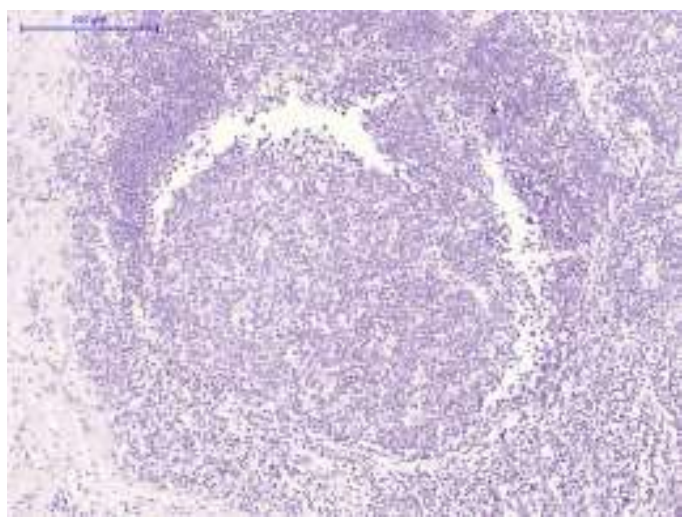

B

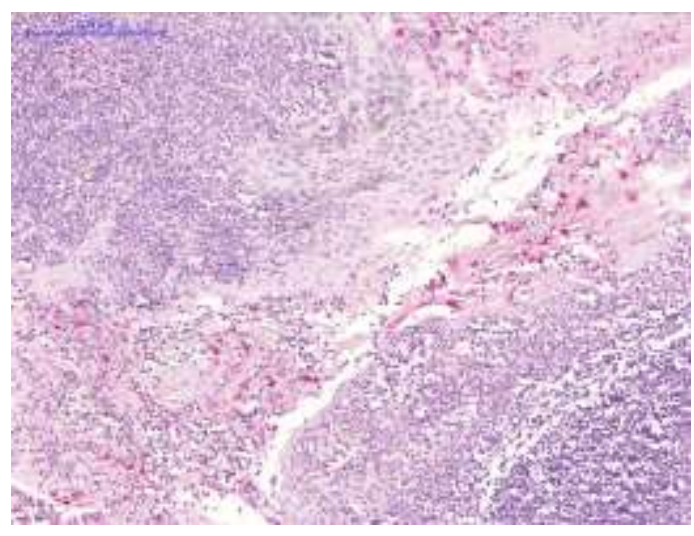

Aumento em 10x de imagens dos controles para IL-1ß. A, controle negativo. B, controle positivo.

Figura 10. Controle IL-1 $\beta$ 
A

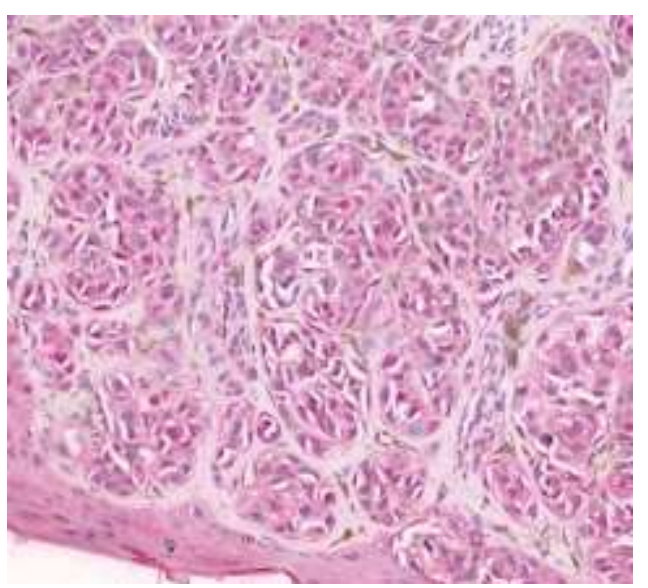

Melanoma espesso

C

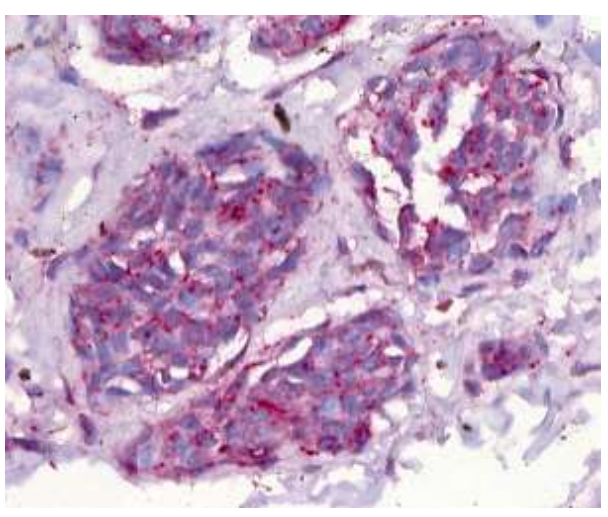

Nevo displásico
B

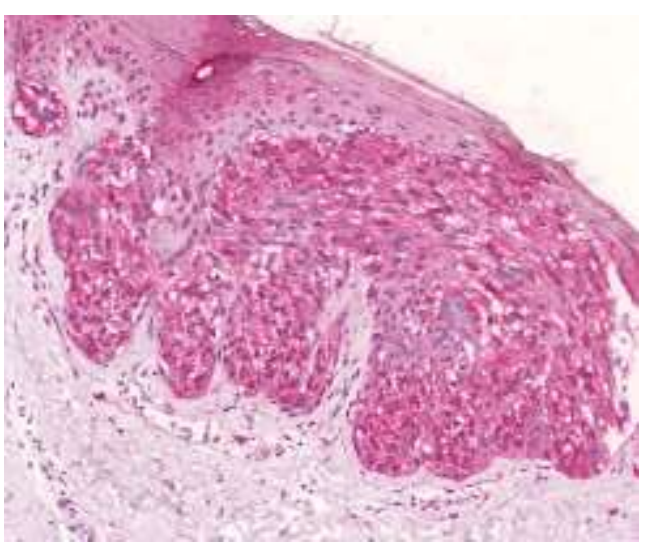

Melanoma fino

D

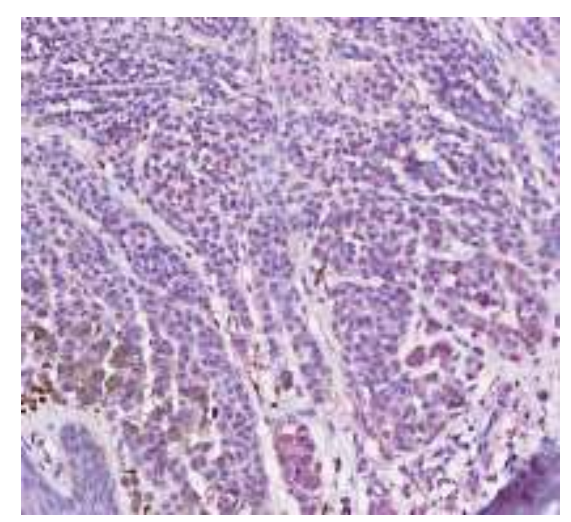

Nevo intradérmico

IL-1 $\beta$. Técnica de imuno-histoquímica. Os 4 casos apresentados evidenciam marcação para IL-1 $\beta$, com maior expressão no melanoma fino. O cromógeno utilizado foi a solução Permanent Red. Slides foram contrastados com Hematoxilina de Carazzi. Aumento de 20x em A, B e D. Aumento de 40x em C A, melanoma espesso. B, melanoma fino. C, nevo displásico. D, nevo intradérmico

Figura 11. IL-1 $\beta$ 


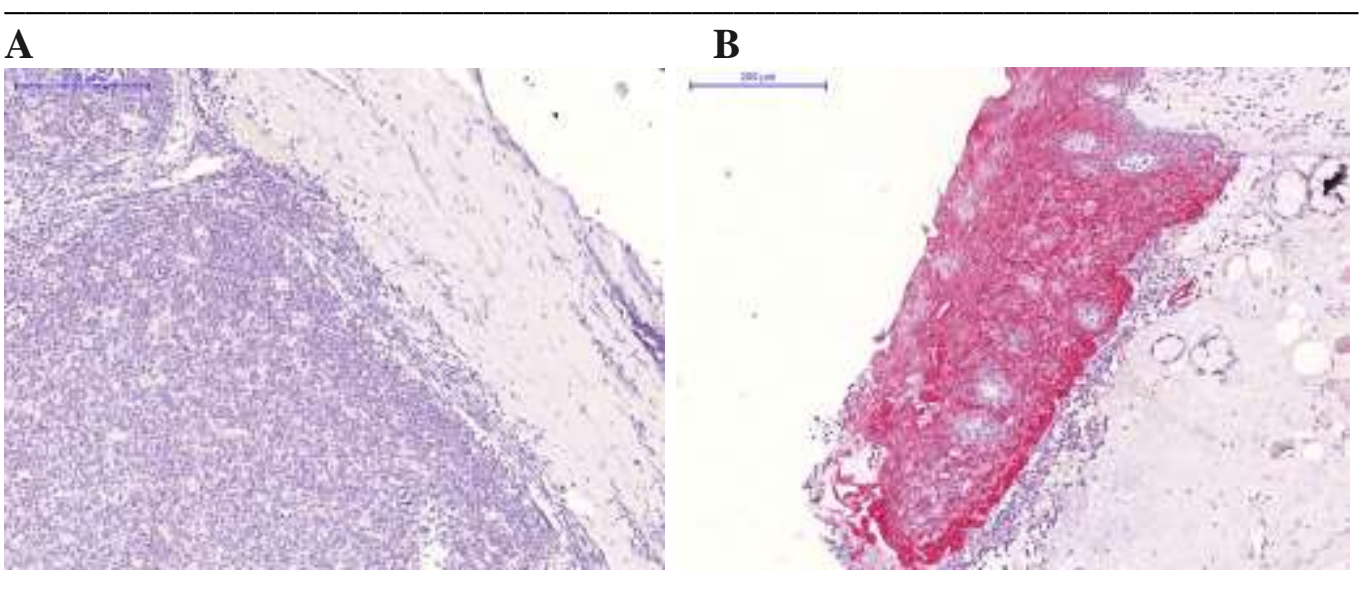

Aumento em 10x de imagens dos controles para NLRP3. A, controle negativo. B, controle positivo.

\section{Figura 12. Controle NLRP3}

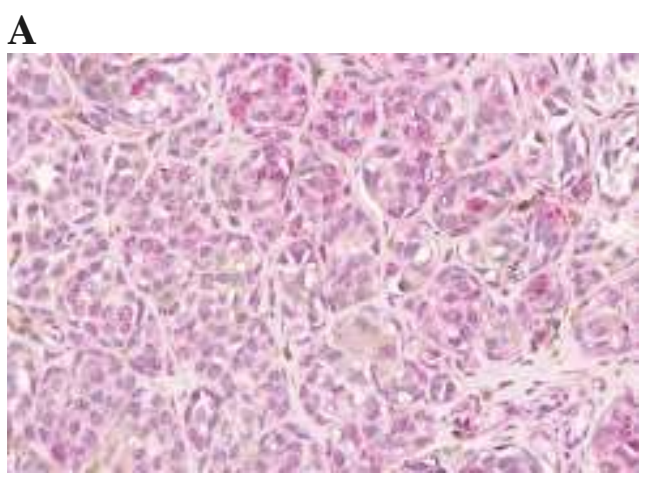

Melanoma espesso

C

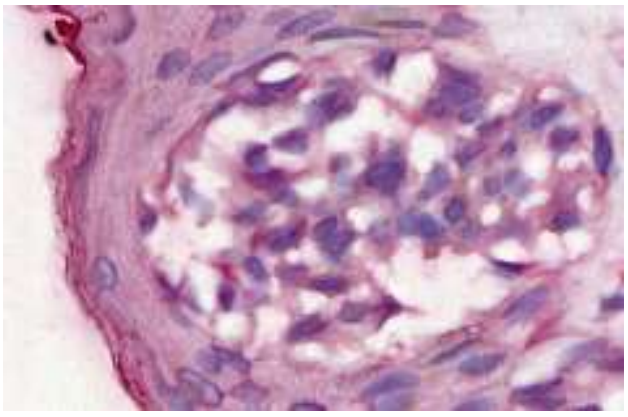

Nevo displásico
B

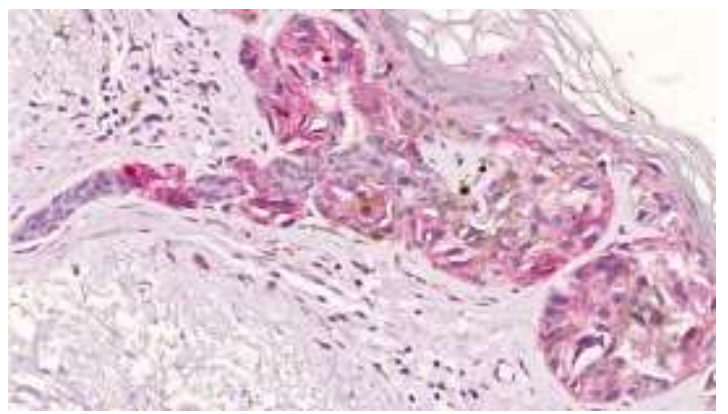

Melanoma fino

D

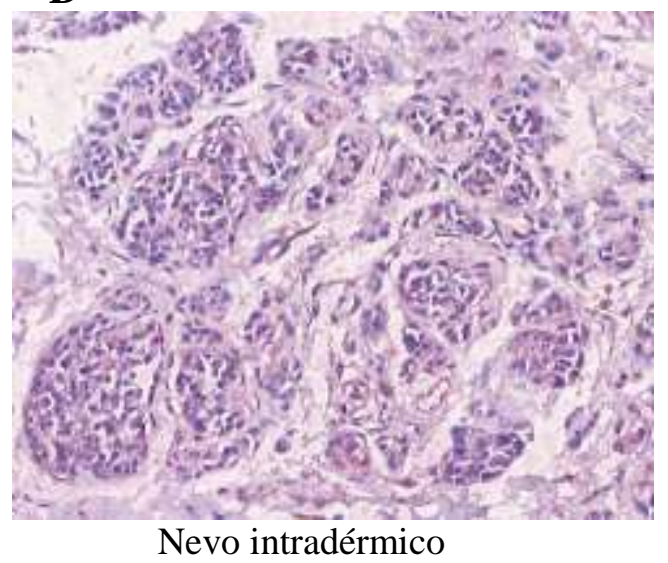

NLRP3. Técnica de imuno-histoquímica. Os 4 casos apresentados evidenciam marcação para NLRP3, com maior expressão no melanoma fino. O cromógeno utilizado foi a solução Permanent Red. Slides foram contrastados com Hematoxilina de Carazzi. Aumento de 20x em A, B e D. Aumento de 40x em C. A, melanoma espesso. B, melanoma fino. $\mathrm{C}$, nevo displásico. D, nevo intradérmico

Figura 13. NLRP3 
Da Figura 14 à Figura 21 apresentam-se as distribuições de positividade dos anticorpos segundo os grupos de estudo (nevo e melanoma) e os subgrupos (nevo intradérmico, nevo displásico, melanoma espesso e melanoma fino).

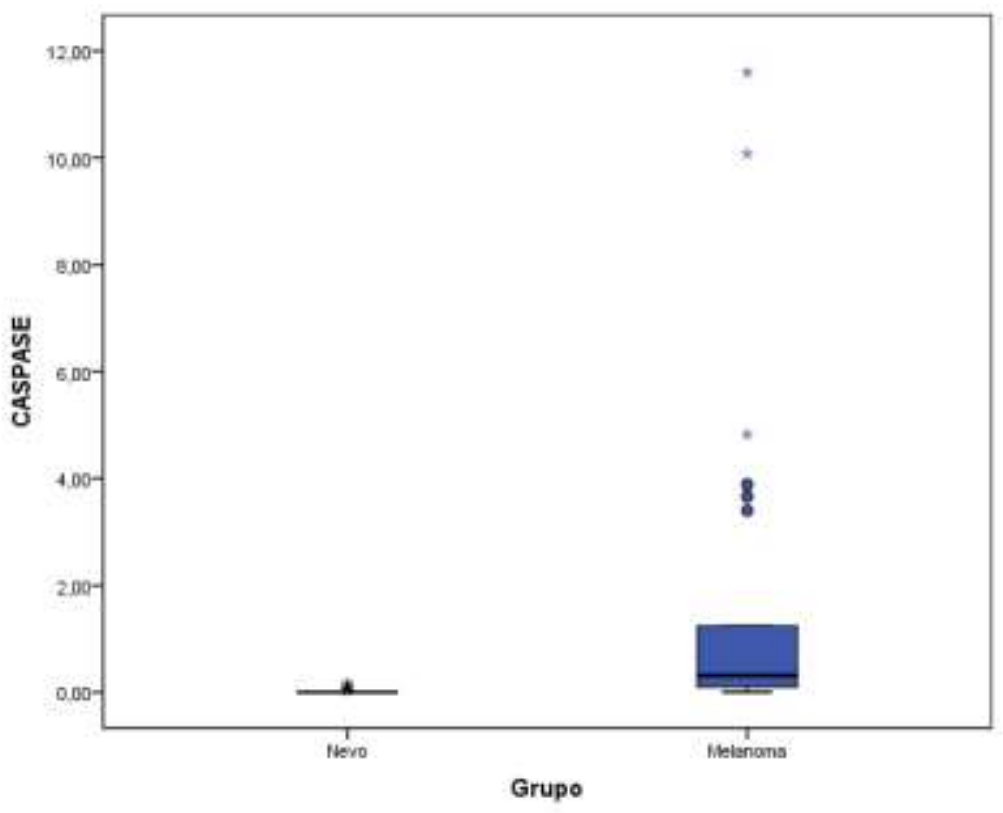

Baixa expressão da Caspase-1. Nos nevos, os níveis foram próximos a zero.

Figura 14. Caspase-1 para os pacientes com nevo e melanoma

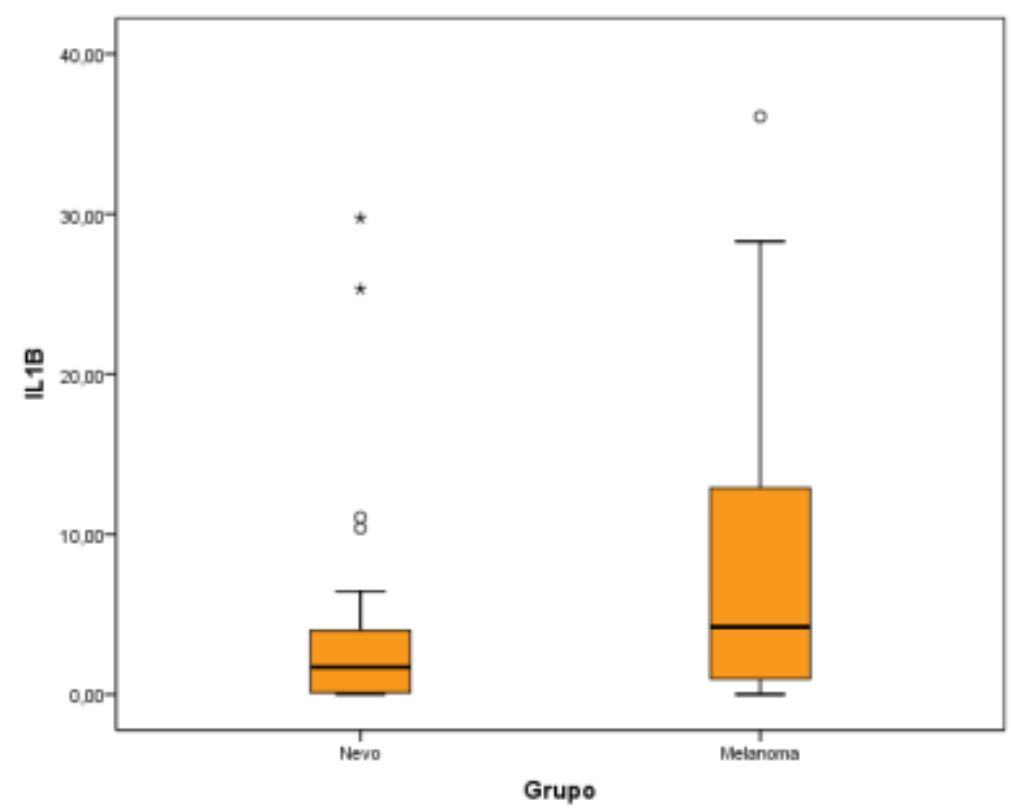

Apesar da maior marcação no grupo dos melanomas, não houve diferença significativa do ponto de vista estatístico.

Figura 15. IL-1 $\beta$ para os pacientes com nevo e melanoma 


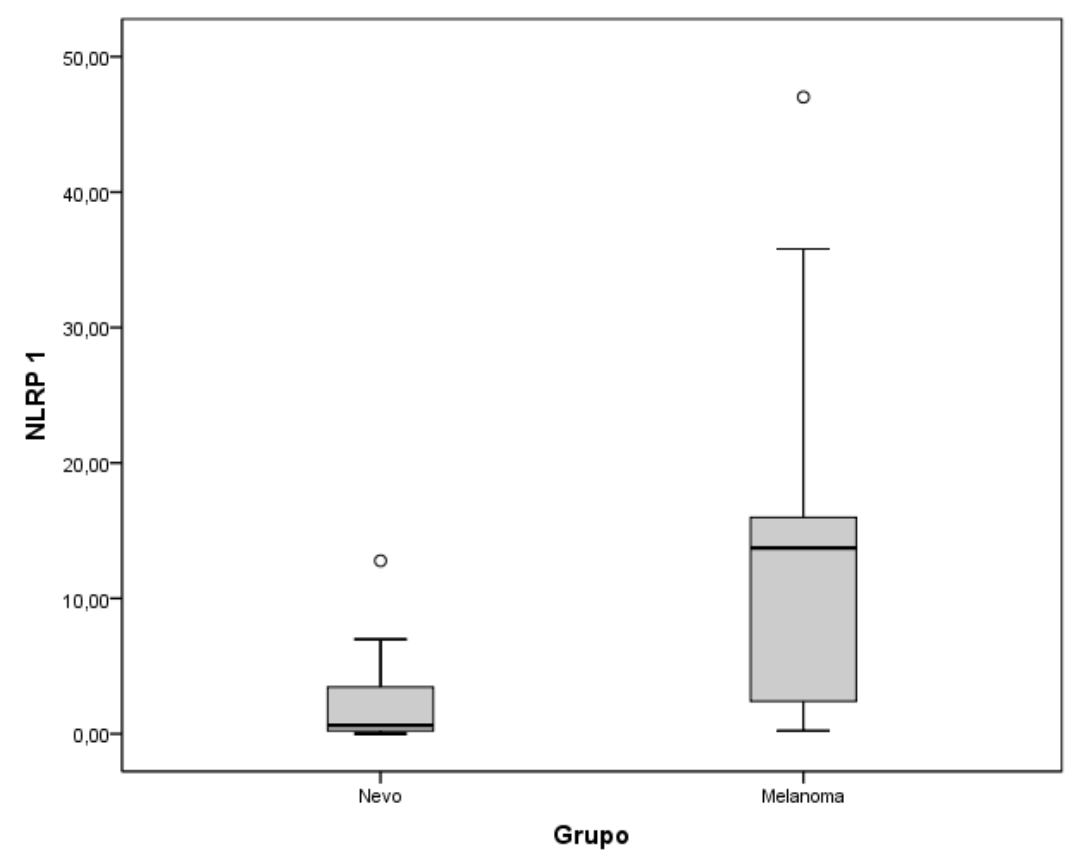

NLRP1 mais expresso nos melanomas do que nos nevos.

Figura 16. NLRP1 para os pacientes com nevo e melanoma

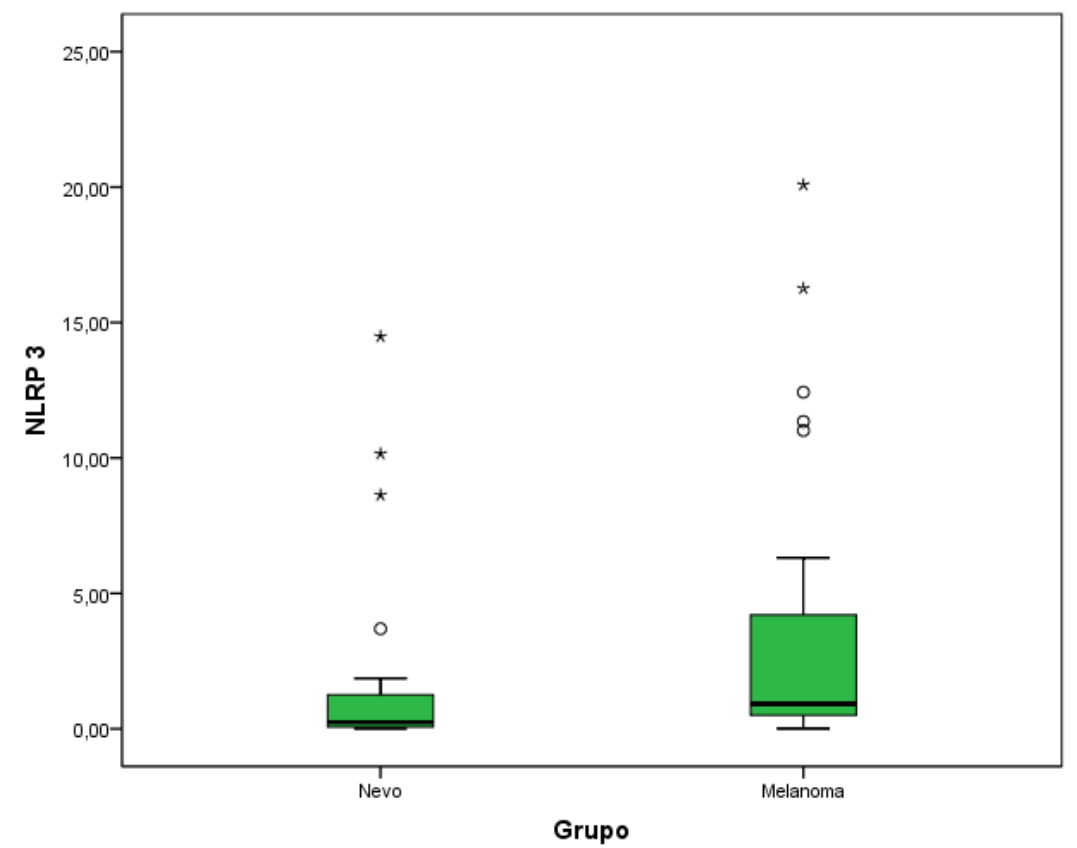

NLRP3. Marcação maior no grupo dos melanomas.

Figura 17. NLRP3 para os pacientes com nevo e melanoma 


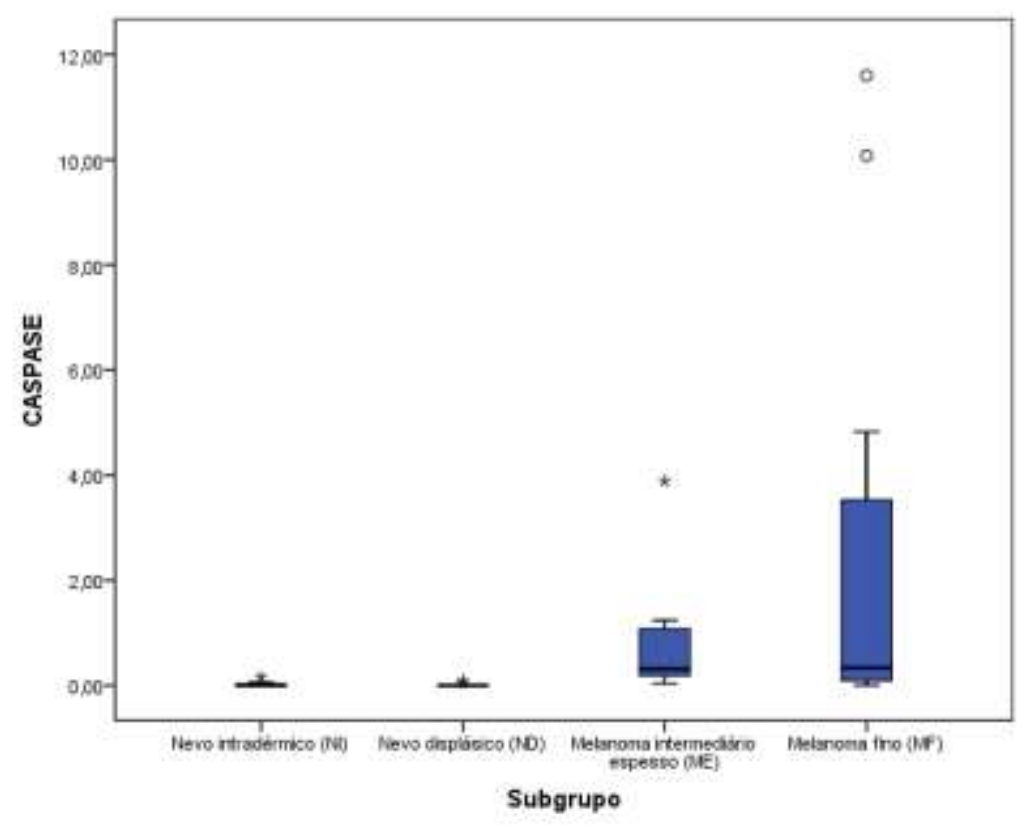

Caspase-1 próximo a zero nos nevos intradérmicos e displásicos. Baixa expressão nos melanomas, mas em maior nível no melanoma fino. Não houve diferença estatisticamente significativa.

Figura 18. Caspase-1 para os subgrupos de nevos e melanomas

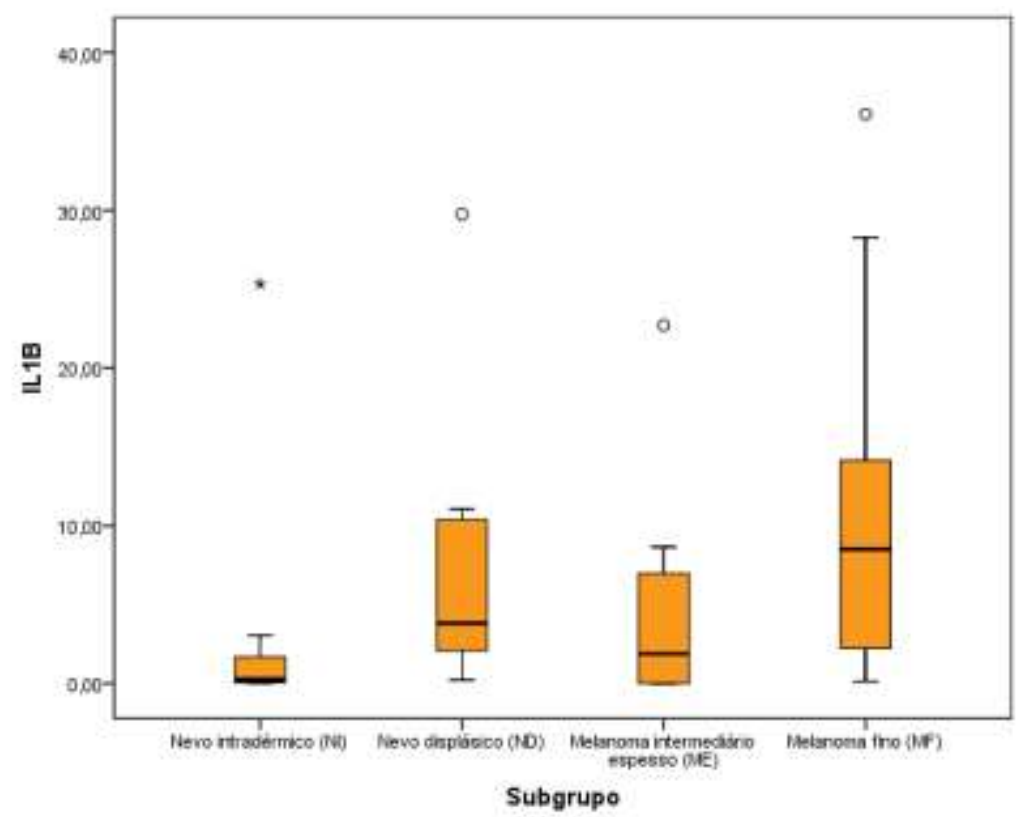

IL-1ß. Sem diferença significativa entre os subgrupos.

Figura 19. IL-1 $\beta$ para os subgrupos de nevos e melanomas 


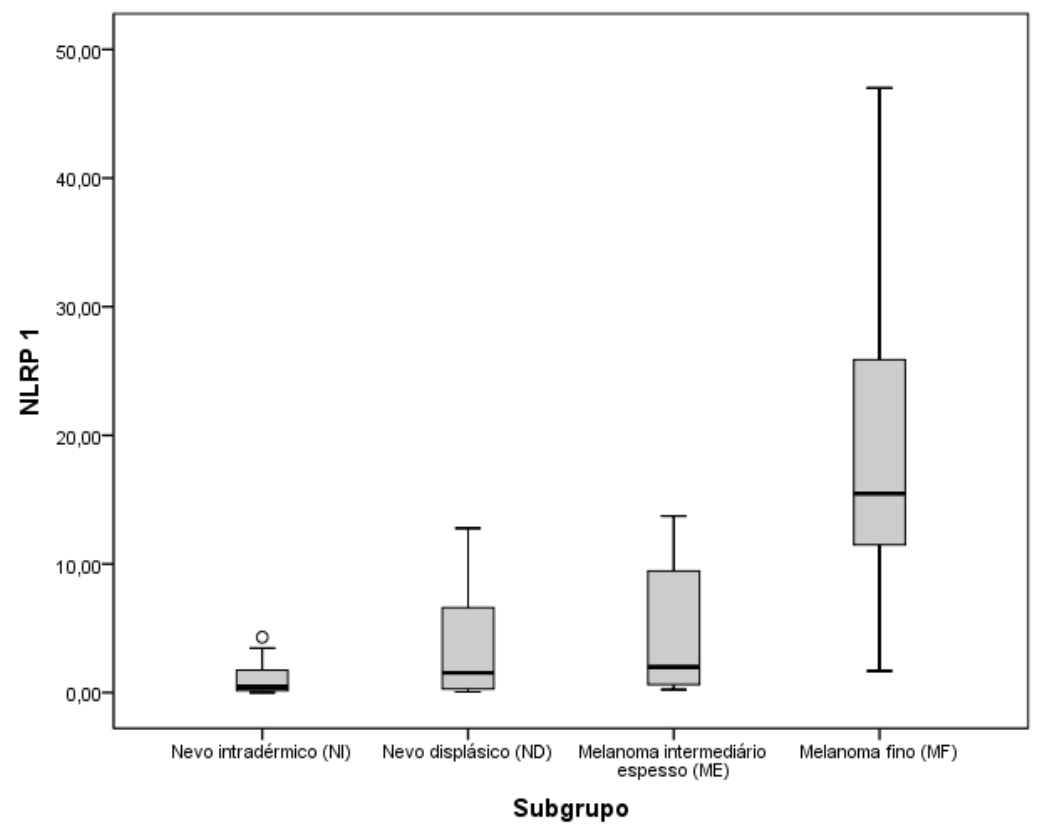

NLRP1. Maior expressão nos melanomas finos em comparação a todos os outros subgrupos.

Figura 20. NLRP1 para os subgrupos de nevos e melanomas

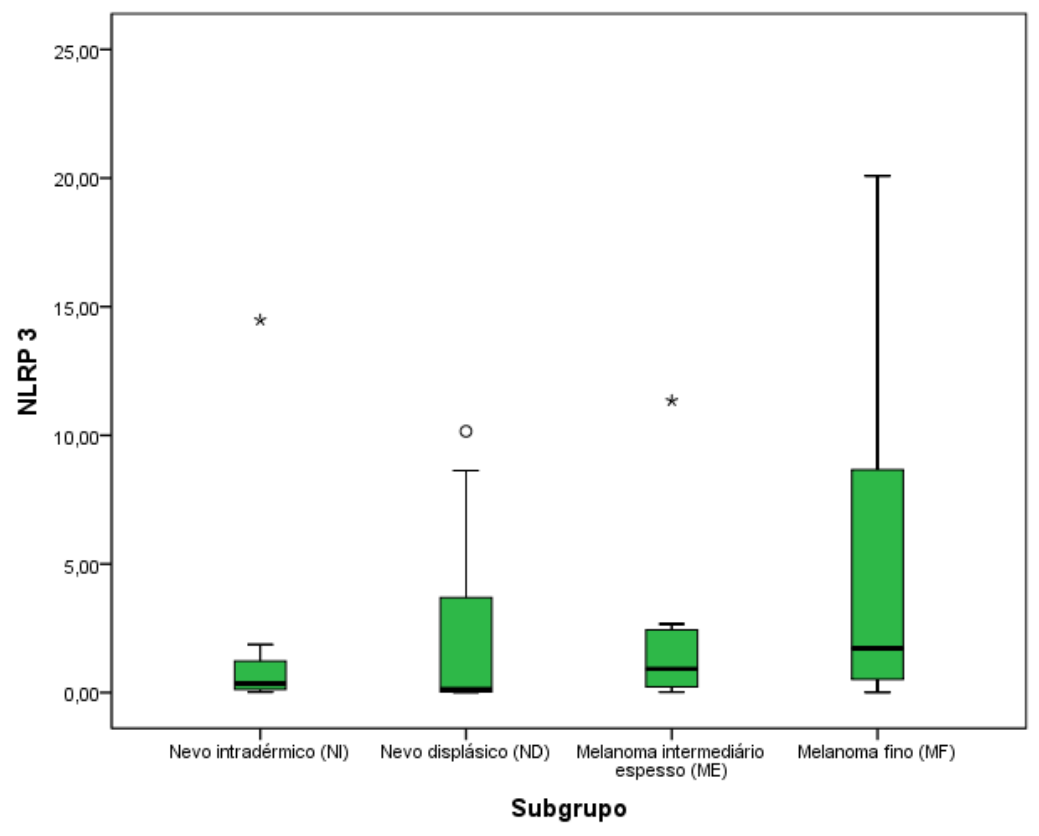

NLRP3. Sem diferença significativa entre os subgrupos.

Figura 21. NLRP3 para os subgrupos de nevos e melanomas 


\subsection{Comparação das características dos pacientes segundo a positividade dos anticorpos}

\section{Nevo}

Não houve diferenças estatisticamente significativas entre a positividade dos anticorpos caspase-1, IL-1 $\beta$, NLRP1 e NLRP3 entre homens e mulheres. Grupos etários também não mostraram diferenças de positividade dos anticorpos.

Avaliação da topografia não mostrou diferenças entre as distribuições de positividade dos diferentes anticorpos.

Positividade dos anticorpos caspase-1, NLRP1 e NLRP3 não foram estatisticamente significativos. Diferenças entre os níveis de positividade dos diferentes tipos histológicos foram observadas para o anticorpo IL-1 $\beta$ (Tabela 7).

\section{Melanoma}

Mulheres apresentaram maior positividade do anticorpo IL-1 $\beta$ comparado com os homens, diferenças na distribuição dos valores foram estatisticamente significativas. Para os outros anticorpos não se encontraram diferenças significativas.

Faixa etária, topografia e tipo histológico não foram significativos em relação a todos os anticorpos estudados (Tabela 8).

Lesões in situ apresentaram maior positividade para o NLRP1 comparada com lesões invasivas $(p=0,001)$ (Tabela 9). A presença de ulceração nas lesões com melanoma apresentaram diferenças significativas para os anticorpos IL-1 $\beta$ e NLRP1. Lesões com mitose maior ou igual a 1 tiveram menor positividade para o anticorpo NLRP1 $(p=0,007)$. A presença de regressão se mostrou associada com o anticorpo NLRP3 $(\mathrm{p}=0,045)$.

Presença de metástase linfonodal apresentou valores menores de positividade comparada com aquelas lesões que não apresentaram metástase linfonodal para os anticorpos IL-1 $\beta(p=0,013)$ e NLRP1 $(p=0,006)$. 
Tabela 7. Características dos pacientes com nevo segundo caspase-1, IL-1 $\beta$, NLRP1 e NLRP3

\begin{tabular}{|c|c|c|c|c|}
\hline \multirow[t]{3}{*}{ Característica } & Caspase-1 & IL-1及 & NLRP1 & NLRP3 \\
\hline & Média (DP) & Média (DP) & Média (DP) & Média (DP) \\
\hline & Mediana (min-máx) & Mediana (min-máx) & Mediana (min-máx) & Mediana (min-máx) \\
\hline \multicolumn{5}{|l|}{ Sexo } \\
\hline \multirow[t]{2}{*}{ Masculino } & $0,01(0,02)$ & $7,75(11,37)$ & $3,27(5,23)$ & $3,28(4,76)$ \\
\hline & $0,002(0-0,04)$ & $2,52(0,03-29,75)$ & $0,29(0,06-12,78)$ & $0,38(0,01-10,16)$ \\
\hline \multirow[t]{2}{*}{ Feminino } & $0,03(0,05)$ & $3,91(6,66)$ & $2,01(2,33)$ & $1,55(3,72)$ \\
\hline & $0,002(0-0,16)$ & $1,15(0,02-25,33)$ & $0,81(0,004-6,98)$ & $0,23(0,01-14,48)$ \\
\hline Valor de $p^{l}$ & 1 & 0,698 & 0,378 & 0,459 \\
\hline \multicolumn{5}{|l|}{ Faixa etária } \\
\hline \multirow[t]{2}{*}{$\leq 40$ anos } & $0,02(0,05)$ & $4,60(7,98)$ & $1,51(2,36)$ & $1,63(4,52)$ \\
\hline & $0,002(0-0,16)$ & $1,71(0,02-25,33)$ & $0,30(0,004-6,98)$ & $0,14(0,01-14,48)$ \\
\hline \multirow[t]{2}{*}{$41-50$ anos } & $0,02(0,03)$ & $2,95(4,32)$ & $2,19(2,55)$ & $2,14(3,65)$ \\
\hline & $0,006(0-0,06)$ & $1,15(0,09-10,37)$ & $0,75(0,23-6,10)$ & $0,56(0,02-8,63)$ \\
\hline \multirow[t]{2}{*}{$51-60$ anos } & $0,01(0,02)$ & $11,38(16,01)$ & $4,69(7,03)$ & $4,01(5,40)$ \\
\hline & $0,001(0-0,04)$ & $3,99(0,40-29,75)$ & $1,24(0,05-12,78)$ & $1,86(0,01-10,16)$ \\
\hline \multirow[t]{2}{*}{$\geq 61$ anos } & $0,03(0,05)$ & $3,44(3,11)$ & $3,22(3,02)$ & $1,29(2,08)$ \\
\hline & $0,005(0-0,09)$ & $3,64(0,23-6,45)$ & $2,25(0,81-6,61)$ & $0,15(0,03-3,69)$ \\
\hline Valor de $p^{2}$ & 0,614 & 0,686 & 0,773 & 0,709 \\
\hline \multicolumn{5}{|l|}{ Topografia } \\
\hline \multirow[t]{2}{*}{ Abdome } & $0,02(0,03)$ & $2,45(2,30)$ & $1,55(2,25)$ & $0,62(1,25)$ \\
\hline & $0,003(0-0,09)$ & $2,63(0,02-6,45)$ & $0,60(0,004-6,61)$ & $0,19(0,01-3,69)$ \\
\hline \multirow[t]{2}{*}{ Cabeça e pescoço } & $0,03(0,06)$ & $3,88(8,72)$ & $1,36(1,61)$ & $2,37(4,94)$ \\
\hline & $0,0003(0-0,16)$ & $0,69(0,02-25,33)$ & $0,06-4,30$ & $0,59(0,02-14,48)$ \\
\hline \multirow[t]{2}{*}{ Extremidades } & $0,01(0,02)$ & $10,92(11,45)$ & $4,29(5,23)$ & $3,79(5,14)$ \\
\hline & $0,002(0,001-0,04)$ & $10,37(1,34-29,75)$ & $6,10(0,29-12,78)$ & $0,12(0,01-10,16)$ \\
\hline Valor de $p^{2}$ & 0,594 & 0,080 & 0,311 & 0,603 \\
\hline \multicolumn{5}{|l|}{ Tipo histológico } \\
\hline \multirow[t]{2}{*}{ Composto displásico } & $0,02(0,03)$ & $8,50(9,33)$ & $4,14(4,72)$ & $2,91(4,21)$ \\
\hline & $0,002(0-0,09)$ & $5,22(1,34-29,75)$ & $3,20(0,05-12,78)$ & $0,37(0,01-10,16)$ \\
\hline \multirow[t]{2}{*}{ Intradérmico } & $0,03(0,05)$ & $3,03(7,46)$ & $1,23(1,47)$ & $1,77(4,26)$ \\
\hline & $0,002(0-0,16)$ & $0,40(0,02-25,33)$ & $0,49(0,004-4,30)$ & $0,25(0,02-14,48)$ \\
\hline \multirow[t]{2}{*}{ Juncional displásico } & $0,002(0,003)$ & $1,93(2,42)$ & $1,53(1,02)$ & $0,09(0,09)$ \\
\hline & $0,002(0-0,005)$ & $1,93(0,23-3,64)$ & $1,53(0,81-2,25)$ & $0,09(0,03-0,15)$ \\
\hline Valor de $p^{2}$ & 0,890 & 0,016 & 0,595 & 0,490 \\
\hline
\end{tabular}

\footnotetext{
${ }^{1}$ Teste Mann-Whitney; ${ }^{2}$ Teste de Kruskal-Wallis.
} 
Tabela 8. Características dos pacientes com melanoma segundo caspase-1, IL-1 $\beta$, NLRP1 e NLRP3

\begin{tabular}{|c|c|c|c|c|}
\hline \multirow[t]{3}{*}{ Característica } & Caspase-1 & 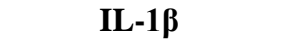 & NLRP1 & NLRP3 \\
\hline & Média (DP) & Média (DP) & Média (DP) & Média (DP) \\
\hline & Mediana (min-máx) & Mediana (min-máx) & Mediana (min-máx) & Mediana (min-máx) \\
\hline \multicolumn{5}{|l|}{ Sexo } \\
\hline \multirow[t]{2}{*}{ Masculino } & $0,73(1,47)$ & $3,23(4,67)$ & $13,15(14,64)$ & $0,55(0,39)$ \\
\hline & $0,17(0,003-4,83)$ & $1,82(0,007-14,38)$ & $12,29(0,23-47,02)$ & $0,67(0,01-1,10)$ \\
\hline \multirow[t]{2}{*}{ Feminino } & $1,83(2,75)$ & $12,43(11,40)$ & $12,67(10,08)$ & $5,27(5,33)$ \\
\hline & $0,64(0,01-10,08)$ & $10,08(0,006-36,09)$ & $11,59(1,16-35,81)$ & $2,99(0,15-16,26)$ \\
\hline Valor de $p^{l}$ & 0,250 & 0,040 & 0,870 & 0,055 \\
\hline \multicolumn{5}{|l|}{ Faixa etária } \\
\hline \multirow[t]{2}{*}{$\leq 40$ anos } & $0,12(0,09)$ & $2,17(4,32)$ & $1,11(0,95)$ & $3,95(4,98)$ \\
\hline & $0,12(0,04-0,21)$ & $0,001(0,006-8,66)$ & $0,90(0,23-2,40)$ & $1,77(0,92-11,35)$ \\
\hline \multirow[t]{2}{*}{$41-50$ anos } & $1,83(2,59)$ & $1,05(1,10)$ & $25,87(1,50)$ & $1,35(1,82)$ \\
\hline & $1,83(0,003-3,66)$ & $1,05(0,27-1,83)$ & $25,87(24,81-26,93)$ & $1,35(0,06-2,64)$ \\
\hline \multirow[t]{2}{*}{$51-60$ anos } & $0,40(0,43)$ & $9,96(13,13)$ & $14,48(9,79)$ & $3,47(5,41)$ \\
\hline & $0,26(0,01-1,24)$ & $4,11(0,13-36,09)$ & $14,28(1,68-35,81)$ & $1,73(0,01-16,26)$ \\
\hline \multirow[t]{2}{*}{$\geq 61$ anos } & $2,55(3,15)$ & $11,59(9,01)$ & $13,69(13,56)$ & $3,30(4,81)$ \\
\hline & $0,97(0,03-10,08)$ & $11,68(0,008-28,29)$ & $11,43(0,60-47,02)$ & $0,67(0,15-12,43)$ \\
\hline Valor de $p^{2}$ & 0,237 & 0,072 & 0,130 & 0,403 \\
\hline \multicolumn{5}{|l|}{ Topografia ${ }^{\S}$} \\
\hline \multirow[t]{2}{*}{ Abdome } & $0,99(1,46)$ & $7,61(7,71)$ & $16,93(14,13)$ & $2,43(3,43)$ \\
\hline & $0,26(0,01-3,66)$ & $5,60(0,007-24,58)$ & $14,81(0,23-47,02)$ & $0,92(0,01-11,01)$ \\
\hline \multirow[t]{2}{*}{ Cabeça e pescoço } & $2,40(2,32)$ & $11,89(8,81)$ & $13,57(2,82)$ & $0,37(0,34)$ \\
\hline & $2,37(0,03-4,83)$ & $11,45(1,98-22,71)$ & $14,37(9,57-15,98)$ & $0,34(0,02-0,77)$ \\
\hline \multirow[t]{2}{*}{ Extremidades } & $1,42(3,08)$ & $9,02(13,09)$ & $10,10(11,84)$ & $4,47(5,64)$ \\
\hline & $0,36(0,003-10,08)$ & $2,26(0,008-36,09)$ & $5,67(0,60-35,81)$ & $1,88(0,06-16,26)$ \\
\hline Valor de $p^{2}$ & 0,687 & 0,500 & 0,235 & 0,141 \\
\hline \multicolumn{5}{|l|}{ Tipo histológico ${ }^{q}$} \\
\hline \multirow[t]{2}{*}{ Extensivo superficial } & $0,70(1,22)$ & $7,67(10,68)$ & $14,70(14,29)$ & $3,20(4,71)$ \\
\hline & $0,26(0,01-3,66)$ & $2,72(0,007-36,09)$ & $14,28(0,23-47,02)$ & $1,01(0,01-16,26)$ \\
\hline \multirow[t]{2}{*}{ Lentigo maligno } & $3,42(3,77)$ & $14,96(9,48)$ & $10,94(4,80)$ & $3,37(5,04)$ \\
\hline & $2,38(0,03-10,08)$ & $14,15(1,98-28,29)$ & $11,65(3,69-15,98)$ & $0,65(0,02-12,43)$ \\
\hline \multirow[t]{2}{*}{ Nodular } & $0,63(0,63)$ & $0,94(1,33)$ & $1,57(0,58)$ & $5,79(7,87)$ \\
\hline & $0,63(0,19-1,08)$ & $0,94(0,006-1,88)$ & $1,57(1,16-1,99)$ & $5,79(0,22-11,35)$ \\
\hline Valor de $p^{2}$ & 0,121 & 0,056 & 0,331 & 0,840 \\
\hline
\end{tabular}

\footnotetext{
${ }^{1}$ Teste Mann-Whitney; ${ }^{2}$ Teste de Kruskal-Wallis; ${ }^{\S}$ Um caso com lesão na nádega não incluído na análise; ${ }^{\text {II }}$
} Um caso de spitzoide não incluído na análise. 
Tabela 9. Características clínicas dos pacientes com melanoma segundo caspase-1, IL-1 $\beta$, NLRP1 e NLRP3.

\begin{tabular}{|c|c|c|c|c|}
\hline \multirow[t]{3}{*}{ Característica } & Caspase-1 & IL-1及 & NLRP1 & NLRP3 \\
\hline & Média (DP) & Média (DP) & Média (DP) & Média (DP) \\
\hline & Mediana (min-máx) & Mediana (min-máx) & Mediana (min-máx) & Mediana (min-máx) \\
\hline \multicolumn{5}{|l|}{ Breslow } \\
\hline \multirow[t]{2}{*}{ In situ } & $1,55(1,82)$ & $10,35(15,12)$ & $25,12(7,27)$ & $3,84(7,03)$ \\
\hline & $0,41(0,003-3,66)$ & $1,83(0,27-36,09)$ & $24,81(15,93-35,81)$ & $0,25(0,01-16,26)$ \\
\hline \multirow[t]{2}{*}{ Invasivo } & $1,33(2,49)$ & $8,14(8,96)$ & $9,65(10,78)$ & $3,16(4,09)$ \\
\hline & $0,26(0,01-10,08)$ & $5,60(0,006-28,29)$ & $9,13(0,23-47,02)$ & $0,92(0,02-12,43)$ \\
\hline Valor de $p^{l}$ & 0,373 & 0,972 & 0,001 & 0,849 \\
\hline \multicolumn{5}{|l|}{ Ulceração } \\
\hline \multirow[t]{2}{*}{ Não } & $1,17(1,54)$ & $9,37(9,67)$ & $15,72(11,71)$ & $3,11(4,76)$ \\
\hline & $0,41(0,003-4,83)$ & $6,98(0,13-36,09)$ & $14,71(1,68-47,02)$ & $0,77(0,01-16,26)$ \\
\hline \multirow[t]{2}{*}{ Sim } & $2,13(4,44)$ & $5,67(12,65)$ & $2,05(3,14)$ & $4,06(4,71)$ \\
\hline & $0,19(0,04-10,08)$ & $0,008(0,006-28,29)$ & $0,63(0,23-7,64)$ & $1,10(0,60-11,35)$ \\
\hline Valor de $p^{l}$ & 0,455 & 0,036 & 0,002 & 0,377 \\
\hline \multicolumn{5}{|l|}{ Mitose } \\
\hline \multirow[t]{2}{*}{$<1$} & $1,90(2,95)$ & $10,72(10,83)$ & $18,43(12,88)$ & $4,24(5,52)$ \\
\hline & $0,41(0,003-10,08)$ & $8,51(0,27-36,09)$ & $15,93(1,68-47,02)$ & $0,79(0,01-16,26)$ \\
\hline \multirow[t]{2}{*}{$\geq 1$} & $0,82(1,16)$ & $6,69(9,44)$ & $6,90(6,15)$ & $2,33(3,45)$ \\
\hline & $0,28(0,04-3,89)$ & $1,93(0,006-24,58)$ & $5,93(0,60-14,81)$ & $0,85(0,02-11,35)$ \\
\hline Valor de $p^{I}$ & 0,639 & 0,137 & 0,007 & 0,349 \\
\hline \multicolumn{5}{|l|}{ Regressão } \\
\hline \multirow[t]{2}{*}{ Não } & $1,53(2,46)$ & $7,29(8,86)$ & $11,91(11,59)$ & $2,32(3,56)$ \\
\hline & $0,31(0,003-10,08)$ & $2,63(0,006-28,29)$ & $9,57(0,23-47,02)$ & $0,77(0,01-12,43)$ \\
\hline \multirow[t]{2}{*}{ Sim } & $0,23(0,20)$ & $17,73(16,17)$ & $19,60(14,23)$ & $10,20(6,51)$ \\
\hline & $0,26(0,01-0,41)$ & $11,49(5,60-36,09)$ & $13,86(9,13-35,81)$ & $11,01(3,32-16,26)$ \\
\hline Valor de $p^{l}$ & 0,358 & 0,150 & 0,452 & 0,045 \\
\hline \multicolumn{5}{|c|}{ Metástase linfonodal } \\
\hline \multirow[t]{2}{*}{ Não } & $1,55(2,45)$ & $9,82(10,31)$ & $14,64(11,67)$ & $3,65(4,90)$ \\
\hline & $0,41(0,003-10,08)$ & $6,98(0,006-36,09)$ & $13,86(1,16-47,02)$ & $0,79(0,01-16,26)$ \\
\hline \multirow[t]{2}{*}{ Sim } & $0,14(0,15)$ & $0,009(0,004)$ & $0,49(0,22)$ & $0,87(0,25)$ \\
\hline & $0,05(0,04-0,31)$ & $0,008(0,007-0,01)$ & $0,60(0,23-0,63)$ & $0,92(0,60-1,10)$ \\
\hline Valor de $p^{l}$ & 0,155 & 0,013 & 0,006 & 0,802 \\
\hline
\end{tabular}

\footnotetext{
${ }^{1}$ Teste Mann-Whitney.
} 
Para avaliar a correlação entre os níveis de Clark e os anticorpos foi calculado o coeficiente de correlação de Spearman (Tabela 10).

Forte associação negativa foi observada entre os níveis de Clark e NLRP1, indicando que um aumento em uma variável produz uma diminuição na outra. Os outros anticorpos não se mostraram correlacionados com os níveis de Clark no grupo de melanomas.

Tabela 10. Correlação entre nível Clark e Caspase-1, IL-1 $\beta$, NLRP1 e NLRP3 em pacientes com melanoma

\begin{tabular}{lcccc}
\hline Característica & Caspase-1 & IL-1 $\beta$ & NLRP1 & NLRP3 \\
\hline Clark & & & & \\
Coeficiente de correlação de Spearman & $-0,155$ & $-0,293$ & $-0,762$ & $-0,059$ \\
Valor de p & 0,470 & 0,175 & $<0,001$ & 0,783 \\
\hline
\end{tabular}




\section{DISCUSSÃo}

As características epidemiológicas dos pacientes analisados mostram uma distribuição similar dos casos de melanoma entre homens e mulheres, condizente com o esperado em estatísticas nacionais e mundiais. ${ }^{34}$ Similaridade também foi observada para a distribuição dos casos de nevos displásicos entre os gêneros. Exceção ocorreu para os nevos intradérmicos, com maioria de pacientes femininos. Estudos anteriores mostraram não haver diferença na incidência ou na quantidade de nevos melanocíticos entre os sexos, havendo apenas variação na distribuição dos mesmos pelo corpo de acordo com o gênero, com predomínio de nevos no tronco nos homens e nas pernas, nas

mulheres. ${ }^{104,105}$ Como os nevos intradérmicos costumam ser de mais fácil identificação clínica, raramente sendo removidos por dúvida diagnóstica, a maioria das excisões podem ocorrer por preocupações estéticas. O pequeno número amostral e um hipotético viés na procura por remoção de nevos intradérmicos podem explicar essa divergência com os dados da literatura.

A associação entre melanomas mais espessos e a presença de ulceração e de metástase linfonodal é esperada, já que ambos são critérios de pior prognóstico e acompanham a maior espessura do Breslow. ${ }^{106}$

NLRP1 tem pelo menos duas funções biológicas distintas: primeiro, como um inflamassoma para ativar caspase-1 e, consequentemente, IL-1 $\beta$ e, segundo, como um polipeptídeo NLRP1 para interagir com outras proteínas contendo CARD (particularmente caspases apoptóticas), promovendo apoptose. ${ }^{116}$ A expressão de NLRP1 em nossas amostras foi maior nos melanomas quando comparada aos nevos e, de forma estatisticamente significativa, maior nos melanomas finos quando comparada com todos os outros grupos. Esses dados podem sugerir um papel de NLRP1 na oncogênese, mas que sua expressão diminui à medida que a doença avança. A relação entre NLRP-1 e melanoma foi demonstrada em alguns trabalhos anteriores. Ellis et al relataram que o efeito inibitório de epigallocatechin-3-gallate, um componente do chá verde, sobre a proliferação de linhas celulares de melanoma metastático humano é mediado pela redução da secreção de IL-1 $\beta$ mediada pelo inflamassoma NLRP-1. ${ }^{101}$ Além disso, 
polimorfismos de NLRP1 tem sido associados à susceptibilidade ao melanoma ${ }^{97}$, e, em nosso estudo anterior, relatamos que um polimorfismo de base única de ganho de função em NLRP1 é um fator de risco para o desenvolvimento do melanoma. Esses achados sugerem que um aumento da NLRP1 pode representar um evento promotor na transformação de melanócitos, mas não está envolvido na progressão tumoral.

Recentemente, Zhai et al, publicaram estudo com alguns resultados que podem se opor a esta teoria. Estes autores sugeriram que o NLRP1 promoveria a tumorigênese no melanoma, aumentando de forma coordenada a ativação de inflamassoma mediada por caspase-1 e suprimindo a via apoptótica mitocondrial mediada por caspase-2 e caspase-9 em melanoma metastático. ${ }^{107}$ Caspase -2 e -9 são proteínas citoplasmáticas e a ligação com NLRP1 em células de melanoma pode interromper a interação dessas caspases apoptóticas com outras proteínas indutoras de apoptose, regulando negativamente a apoptose em células de melanoma. Diferentemente do nosso estudo, neste não houve avaliação quanto a espessura do Breslow, o que impede avaliação entre os diferentes estágios da neoplasia primária.

IL-1 $\beta$ é uma citocina pró-inflamatória pleiotrópica liberada após infecção, lesão celular ou outro estímulo antigênico. Essa citocina atua diretamente em vários tipos celulares, isolados ou em combinação com outras citocinas, para induzir um estado inflamatório. Os macrófagos são os principais produtores de IL-1 $\beta$, entretanto outras células e tecidos também demonstram a capacidade de produzi-la, como tecido epidérmico, células epiteliais da mucosa e células acinares e ductais das glândulas salivares. ${ }^{108}$ Há evidências crescentes que sugerem que a IL-1 $\beta$ desempenha um papel fundamental na progressão do câncer, estando envolvida na proliferação celular, diferenciação, regeneração tecidual e regulação imune. Tem-se demonstrado ainda que células tumorais que secretam IL-1 $\beta$ têm maior propensão para invasão, angiogênese e metástase. ${ }^{109}$

Krelin et al mostraram no microambiente da carcinogênese da pele induzida por 3-metilcolantrene, que tumores se desenvolveram mais devagar e apenas em alguns dos camundongos com deficiência de IL-1 $\beta$ em comparação com camundongos de tipo selvagem, ${ }^{110}$ suportando a hipótese de que no microambiente da inflamação crônica, a IL-1 $\beta$ afeta a carcinogênese e determina o potencial invasivo das células malignas. ${ }^{111}$ Kholmanskikh et al mostraram que a repressão dos genes de diferenciação de melanócitos pela IL-1 produzida por células estromais ou pelas próprias células tumorais pode representar um mecanismo adicional de escape imune do melanoma. ${ }^{112}$ 
Estudos recentes sugeriram que ocorre uma ativação do inflamassoma à medida que o melanoma progride. ${ }^{96}$ No nosso estudo, a expressão de IL-1 $\beta$ analisada não conseguiu mostrar diferenças estatisticamente significativas entre os grupos de nevos e melanomas, nem entre os 4 subgrupos (melanomas finos, melanomas intermediáriosespessos, nevos displásicos e nevos intradérmicos). O tamanho da amostra pode ter contribuído para a incapacidade de demonstrarmos diferenças com relevância estatística. Apesar disso, é válido ressaltar a maior expressão nos casos de melanomas quando comparados aos nevos. Ao dividirmos nos 4 subgrupos estudados, vimos uma maior expressão nos melanomas finos, seguidos pelos casos de nevos displásicos, depois, pelos melanomas de espessura intermediária-espessa, e por últimos pelos casos de nevos intradérmicos. Digno de nota, é o resultado da maior expressão de IL-1 $\beta$ nos nevos displásicos, quando comparados aos melanomas espessos. De forma geral, em todos os subgrupos pudemos evidenciar expressão da IL-1 $\beta$, sugerindo que os tumores melanocíticos malignos e benignos podem sintetizar esta importante citocina.

Okamoto et al mostraram secreção ativa de IL-1 $1 \beta$ no melanoma e que se tornou cada vez mais autônoma durante a progressão da doença. As células metastáticas liberaram espontaneamente IL-1 $\beta$, através da ativação constitutiva do inflamassoma NLRP3, apresentando uma característica de doença autoinflamatória. Neste estudo, eles também mostraram por imuno-histoquímica que nenhuma das cinco amostras de melanomas primários (tumores primários cujos pacientes desenvolveram metástases posteriormente) coraram para IL-1 $\beta$, enquanto que oito de dez amostras de melanomas metastáticos apresentaram positividade para IL-1 $\beta .{ }^{96}$ Nosso estudo não incluiu melanomas metastáticos, mas nossos resultados diferiram da ausência completa de expressão da IL-1 $\beta$ em melanomas primários cutâneos observada por Okamoto. Em contraste com os resultados relatados pelo grupo de Okamoto, Gehrke et al demonstraram que as células de melanoma metastático não secretam IL-1 $\beta$, devido à falta de expressão de um ou mais componentes do inflamassoma. Por outro lado, um ou mais fatores provenientes de células de melanoma necrótico podem promover a produção de IL-1 $\beta$ por macrófagos. ${ }^{99}$

Recentemente, nosso grupo mostrou uma regulação positiva da IL-1 $\beta$ no melanoma versus nevo, principalmente em melanoma metastático, embora não tenha sido alcançada significância estatística. No mesmo estudo, os polimorfismos de nucleotídeos de IL-1 $\beta$ foram associados ao índice Breslow mais baixo e o tag-SNP rs1143643 em IL-1 $\beta$ foi associado à invasividade, enfatizando que a IL-1 $\beta$ exerce um papel importante no desenvolvimento do melanoma. ${ }^{113}$ 
Qin et al, avaliando nevos e melanomas, mostraram não haver marcação em técnica de imuno-histoquímica para IL-1ß nos nevos, mas com positividade nos melanomas primários e metastáticos. ${ }^{114}$ Esses resultados divergem dos encontrados por Okamoto et al que não observaram marcação nos melanomas primários e dos nossos resultados, já que encontramos positividade também nos nevos (Tabela 11).

Tabela 11. Estudos que avaliaram expressão de IL-1ß por imuno-histoquímica

\begin{tabular}{lccc}
\hline Tipo de lesão & de Sa et al & Okamoto et al & Qin et al \\
\hline Nevos melanocíticos & + & não avaliado & - \\
Melanoma primário & + & - & + \\
Melanoma metastático & não avaliado & ++ & + \\
\hline
\end{tabular}

Comparando-se os resultados por gênero, observou-se uma maior expressão de IL-1ß em lesões de melanoma no sexo feminino. Este achado isoladamente não nos permite uma conclusão, mas pode representar um ponto a ser estudado, considerando-se que mulheres com melanoma apresentam um melhor prognóstico do que os homens, mas a explicação para esse comportamento menos agressivo no sexo feminino ainda é incerto. $^{117}$

Baixa expressão foi observada quando a caspase-1 foi pesquisada. Nos nevos melanocíticos, tanto nos intradérmicos, quanto nos displásicos, a expressão foi próxima a zero. Nos melanomas finos houve uma expressão discreta, mas um pouco maior que nos melanomas intermediários/espessos, apesar de não ter havido diferença estatística. Essa baixa expressão da caspase-1 contrasta com a marcação evidenciada para IL-1 $\beta$, já que se espera que a presença desta citocina acompanhe a ativação da pró-caspase- 1 em caspase-1. Entretanto, outra via para a síntese de IL-1 $\beta$ é possível, como a demonstrada por Maelfait et al, em que há ativação da pró- IL-1 $\beta$ por meio da caspase-8, em resposta à estimulação de receptores tipo Toll (TLR3 e TLR4). Além disso, neste mesmo estudo, a caspase- 8 recombinante foi capaz de clivar a pró-IL-1 $\beta$ in vitro exatamente no mesmo sítio que a caspase-1. ${ }^{115}$ Recentemente, Ketelut-Carneiro et al, revelaram que a síntese de IL-1 $\beta$ durante a resposta imune inata das células hospedeiras à infecção por Paracoccidioides brasiliensis, pode ser feita através da ativação de inflamassomas não canônicos por meio da caspase- $8 .{ }^{116}$ A possibilidade de outra via para síntese de IL-1 $\beta$ 
pode explicar a presença desta citocina em situações de baixa expressão ou mesmo na ausência da caspase-1. Entretanto deve-se considerar ainda a possibilidade de o teste não ter sido suficientemente sensível para detectar a caspase-1.

A expressão de NLRP3 foi baixa em todos os subgrupos de melanomas e nevos, sem diferença significativa entre estes quatro subgrupos. Mas quando comparados todos os melanomas com todos os nevos, a diferença foi estatisticamente significativa em favor dos melanomas, apesar de a expressão ainda ser considerada baixa (média de $3,3 \%$ no grupo de melanoma x 2,04\% no grupo de nevos). Esses achados diferem dos descritos por Okamoto et al, que mostraram que o inflamassoma NLRP3 é constitutivamente montado e ativado em células de melanoma humano. ${ }^{96}$ Verma et al demonstraram que os polimorfismos NLRP3 estão associados à susceptibilidade ao melanoma, principalmente pelo melanoma nodular. ${ }^{97} \mathrm{Em}$ um estudo com linhas celulares de melanoma humano e de rato, Ahmad et al mostraram que a tireoquinona inibiu a atividade da caspase-1, diminuiu a secreção de IL-1 $\beta$ e IL-18 e inibiu a migração de células de melanoma visando a subunidade NLRP3 do inflamassoma. ${ }^{100}$

Nenhum de nossos resultados mostrou diferença estatisticamente significante entre nevos intradérmicos e nevos displásicos, mostrando que, pelo menos em relação à expressão do inflamassoma, essas duas entidades não podem ser distinguidas.

Ao considerarmos a participação da via do inflamassoma nas lesões melanocíticas, havíamos imaginado um modelo no qual os receptores NLRP1 ou NLRP3 se ligariam à caspase-1, levando à ativação de IL-1 $\beta$. Procedemos então a avaliação se a IL-1 $\beta$ seria uma função dos outros dois anticorpos (caspase-1 + NLRP1 ou caspase-1 + NLRP3) nos nossos casos. Entretanto, os baixos níveis de expressão de caspase-1 identificados em todos os subgrupos, nos levou a considerar a hipótese de outras vias para a síntese de IL-1 $\beta$, como, por exemplo, a ativação de inflamassomas não canônicos por meio da caspase-8. ${ }^{116}$ Desta forma, consideramos que a capacidade de construirmos estes modelos com a caspase- 1 seria limitada.

Também avaliamos a correlação entre a expressão das diferentes proteínas estudadas, e associações positivas foram encontradas tanto em nevos como em melanomas. A correlação entre NLRP1 e IL-1 $\beta$ foi a que mais pode ser demonstrada nos diferentes grupos, com a associação mais forte tendo sido identificada nos melanomas de maior espessura. Apesar dos maiores níveis de expressão de NLRP1 e de IL-1 $\beta$ terem sido observados nos melanomas finos, não se conseguiu demonstrar uma relevância estatística na associação destas proteínas nestes casos. 
De forma crítica, temos que considerar as limitações de um estudo que avalia os componentes protéicos de uma via inflamatória através da análise imuno-histoquímica, uma vez que a função de todas as proteínas estudadas (NLRP1, NLRP3, caspase-1, IL-1 $\beta$ ) está relacionada à atividade biológica e não apenas à expressão das mesmas.

Em suma, os componentes do inflamassoma parecem estar mais expressos nos melanomas do que nos nevos. Pela primeira vez, para o nosso conhecimento, relatamos a maior expressão de NLRP1 em melanomas quando comparados com nevos melanocíticos. De forma inesperada, a descoberta mais interessante foi uma maior expressão de NLRP1 em melanomas finos do que nos tumores mais espessos. No entanto, os nevos também mostraram expressão de IL-1 $\beta$, o produto final da via do inflamassoma. A ligação entre as proliferações melanocíticas e o inflamassoma ainda deve ser determinada, e estudos adicionais são necessários para esclarecer esta complexa relação. 


\section{CONCLUSÕES}

A associação entre resposta inflamatória e câncer segue controversa e estudos têm evidenciado o papel da ativação do inflamassoma na tumorigênese, tanto como fator protetor quanto como fator estimulador. Tínhamos como hipótese que identificaríamos uma maior expressão dos componentes do inflamassoma nos melanomas quando comparados aos nevos melanocíticos, e que essa expressão seria maior à medida que lesões mais avançadas fossem estudadas.

Através da técnica de imuno-histoquímica, demonstramos haver maior expressão dos receptores NLRP1 e NLRP3 e da enzima caspase-1 nas lesões de melanoma quando comparadas aos nevos.

Em relação à caspase-1, ainda que tenha havido uma maior expressão nos melanomas, ressaltamos que esses níveis de expressão foram muito baixos em todos os subgrupos, nos levando a ponderar que outros mecanismos para a síntese de IL-1 $\beta$ devam ser considerados.

No que tange à IL-1 $\beta$, não houve diferença considerada relevante do ponto de vista estatístico, mas pudemos observar que tanto os nevos quanto os melanomas expressaram esta citocina, destacando-se uma maior marcação nos melanomas finos quando comparados aos demais subgrupos. Mesmo sem relevância estatística, surpreendeu a maior expressão nos nevos displásicos quando comparados aos melanomas espessos.

Os dados mais relevantes relacionaram-se ao receptor NLRP1. Uma maior expressão foi evidenciada nos melanomas finos em comparação a todos os outros subgrupos. Este achado foi considerado surpreendente, pois esperávamos um aumento da expressão à medida que a doença progredisse. Este dado nos levou a elaborar a hipótese de que um aumento da NLRP1 poderia representar um evento promotor na transformação dos melanócitos, mas que não estaria envolvido na progressão tumoral.

Estudos futuros são necessários para esclarecer esta complexa relação entre a via do inflamassoma e a evolução das lesões melanocíticas, podendo-se constituir um ponto chave no entendimento das diferenças entre nevo melanocítico e melanoma. 


\section{ANEXOS}

Anexo. Lista completa das características de cada paciente com o resultado da expressão dos anticorpos.

\begin{tabular}{|c|c|c|c|c|c|c|c|c|c|c|c|c|c|}
\hline \multirow[b]{2}{*}{ ID } & \multirow[b]{2}{*}{ Sexo } & \multirow[b]{2}{*}{ Idade } & \multirow[b]{2}{*}{ Histologia } & \multirow[b]{2}{*}{ Breslow } & \multirow[b]{2}{*}{ Clark } & \multirow[b]{2}{*}{ Ulceração } & \multirow[b]{2}{*}{\begin{tabular}{|l|} 
Regressão \\
\end{tabular}} & \multicolumn{2}{|c|}{ Metástase } & \multicolumn{4}{|c|}{ Expressão } \\
\hline & & & & & & & & \begin{tabular}{|l|} 
Linfonodal \\
\end{tabular} & Visceral & NLRP1 & NLRP3 & Caspase-1 & IL-1B \\
\hline MIE 1 & $\mathrm{M}$ & 35 & MES & \begin{tabular}{|l|}
10.0 \\
\end{tabular} & $\mathrm{~V}$ & $\mathrm{~S}$ & \begin{tabular}{|l|}
$\mathrm{N}$ \\
\end{tabular} & $\mathrm{S}$ & $\mathrm{S}$ & 0.006 & \begin{tabular}{|l|}
0.011 \\
\end{tabular} & 0.000 & 0.000 \\
\hline MIE 2 & $\mathrm{~F}$ & 35 & MN & 4.0 & IV & $\mathrm{S}$ & $\mathrm{N}$ & $\mathrm{N}$ & $\mathrm{N}$ & 0.012 & 0.114 & 0.002 & 0.000 \\
\hline MIE 3 & M & 40 & MES & 7.0 & $\mathrm{~V}$ & $\mathrm{~S}$ & $\mathrm{~N}$ & $\mathrm{~S}$ & $\mathrm{~N}$ & 0.002 & 0.009 & 0.001 & 0.000 \\
\hline MIE 4 & $\mathrm{~F}$ & 65 & LM & 4.3 & V & $\mathrm{N}$ & $\mathrm{N}$ & $\mathrm{N}$ & $\mathrm{N}$ & 0.137 & 0.002 & 0.039 & 0.230 \\
\hline MIE 5 & $\mathrm{~F}$ & 35 & MES & 1.7 & IV & $\mathrm{N}$ & $\mathrm{N}$ & $\mathrm{N}$ & $\mathrm{N}$ & 0.024 & 0.024 & 0.002 & 0.090 \\
\hline MIE 6 & $\mathrm{~F}$ & 62 & MN & 1.5 & IV & $\mathrm{N}$ & $\mathrm{N}$ & $\mathrm{N}$ & $\mathrm{N}$ & 0.020 & 0.002 & 0.011 & 0.020 \\
\hline MIE 7 & $\mathrm{~F}$ & 52 & \begin{tabular}{|l|} 
Spitzóide \\
\end{tabular} & 1.4 & IV & $\mathrm{N}$ & $\mathrm{N}$ & $\mathrm{N}$ & $\mathrm{N}$ & 0.094 & 0.027 & 0.012 & 0.070 \\
\hline MIE 8 & $\mathrm{M}$ & 65 & \begin{tabular}{|l|} 
MES \\
\end{tabular} & 3.3 & IV & $\mathrm{S}$ & $\mathrm{N}$ & $\mathrm{S}$ & $\mathrm{N}$ & 0.006 & 0.006 & 0.003 & 0.000 \\
\hline MIE 9 & $\mathrm{M}$ & 57 & LM & 1.7 & III & $\mathrm{N}$ & $\mathrm{N}$ & $\mathrm{N}$ & $\mathrm{N}$ & 0.096 & 0.00 & 0.009 & 0.020 \\
\hline MF 1 & $\mathrm{M}$ & 28 & & In situ & I & $\mathrm{N}$ & $\mathrm{N}$ & $\mathrm{N}$ & $\mathrm{N}$ & 0.356 & 0.201 & 0.12 & \\
\hline MF 2 & $\mathrm{~F}$ & 65 & MES & In situ & I & $\mathrm{N}$ & $\mathrm{N}$ & $\mathrm{N}$ & $\mathrm{N}$ & 0.221 & 0.002 & 0.03 & 0.119 \\
\hline MF 3 & $\mathrm{~F}$ & 49 & MES & In situ & I & $\mathrm{N}$ & $\mathrm{N}$ & $\mathrm{N}$ & $\mathrm{N}$ & 0.269 & 0.026 & 0.04 & 0.018 \\
\hline MF 4 & $\mathrm{M}$ & 43 & & In situ & I & $\mathrm{N}$ & $\mathrm{N}$ & $\mathrm{N}$ & $\mathrm{N}$ & 0.248 & 0.001 & 0.00 & 0.003 \\
\hline MF 5 & $\mathrm{~F}$ & 56 & MES & In situ & $\mathrm{I}$ & $\mathrm{N}$ & $\mathrm{S}$ & $\mathrm{N}$ & $\mathrm{N}$ & 0.358 & 0.163 & 0.00 & 0.361 \\
\hline MF 6 & $\mathrm{M}$ & 58 & MES & In situ & $\mathrm{I}$ & $\mathrm{N}$ & $\mathrm{N}$ & $\mathrm{N}$ & $\mathrm{N}$ & 0.159 & 0.000 & 0.00 & 0.017 \\
\hline MF 7 & $\mathrm{~F}$ & 53 & MES & 0.3 & II & $\mathrm{N}$ & $\mathrm{S}$ & $\mathrm{N}$ & $\mathrm{N}$ & 0.139 & 0.033 & 0.00 & 0.056 \\
\hline MF 8 & $\mathrm{M}$ & 76 & LM & 0.4 & II & $\mathrm{N}$ & $\mathrm{N}$ & $\mathrm{N}$ & $\mathrm{N}$ & 0.160 & 0.008 & 0.05 & 0.144 \\
\hline MF 9 & $\mathrm{~F}$ & 56 & MES & 0.4 & II & $\mathrm{N}$ & $\mathrm{N}$ & $\mathrm{N}$ & $\mathrm{N}$ & 0.148 & 0.005 & 0.00 & 0.246 \\
\hline MF 10 & M & 77 & LM & 0.3 & II & $\mathrm{N}$ & $\mathrm{N}$ & $\mathrm{N}$ & $\mathrm{N}$ & 0.150 & 0.005 & 0.00 & 0.085 \\
\hline MF 11 & $\mathrm{~F}$ & 57 & MES & 0.9 & IV & $\mathrm{N}$ & $\mathrm{N}$ & $\mathrm{N}$ & $\mathrm{N}$ & 0.147 & 0.042 & 0.00 & 0.001 \\
\hline MF 12 & $F$ & 79 & LM & 0.3 & II & $\mathrm{N}$ & $\mathrm{N}$ & $\mathrm{N}$ & $\mathrm{N}$ & 0.037 & 0.124 & 0.01 & 0.139 \\
\hline MF 13 & $\mathrm{M}$ & 51 & MES & 0.3 & III & $\mathrm{N}$ & $\mathrm{N}$ & $\mathrm{N}$ & $\mathrm{N}$ & 0.017 & 0.008 & 0.00 & 0.026 \\
\hline MF 14 & $\mathrm{M}$ & 62 & MES & 0.3 & II & $\mathrm{N}$ & $\mathrm{N}$ & $\mathrm{N}$ & $\mathrm{N}$ & 0.470 & 0.007 & 0.01 & 0.028 \\
\hline MF 15 & $\mathrm{~F}$ & 68 & LM & 0.8 & II & $\mathrm{S}$ & $\mathrm{N}$ & $\mathrm{N}$ & $\mathrm{N}$ & 0.076 & 0.063 & 0.10 & 0.283 \\
\hline MF 16 & $\mathrm{~F}$ & 64 & MES & 0.4 & II & $\mathrm{N}$ & $\mathrm{S}$ & $\mathrm{N}$ & $\mathrm{N}$ & 0.091 & 0.110 & 0.00 & 0.115 \\
\hline NI 1 & $\mathrm{~F}$ & 48 & NI & & & & & & & 0.002 & 0.006 & 0.000 & 0.012 \\
\hline NI 2 & $\mathrm{~F}$ & 26 & $\mathrm{NI}$ & & & & & & & 0.043 & 0.145 & 0.000 & 0.253 \\
\hline NI 3 & $\mathrm{~F}$ & 46 & NI & & & & & & & 0.008 & 0.000 & 0.000 & 0.001 \\
\hline NI 4 & $\mathrm{~F}$ & 27 & $\mathrm{NI}$ & & & & & & & 0.023 & 0.002 & 0.000 & 0.022 \\
\hline NI 5 & $\mathrm{~F}$ & 50 & NI & & & & & & & 0.035 & 0.013 & 0.001 & 0.020 \\
\hline NI 6 & $\mathrm{~F}$ & 59 & NI & & & & & & & 0.012 & 0.019 & 0.000 & 0.004 \\
\hline NI 7 & $\mathrm{~F}$ & 38 & NI & & & & & & & 0.003 & 0.001 & 0.000 & 0.010 \\
\hline NI 8 & $\mathrm{~F}$ & 48 & NI & & & & & & & 0.004 & 0.003 & 0.001 & 0.031 \\
\hline NI 9 & $\mathrm{F}$ & 39 & NI & & & & & & & 0.000 & 0.005 & 0.000 & 0.000 \\
\hline NI 10 & $\mathrm{~F}$ & 32 & NI & & & & & & & 0.005 & 0.001 & 0.002 & 0.000 \\
\hline NI 11 & $\mathrm{M}$ & 68 & NI & & & & & & & 0.001 & 0.012 & 0.000 & 0.001 \\
\hline NI 12 & $\mathrm{M}$ & 21 & NI & & & & & & & 0.001 & 0.002 & 0.000 & 0.000 \\
\hline ND 1 & $\mathrm{~F}$ & 61 & ND & & & & & & & 0.008 & 0.001 & 0.000 & 0.036 \\
\hline ND 2 & $\mathrm{~F}$ & 18 & ND & & & & & & & 0.070 & 0.000 & 0.000 & 0.111 \\
\hline ND 3 & $\mathrm{~F}$ & 66 & ND & & & & & & & 0.023 & 0.000 & 0.000 & 0.002 \\
\hline ND 4 & $\mathrm{M}$ & 22 & ND & & & & & & & 0.001 & 0.006 & 0.000 & 0.029 \\
\hline ND 5 & $F$ & 56 & ND & & & & & & & 0.000 & 0.000 & 0.000 & 0.040 \\
\hline ND 6 & $\mathrm{M}$ & 27 & ND & & & & & & & 0.003 & 0.000 & 0.000 & 0.013 \\
\hline ND 7 & $\mathrm{M}$ & 23 & ND & & & & & & & 0.003 & 0.001 & 0.000 & 0.021 \\
\hline ND 8 & $\mathrm{M}$ & 45 & ND & & & & & & & 0.061 & 0.086 & 0.000 & 0.104 \\
\hline ND 9 & $\mathrm{M}$ & 59 & ND & & & & & & & 0.128 & 0.102 & 0.001 & 0.297 \\
\hline ND 10 & $\mathrm{F}$ & 74 & ND & & & & & & & 0.066 & 0.037 & & 0.064 \\
\hline
\end{tabular}

MIE: melanoma intermediário/espesso; MF: melanoma fino; NI: nevo intradérmico; ND: nevo displásico;

MES: melanoma extensivo superficial; LM: lentigo maligno; MN: melanoma nodular; S: sim; N: não.

Índice de Breslow está em milímetros.

Espaço em branco: resultado não disponível ou informação que não se aplica ao caso. 


\section{REFERÊNCIAS}

1 - Keibel A, Singh V, Mahesh C. Sharma MC. Inflammation, Microenvironment, and the Immune System in Cancer Progression Current Pharmaceutical Design. 2009;15:1949-55.

2- Tracy RP. The five cardinal signs of inflammation: calor, dolor, rubor, tumor ... and penuria (apologies to aulus cornelius celsus, de medicina, c. A. D. 25). J Gerontol. 2006:1051-2.

3 - Patel S. Inflammasomes, the cardinal pathology mediators are activated by pathogens, allergens and mutagens: A critical review with focus on NLRP3. Biomed Pharmacother. 2017 Aug;92:819-25.

4 - Plytycz B, Seljelid R. From inflammation to sickness: historical perspective. Arch Immunol Ther Exp. 2003;51(2):105-9.

5- Kolb R, Liu GH, Janowski AM, Sutterwala FS, Zhang W. Inflammasomes in cancer: a double-edged sword. Protein Cell. 2014 Jan;5(1):12-20.

6- Balkwill F, Mantovani A. Inflammation and cancer: back to Virchow? Lancet. $2001 \mathrm{Feb} ; 357(9255): 539-45$.

7- Chow MT, Möller A, Smyth MJ. Inflammation and immune surveillance in cancer. Semin Cancer Biol. 2012 Feb;22(1):23-32.

8- Grivennikov SI, Greten FR, Karin M. Immunity, inflammation, and cancer. Cell 2010;140:883-99.

9- Morrison, W. B. Inflammation and Cancer: A Comparative View. J Vet Intern Med. 2012;26:18-31. 
10- Mantovani A, Allavena P, Sica A, Balkwill F. Cancer-related inflammation. Nature. 2008;454:436-44.

11- Ribatti D, Ennas MG, Vacca A, et al. Tumor vascularity and tryptase-positive mast cells correlate with a poor prognosis in melanoma, Eur J Clin Invest. 2003: 420-5.

12- Coca S, Perez-Piqueras J, Martinez D, Colmenarejo A, Saez MA, Vallejo C, Martos JA, Moreno M. The prognostic significance of intratumoral natural killer cells in patients with colorectal carcinoma. Cancer. 1997 Jun15;79(12):2320-8.

13- Leek RD, Lewis CE, Whitehouse R, et al. Association of macrophage infiltration with angiogenesis and prognosis in invasive breast carcinoma. Cancer Res. 1996;56:4625-9.

14 - Hussain SP, Harris CC. Inflammation and cancer: An ancient link with novel potentials. Int J Cancer. 2007;121:2373-80.

15- Bandarchi B, Jabbari CA, Vedadi A, Navab R. Molecular biology of normal melanocytes and melanoma cells. J Clin Pathol. 2013 Aug;66(8):644-8.

16- Bastian BC. The molecular pathology of melanoma: an integrated taxonomy of melanocytic neoplasia. Annual Review of pathology. 2014;9:239-71

17- Bastian BC. The molecular pathology of melanoma: an integrated taxonomy of melanocytic neoplasia. Annual Review of Pathology. 2014;9:239-71.

18- Damsky WE, Bosenberg M. Melanocytic nevi and melanoma: unraveling a complex relationship. Oncogene. 2017 Oct 19;36(42):5771-92.

19- Roh MR, Eliades P, Gupta S, Tsao H. Genetics of Melanocytic Nevi. Pigment Cell Melanoma Res. 2015;28(6):661-72. 
20- Huang JM, Chikeka I, Hornyak TJ. Melanocytic Nevi and the Genetic and Epigenetic Control of Oncogene-Induced Senescence. Dermatologic Clinics. 2017;35(1):85-93.

21- Kuilman T, Michaloglou C, Vredeveld LCW, et al. Oncogene-induced senescence relayed by an interleukin-dependent inflammatory network. Cell. 2008;133(6):1019-31.

22- Argenziano G, Zalaudek I, Ferrara G, Hofmann-Wellenhof R, Soyer HP. Proposal of a new classification system for melanocytic naevi. Br J Dermatol. 2007 Aug;157(2):217-27.

23- Clark Jr WH, Reimer RR, Greene M, et al. Origin of familial malignant melanomas from heritable melanocytic lesions: 'the b-k mole syndrome' Arch Dermatol. 1978;114:732-8.

24- Colebatch AJ, Scolyer RA. Trajectories of premalignancy during the journey from melanocyte to melanoma. Pathology. 2018 Jan;50(1):16-23.

25- Elder DE, Goldman LI, Goldman SC, Greene MH, Clark Jr WH .Dysplastic nevus syndrome: a phenotypic association of sporadic cutaneous melanoma. Cancer. 1980;46:1787-94.

26- NIH Consensus conference. Diagnosis and treatment of early melanoma. JAMA. 1992;268:1314-9.

27- Duffy K, Grossman D. The dysplastic nevus: from historical perspective to management in the modern era: part I. Historical, histologic, and clinical aspects. J Am Acad Dermatol. 2012;67(1):e1-16.

28- Rezze GG, Leon A, Duprat J. Nevos displásicos (nevos atípicos). An Bras Dermatol. 2010 Nov-Dec;85(6):863-71 
29- Pampena R, Kyrgidis A, Lallas A, Moscarella E, Argenziano G, Longo C. A metaanalysis of nevus-associated melanoma: Prevalence and practical implications. J Am Acad Dermatol. 2017 Nov;77(5):938-45.

30- SEER Cancer Stat Facts: Melanoma of the Skin. Bethesda (MD): National Cancer Institute. 2016. Disponível em: http://seer.cancer.gov/statfacts/html/melan.html

31- U.S. Department of Health and Human Services. The Surgeon General's Call to Action to Prevent Skin Cancer. Washington, DC: U.S. Department of Health and Human Services, Office of the Surgeon General; 2014

32- Siegel RL, Miller KD, Jemal A. Cancer statistics, 2016. CA Cancer J Clin. 2016;66:7-30.

33- Weir HK, Thompson TD, Soman A, Møller B, Leadbetter S, White MC. Meeting the Healthy People 2020 Objectives to Reduce Cancer Mortality. Preventing Chronic Disease. 2015;12:E104.

34- Estimativa 2016: incidência de câncer no Brasil / Instituto Nacional de Câncer José Alencar Gomes da Silva - Rio de Janeiro: INCA, 2015.

35- Lazovich D, Vogel RI, Berwick M, et al. Indoor tanning and risk of melanoma: a case-control study in a highly exposed population. Cancer Epidemiol Biomarkers Prev. 2010 Jun;19(6):1557-68.

36- MacKie RM, Hauschild A, Eggermont AMM. Epidemiology of invasive cutaneous melanoma. Ann Oncol. 2009 Aug;20 Suppl 6:vi1-7.

37- Whiteman DC, Watt P, Purdie DM et al. Melanocytic nevi, solar keratoses, and divergent pathways to cutaneous melanoma. J Natl Cancer Inst 2003;95:806-12.

38- Anger M, Friedhofer H, Fukutaki MF, Ferreira MC, Landman G. Primary cutaneous melanoma: an 18-year study. Clinics 2010;65(3):257-63. 
39- Erdei E, Salia SM, Torres M. A new understanding in the epidemiology of melanoma. Expert Rev Anticancer Ther. 2010 November;10(11):1811-23.

40- Bulliard JL, Cox B, Elwood JM. Comparison of the site distribution of melanoma in New Zealand and Canada. Int J Cancer. 1997;72:231-5.

41- NCCN Clinical Practice Guidelines in Oncology (NCCN Guidelines ${ }^{\circledR}$ ) Melanoma Version 1.2018 - October 11. 2017

42- Paxton V. Dickson, MD and Jeffrey E. Gershenwald. Staging and Prognosis of Cutaneous Melanoma. Surg Oncol Clin N Am. 2011 January;20(1):1-17.

43- Balch CM. Melanoma of the Skin. In: Edge SB, Byrd DR, Compton CC, et al. AJCC Cancer Staging Manual. 7th ed. New York: Springer Verlag; 2009.

44- Gershenwald JE, Soong SJ, Balch CM. TNM Staging System for Cutaneous Melanoma... and Beyond. Ann Surg Oncol. 2010;17:1475-77.

45- Gershenwald JE, Scolyer RA, Hess KR, et al. Melanoma staging: Evidence-based changes in the American Joint Committee on Cancer eighth edition cancer staging manual. Cancer J Clin. 2017 Nov;67(6):472-92.

46- Roncati L, Pusiol T, Piscioli F. Thin Melanoma: A Generic Term Including Four Histological Subtypes of Cutaneous Melanoma. Acta Dermatovenerol Croat. 2017 Jul;25(2):159-60.

47- Durham AB, Schwartz JL, Lowe L, et al. The natural history of thin melanoma and the utility of sentinel lymph node biopsy. J Surg Oncol. 2017 Dec;116(8):1185-92.

48- Final Version of 2009 AJCC Melanoma Staging and Classification. Balch CM, Gershenwald JE, Soong S, et al. J Clin Oncol. 2009 Dec;27(36):6199-206. 
49- Yonick DV, Ballo RM, Kahn E, et al. Predictors of positive sentinel lymph node in thin melanoma. Am J Surg 2011;201:324-7.

50- Martinon F, Burns K, Tschopp J. The inflammasome: a molecular platform triggering activation of inflammatory caspases and processing of proIL-beta. Mol. Cell. 2002;10:417-26.

51- Dunn JH, Ellis LZ, Fujita M. Inflammasomes as molecular mediators of inflammation and cancer: Potential role in melanoma. CancerLett. 2012 Jan $1 ; 314(1): 24-33$

52- Vanaja S, Rathinam VK, Fitzgerald KA. Mechanisms of inflammasome activation: recent advances and novel insights. Trends Cell Biol. 2015 May;25(5):308-15

53- Guo H, Callaway JB, Ting JP. Inflammasomes: mechanism of action, role in disease, and therapeutics. Nat Med. 2015 Jul;21(7):677-87.

54- Takeuchi O, Akira S. Pattern Recognition Receptors and Inflammation. Cell. 2010 Mar19;140(6):805-20.

55- Gross O, Thomas CJ, Guarda G et al. The inflammasome: an integrated view. Immunol Rev. 2011 Sep;243(1):136-51

56- de Zoete MR, Palm NW, Zhu S et al. Inflammasomes. Cold Spring Harb Perspect Biol. 2014 Oct 16;6(12):a016287.

57- Schroder K, Tschopp J. The inflammasomes. Cell. 2010 Mar 19;140(6):821-32.

58- Mullen LM, Chamberlain G, Sacre S. Pattern recognition receptors as potential therapeutic targets in inflammatory rheumatic disease. Arthritis Res Ther. 2015;17(1):122. 
59- Schattgen, S.A. and Fitzgerald, K.A. The PYHIN protein family as mediators of host defenses. Immunol. Rev. 2011;243:109-18.

60- Ruland, J. Inflammasome: putting the pieces together. Cell. 2014;156:1127-29.

61- Lu A, Magupalli V, Ruan J et al. Unified polymerization mechanism for the assembly of ASC-dependent inflammasomes. Cell. 2014;156:1193-206.

62- Cai X, Chen J, Xu H et al. Prion-like polymerization underlies signal transduction in antiviral immune defense and inflammasome activation. Cell. 2014;156:1207-22.

63- Faustin B, Lartigue L, Bruey JM, Luciano F, Sergienko E, Bailly-Maitre B, et al. Reconstituted NALP1 inflammasome reveals two-step mechanism of caspase-1 activation. Mol Cell. 2007;25:713-24.

64- Wen H, Miao EA, Ting JP. Mechanisms of NOD-like receptor-associated inflammasome activation. Immunity. 2013;39:432-441.

65- Miao EA, Rajan JV, Aderem A. 2011. Caspase-1-induced pyroptotic cell death. Immunol Rev. 243:206-14.

66- Kesavardhana S, Kanneganti D. Mechanisms governing inflammasome activation, assembly and pyroptosis induction. Int Immunol. 2017 May 1;29(5):201-10.

67- Place DE, Kanneganti TD. Recent advances in inflammasome biology. Curr Opin Immunol. 2017 Nov 9;50:32-8.

68- Menu P, Vince JE. The NLRP3 inflammasome in health and disease: the good, the bad and the ugly. Clin Exp Immunol. 2011 Oct;166(1):1-15.

69- Goldbach-Mansky R, Kastner DL. Autoinflammation: the prominent role of IL-1 in monogenic autoinflammatory diseases and implications for common illnesses. $\mathbf{J}$ Allergy Clin Immunol. 2009 Dec;124(6):1141-9. 
70- Strowig T, Henao-Mejia J, Elinav E et al. Inflammasomes in health and disease. Nature. 2012 Jan 18;481(7381):278-86.

71- Pontillo A, Catamo E, Arosio B et al. NALP1/NLRP1 GeneticVariants are Associated With Alzheimer Disease. Alzheimer Dis Assoc Disord. 2012 JulSep;26(3):277-81.

72- Mamik MK, Power C. Inflammasomes in neurological diseases: emerging pathogenic and therapeutic concepts. Brain. 2017 Sep 1;140(9):2273-85.

73- Magitta NF, Bøe Wolff AS, Johansson S et al. A codingpolymorphism in NALP1 confersriskfor autoimmune Addison's disease and type 1diabetes. Genes Immun. 2009 Mar;10(2):120-4

74- Pontillo A, Girardelli M, Kamada AJ et al. Polimorphisms in inflammasome genes are involved in the predisposition to systemic lupus erythematosus. Autoimmunity. 2012 Jun;45(4):271-8.

75- Pontillo A, Oshiro TM, Girardelli M et al. Polymorphisms in inflammasome' genes and susceptibility to HIV-1 infection. J Acquir Immune Defic Syndr. 2012 Feb $1 ; 59(2): 121-5$.

76- Dorhoi A, Nouailles G, Jörg S et al. Activation of the NLRP3 inflammasome by Mycobacterium tuberculosis is uncoupled from susceptibility to active tuberculosis. Eur J Immunol. 2012 Feb;42(2):374-84.

77- Wu J, Fernandes-Alnemri T, Alnemri ES. Involvement of the AIM2, NLRC4, and NLRP3 inflammasomes in caspase-1 activation by Listeria monocytogenes. J Clin Immunol. 2010 Sep;30(5):693-702.

78- Gavrilin MA, Wewers MD. Francisella Recognition by Inflammasomes: Differences between Mice and Men. Front Microbiol. 2011 Feb 9;2:11. 
79- Case CL, Shin S, Roy CR. Asc and Ipaf Inflammasomes direct distinct pathways for caspase-1 activation in response to Legionella pneumophila. Infect Immun. 2009 May;77(5):1981-91.

80- Witzenrath M, Pache F, Lorenz D et al. The NLRP3 inflammasome is differentially activated by pneumolysin variants and contributes to host defense in pneumococcal pneumonia. J Immunol. 2011 Jul 1;187(1):434-40.

81- Kolb R, Liu GH, Janowski AM et al. Inflammasomes in cancer: a double-edged sword. Protein Cell. 2014 Jan;5(1):12-20.

82- Liu R, Truax AD, Chen L et al. Expression profile of innate immune receptors, NLRs and AIM2, in human colorectal cancer: correlation with cancer stages and inflammasome components. Oncotarget. 2015 Oct 20;6(32):33456-69.

83- El-Omar EM, Carrington $\mathrm{M}$, Chow $\mathrm{WH}$, et al. Interleukin-1 polymorphisms associated with increased risk of gastric cancer. Nature 2000;404:398-402.

84- Machado JC, Pharoah P, Sousa S, et al. Interleukin 1B and interleukin 1RN polymorphisms are associated with increased risk of gastric carcinoma. Gastroenterology. 2001;121:823-9.

85- Liu X, Wang Z, Yu J, et al. Three polymorphisms in interleukin-1 beta gene and risk for breast cancer: a meta-analysis. Breast Cancer Res Treat 2010;124:821-5.

86- Drexler SK, Yazdi AS. Complex Roles of Inflammasomes in Carcinogenesis. Cancer J. 2013 Nov-Dec;19(6):468-72.

87- Terlizzi M, Casolaro V, Pinto A, Sorrentino R. Inflammasome: Cancer's friend or foe? PharmacolTher. 2014 Jul;143(1):24-33. 
88- Krelin, Y, Voronov E, Dotan S et al. Interleukin-1 $\beta$-driven inflammation promotes the development and invasiveness of chemical carcinogen-induced tumors. Cancer Res. 2007;67:1062-71.

89- Hagemann, T., Balkwill, F. \& Lawrence, T. Inflammation and cancer: a doubleedged sword. Cancer Cell. 2007; 12:300-1.

90- Ghiringhelli F, Apetoh L, Tesniere A, et al. Activation of the NLRP3 inflammasome in dendritic cells induces IL-1beta- dependent adaptive immunity against tumors. Nat. Med. 2009;15:1170-8.

91- Allen IC, TeKippe EM, Woodford RM, et al. The NLRP3 inflammasome functions as a negative regulator of tumorigenesis during colitis- associated cancer. J Exp Med. 2010;207:1045-56.

92- Chen IF, Ou-Yang F, Hung JY, et al. AIM2 suppresses human breast cancer cell proliferation in vitro and mammary tumor growth in a mouse model. Mol Cancer Ther. 2006;5:1-7.

93- Patsos G, Germann A, Gebert J, Dihlmann S. Restoration of absent in melanoma 2 (AIM2) induces G2/M cell cycle arrest and promotes invasion of colorectal cancer cells. Int J Cancer. 2010;126:1838-49.

94- Hu B, Elinav E, Flavell RA. Inflammasome-mediated suppression of inflammationinduced colorectal cancer progression is mediated by direct regulation of epithelial cell proliferation. Cell Cycle. 2011;10:1936-9.

95- Karki R, Man SM, Kanneganti TD. Inflammasomes and Cancer. Cancer Immunol Res. 2017 Feb;5(2):94-9.

96- Okamoto M, Liu W, Luo Y et al. Constitutively active inflammasome in human melanoma cells mediating autoinflammation via caspase-1 processing and secretion of interleukin-1beta. J Biol Chem. 2010; 26;285(9):6477-88. 
97- Verma D, Bivik C, Farahani E et al. Inflammasome polymorphisms confer susceptibility to sporadic malignant melanoma. Pigment Cell Melanoma Res. 2012 Jul;25(4):506-13.

98- Liu W, Luo Y, Dunn JH et al. Dual role of apoptosis-associated speck-like protein containing a CARD (ASC) in tumorigenesis of human melanoma. J Invest Dermatol. 2013 Feb;133(2):518-27.

99- Gehrke S, Otsuka A, Huber R et al. Metastatic melanoma cell lines do not secrete IL-1 $\beta$ but promote IL-1 $\beta$ production from macrophages. J Dermatol Sci. 2014 May;74(2):167-9.

100- Ahmad I, Muneer KM, Tamimi IA et al.Thymoquinone suppresses metastasis of melanoma cells by inhibition of NLRP3 inflammasome. Toxicol Appl Pharmacol. 2013 Jul 1;270(1):70-6.

101- Ellis LZ, Liu W, Luo Y et al. Green tea polyphenol epigallocatechin-3-gallate suppresses melanoma growth by inhibiting inflammasome and IL-1 $\beta$ secretion. Biochem Biophys Res Commun. 2011 Oct 28;414(3):551-6.

102- Masumoto J, Taniguchi S, Nakayama J, et al. Expression of apoptosis- associated speck-like protein containing a caspase recruitment do- main, a pyrin $\mathrm{N}$-terminal homology domain-containing protein, in normal human tissues. J Histochem Cytochem. 2001;49:1269-75.

103- Kummer JA, Broekhuizen R, Everett H,et al. Inflammasome Components NALP1 and 3 Show Distinct but Separate Expression Profiles in Human Tissues Suggesting a Site-specific Role in the Inflammatory Response. J Histochem Cytochem. 2007 May;55(5):443-52.

104 - Pagliarello C, Stanganelli I, Zambito-Spadaro F, et al. Sex Differences in Axial and Limb Distribution of Melanocytic Naevi. Acta Derm Venereol. 2017 Feb 8;97(2):266-7. 
105- Bauer J, Buttner P, Wiecker TS et al. Risk factors of incident melanocytic nevi: a longitudinal study in a cohort of 1,232 young German children. International journal of cancer Journal international du cancer. 2005;115:121-6.

106- Bartlett EK, Karakousis GC. Current staging and prognostic factors in melanoma. Surg Oncol Clin N Am. 2015 Apr;24(2):215-27

107- Zhai Z, Liu W, Kaur M, Luo Y, Domenico J, Samson JM, Shellman YG, Norris DA, Dinarello CA, Spritz RA, Fujita M. NLRP1 promotes tumor growth by enhancing inflammasome activation and suppressing apoptosis in metastatic melanoma. Oncogene 2017;36(27):3820-30.

108- Idris A, Ghazali NB, Koh D. Interleukin $1 \beta$-A Potential Salivary Biomarker for Cancer Progression? Biomarkers in Cancer. 2015;7:25-9.

109- Song X, Krelin Y, Dvorkin T, et al. ApteCD11b+/Gr-1+ immature myeloid cells mediate suppression of T cells in mice bearing tumors of IL-1beta-secreting cells. J Immunol. 2005;175:8200-8.

110- Krelin Y, Voronov E, Dotan S, et al. Interleukin-1beta-driven inflammation promotes the development and invasiveness of chemical carcinogen-induced tumors. Cancer Research. 2007 Feb 1;67(3):1062-71.

111- Dinarello CA. Why not treat human cancer with interleukin-1 blockade? Cancer Metastasis Rev. 2010;29(2):317-29

112- Kholmanskikh O, van Baren N, Brasseur F, et al. Interleukins 1alpha and 1beta secreted by some melanoma cell lines strongly reduce expression of MITF-M and melanocyte differentiation antigens. Int J Cancer. 2010 Oct 1;127(7):1625-36.

113- da Silva WC, Oshiro TM, de Sá DC, Franco DGS, FestaNeto C, Pontillo A (2016) Genotyping and differential expression analysis of inflammasome genes in sporadic malignant melanoma reveal novel contribution of CARD8, IL1B and IL18 in melanoma susceptibility and progression. Cancer Genetics 2009:474-80. 
114- Qin Y, Ekmekcioglu S, Liu P, et al. Constitutive Aberrant Endogenous Interleukin-1 Facilitates Inflammation and Growth in Human Melanoma. Molecular Cancer Research. 2011;9(11):1537-50.

115- Maelfait J, Vercammen E, Janssens S, et al. Stimulation of Toll-like receptor 3 and 4 induces interleukin-1 $\beta$ maturation by caspase-8. Journal of Experimental Medicine. 2008 Sep;205(9):1967-73.

116- Ketelut-Carneiro N, Ghosh S, Levitz SM, Fitzgerald KA, da Silva JS. A Dectin-1Caspase-8 Pathway Licenses Canonical Caspase-1 Inflammasome Activation and Interleukin-1 $\beta$ Release in Response to a Pathogenic Fungus. J Infect Dis. 2018 Jan $4 ; 217(2): 329-39$.

117- Voinea S, Blidaru A, Panaitescu E, Sandru A. Impact of gender and primary tumor location on outcome of patients with cutaneous melanoma. J Med Life. 2016 Oct-Dec;9(4):444-8. 